NBSIR 87-3595

\title{
Users' Guide to FIRST, A Comprehensive Single-Room Fire Model
}

Henri E. Mitler

John A. Rockett

U.S. DEPARTMENT OF COMMERCE

National Bureau of Standards

National Engineering Laboratory

Center for Fire Research

Gaithersburg, MD 20899

September 1987

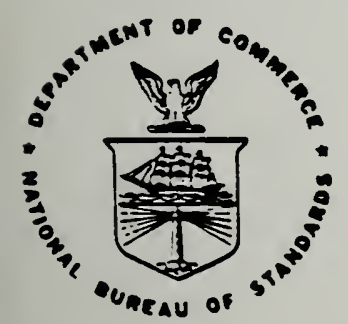

U.S. DEPARTMENT OF COMMERCE NATIONAL BUREAU OF STANDARDS 

NBSIR 87-3595

USERS' GUIDE TO FIRST, A

COMPREHENSIVE SINGLE-ROOM FIRE

MODEL

Henri E. Mitler

John A. Rockett

U.S. DEPARTMENT OF COMMERCE

National Bureau of Standards

National Engineering Laboratory

Center for Fire Research

Gaithersburg, MD 20899

September 1987

U.S. DEPARTMENT OF COMMERCE, Clarence J. Brown, Acting Secretary NATIONAL BUREAU OF STANDARDS, Ernest Ambler, Director 

FOREWORD

Although considerable effort has been expended to make the program easy to run, it is not meant to be used as a "black box" by a complete novice to fire science: like any sophisticated tool, it should be used by someone who understands its limitations as well as its strengths. Those limitations are listed in Appendix D. It may also be appropriate to say here that a single run will rarely if ever be adequate, in attempting to simulate a fire - aside from the inaccuracies of the model inherent in the various simplifying assumptions and approximations which were made in constructing this model, there often are even larger uncertainties in the input data.

It should be possible for a user to sit at the console and run the program by following the instructions which appear on the screen when the program is started; that process will be much easier if this manual is read (or at least skimmed) beforehand, however. One goal in writing this guide has been that it should contain a minimum of jargon or other difficulties, so that an intelligent layman could follow it easily. It is hoped that this goal has been met.

Before attempting to compile this program, please refer to the comments in section 2.2 . 
Abstract $\ldots \ldots \ldots \ldots \ldots \ldots \ldots \ldots \ldots \ldots \ldots \ldots \ldots \ldots \ldots \ldots \ldots \ldots$

1. INTRODUCTION $\ldots \ldots \ldots \ldots \ldots \ldots \ldots \ldots \ldots \ldots \ldots \ldots \ldots \ldots \ldots$

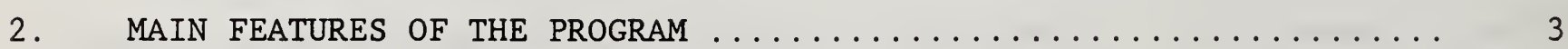

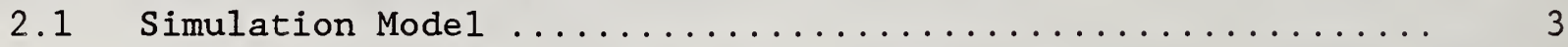

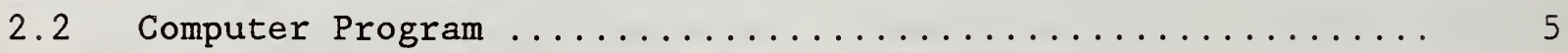

3. INPUT $\ldots \ldots \ldots \ldots \ldots \ldots \ldots \ldots \ldots \ldots \ldots \ldots \ldots \ldots \ldots \ldots \ldots \ldots \ldots$

3.1 Needed Information ....................... 8

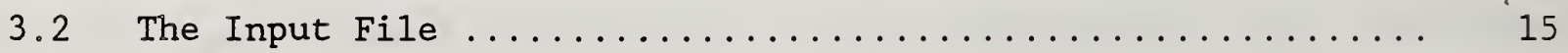

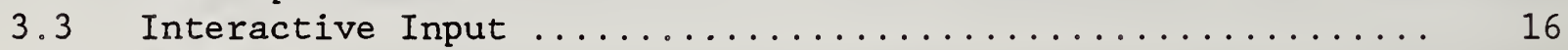

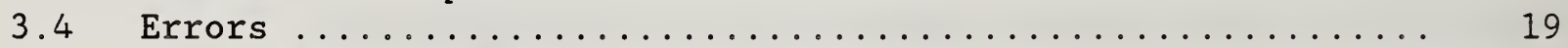

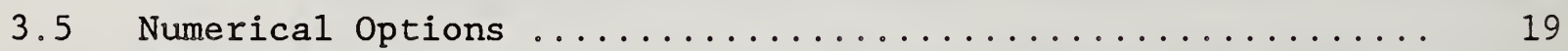

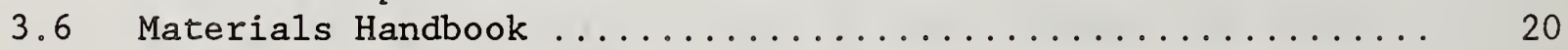

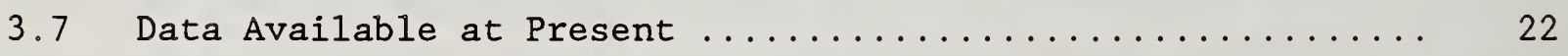

4. SAMPLE SESSIONS AT THE TERMINAL: OPERATING IN INTERACTIVE MODE .. 24

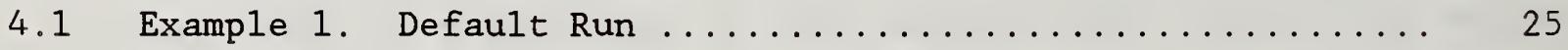

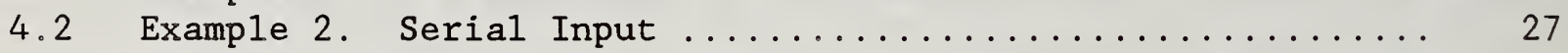

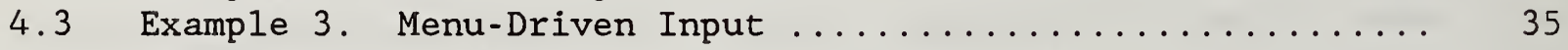

4.4 Example 4. A Variable-Flow Gas Burner Fire ............ 39

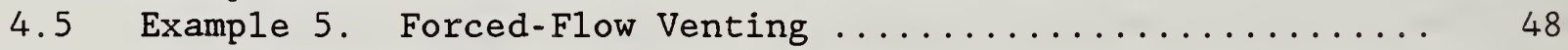

4.6 Example 6. Alternative Algorithms for Physics .......... 55

4.7 Example 7. Use of Input Files and Data Bank ............ 57

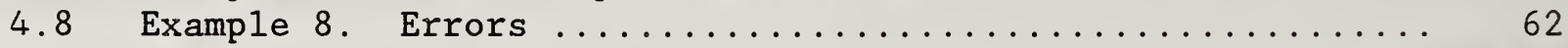

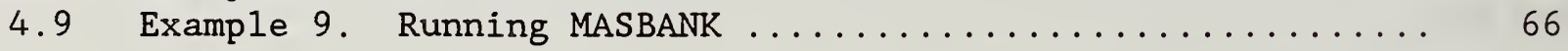

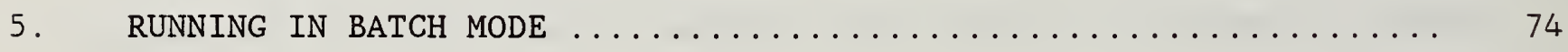

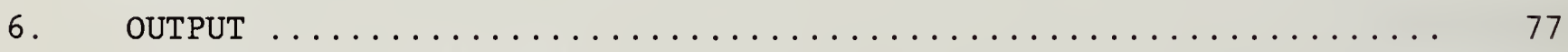

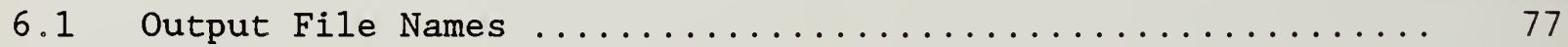

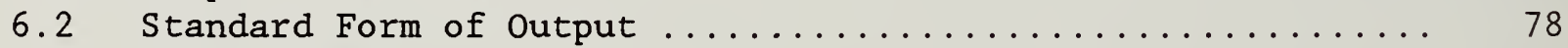

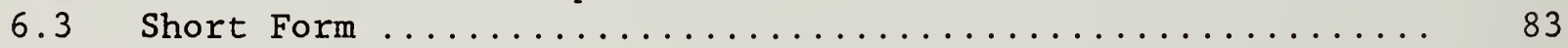

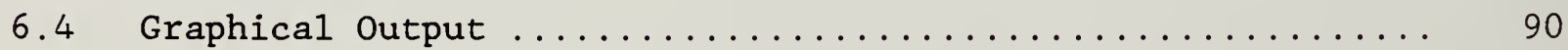

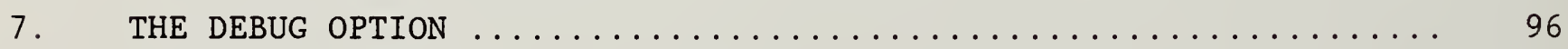

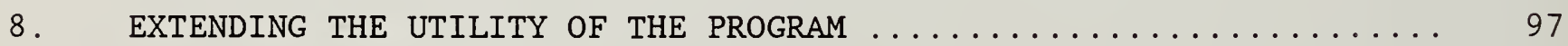

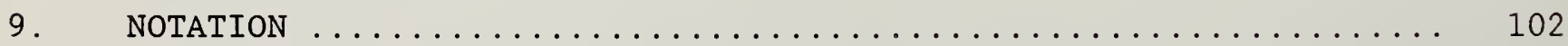

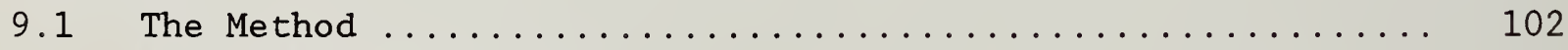

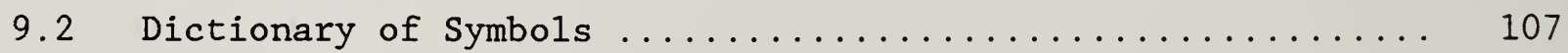

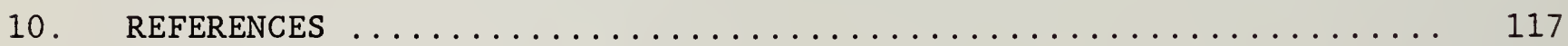


APPENDIX A. Derivation of Values Used for Heptane in Table I ....... 120

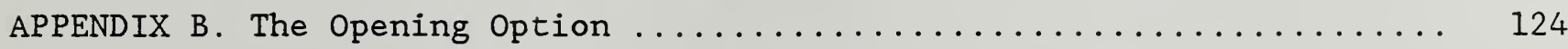

APPENDIX C. Summary of Improvements in FIRST, Over Harvard Mark $5 \ldots \ldots$

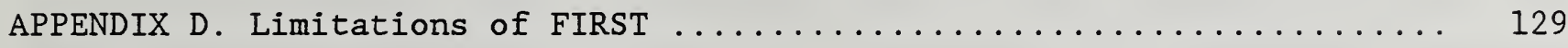

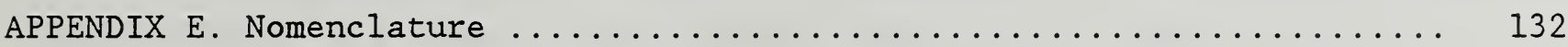

LIST OF TABLES

$\underline{\text { Page }}$

Table 1. Thermophysical/chemical values chosen for the materials data bank

Figure 1. Schematic of the enclosure, showing mass fluxes in and out of the room and radiative fluxes to the target from the

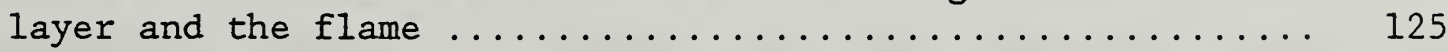

Figure 2. Schematic of a flame on a horizontal surface .......... 12 

USER'S GUIDE TO FIRST, A COMPREHENSIVE SINGLE-ROOM FIRE MODEL

Henri E. Mitler and John A. Rockett

Abstract

This document is an instructional manual which will facilitate use of the computer program FIRST. (The name "FIRST" is an acronmym; it stands for FIRe simulation Technique.) This is a prototype of a "benchmark" computer model of how a fire develops in a single compartment. Given a fire (or fires) ignited on one or more fuel sources, FIRST describes the principal phenomena which occur, such as the movement of gases in and out of the compartment, the growth of the fire(s), the development of a hot layer, etc. This guide is not meant to be documentation for the model, and so detailed descriptions of the physics or of the program structure have been kept to a minimum. The principal emphasis has been on how to input the information needed to run the program, and on the output obtained. Only a dozen pages of instruction are needed for the input, but an extensive section has been included which gives "worked examples" of the use of the program. There is also a section which gives suggestions for using it to simulate fires and situations for which no explicit provision has been made. Finally, a short table of thermophysical data appropriate for running the program has been included.

Keywords: compartment fires; computer modeling; fire modeling; FIRST; modeling; user's guide.

\section{INTRODUCTION}

About ten years ago, an effort was undertaken at Harvard University to construct a general-purpose mathematical model of how fires develop in enclosures; this was under the guidance of Professor H.W. Emmons, one of the pioneers of fire science. The work was principally supported by grants from the Center for Fire Research at the National Bureau of Standards (NBS). A number of versions, of increasing complexity and sophistication, resulted (see ref. [1-4]), culminating in what came to be known as Harvard Mark 5 (CFC V) 
and Mark $6^{1}$ (Mark 5 is a single-room model; Mark 6 a multiple-room version of Mark 5). That project was terminated at Harvard in 1983. Development of Mark 5, originally documented in 1981 [2], has continued at NBS, however. In 1985, it was decided to develop a new "generation" of benchmark-quality compartment fire models at NBS [5]. As the first stage in this process, the numerous improvements and enrichments which have been made to Mark 5 since 1981 have been merged into a new computer code, FIRST. It must be noted that the validation of the new algorithms is limited; the extent of the validation is discussed in Appendix $C$.

By "benchmark", we mean a model whose every component is nearly as good as possible, consistent with the constraints that the program run in a reasonably short time, and that any effect need not be calculated to better than 18 accuracy. This program ("FIRST") is a prototype, and - although very good in many ways - it is not quite of benchmark quality.

This document will describe the capabilities of FIRST only briefly, concentrating principally on descriptions of how to use it. The units usedfor input, output, and internally - are generally the Systeme International (SI units). This is a variant of the Mks (meter-kilogram-second) system. The only exceptions at present are for fuel flow rate (in $\mathrm{g} / \mathrm{s}$, rather than $\mathrm{kg} / \mathrm{s}$ ), and for pressure (meters equivalent of air, rather than Pascals). The rest of the paper consists of eight sections, the two largest being section 3 , describing the input, and 4, which gives nine examples of how to enter different cases. A nice feature which simplifies and facilitates input is decribed in section 3.6 .

1 There are other fire models which we will not touch on here; the interested reader may see references [6-10]. 


\section{MAIN FEATURES OF THE PROGRAM}

\subsection{Simulation Model}

FIRST is a deterministic and time-dependent solution of simplified mass and energy transfer processes which describe fire growth in a compartment. It is a zone model, the principal geometrical zones in the compartment being the burning object, a hot upper layer; a cooler lower layer; the thermal plume(s) from the fire(s); the wall, ceiling, and floor areas; the vent areas; the flame(s); and any objects of interest which are exposed to heating fluxes. The zones and dynamics of the fire may be made clearer by referring to figure 1, taken from refs. [2] and [3]. The following is a very brief summary of the physical processes involved; for greater detail, the reader may wish to see refs. [8], [3], and [17].

Three types of fire may be simulated, at present: a fire growing on a horizontal surface, a pool fire, and a burner fire. The spread rate of the growing fire is accelerated by the heat feedback from its own combustion zone, from those of other fires, and from the hot layer and ceiling; it generally grows exponentially in time under free-burn or open-burning conditions. The pool fire has a fixed area. The burner fire is a very general fire, as it permits the user to specify the gas flow rate as he wishes; this permits one to simulate furniture items, wood cribs, etc. (However, if the open-air burning rate is used to simulate then, that neglects the effects of radiation feedback from the enclosure, which is taken into account in the growing-fire and pool-fire algorithms). Because of its generality, this variable-flow burner algorithm is very powerful.

Each burning item generates heat and prescribed combustion products, comprising smoke particulates, $\mathrm{CO}, \mathrm{CO}_{2}, \mathrm{H}_{2} \mathrm{O}$, etc.

Forced ventilation is incorporated in the model (see Mitler [11]); here the user must specify the volumetric flow rate through (into or out of) the given vent. It is important, however, to note that there must always be at least one free (natural) vent for the enclosure. A photoelectric smoke 
detector of user-specified sensitivity may be placed in the upper part of the room.

Among other variables, the program calculates the concentration of $\mathrm{O}_{2}$, $\mathrm{CO}, \mathrm{CO}_{2}, \mathrm{H}_{2} \mathrm{O}$, smoke, and total hydrocarbons in the two layers, as a function of time. It then calculates the extinction in these two zones.

The program is DIMENSIONEd so that up to four objects and five vents can be treated in any one run. In fact, however, each object (there are "o" of them) requires up to 15 variables; each wall/floor/ceiling construction, 12 "w" variables; the room, 22 variables; and each vent, 6 "v" variables. Thus the total number of variables is

$$
N=22+150+12 w+6 v
$$

The present numerical package permits a maximum of 100 variables to be treated. Hence a room with one wall/floor/ceiling, must have $150+6 \mathrm{v} \leq 66$ Thus, we can have no more than two objects if there are four or five vents, three objects if there are two or three vents, and never more than four objects.

Target objects get heated by radiative and convective fluxes from the various sources (hot layer, hot surfaces, flames, etc.); an object is assumed to ignite when its exposed surface reaches a user-specified ignition temperature. The flame then rapidly spreads over the entire object. The effect on the flame of oxygen vitiation in the upper layer is taken into account, albeit crudely. The mass fluxes (in and out) through each vent are calculated. These are based on cross-vent pressure differences which result from differences which result from differences in cross-vent gas buoyancy (temperature) and other considerations. Whereas Mark 5 and other versions of the Harvard and NBS/Harvard codes assume that the lower layer is always at ambient temperature, FIRST more realistically takes into account the fact that there is mixing of some of the upper hot gases with the incoming cool air, at a vent. This entering flow of smoke-contaminated air enters the lower layer which 
gradually heats up and becomes less transparent to radiation. This is in agreement with what is experimentally observed. ${ }^{2}$

\subsection{Computer Program}

FIRST is written in ANSI 177 FORTRAN; it has about 11700 lines of code, including comments; this is 560 kilobytes. The convergence accuracy of the calculation is user-chosen; a value of the order of one part in $10^{4}$ has generally been used (see paragraph 2 in section 3.5 for the definition of this term). The inaccuracies in the physics and in the thermophysical data generally far exceed this level. The compiled program is 476 kilobytes long (including the library routines), when compiled with the profort FORTRAN compiler on an IBM PC (AT or XT) computer.

We want the computer to read (input) from the keyboard and to write (output) to the screen; these are usually logical units 5 and 6 , respectively. For many computers, this is the default option, and the program will run as is. Unfortunately, it is impossible to write a completely machine-independent program, even in standard FORTRAN. Thus for some computers, these logical units must be assigned; however, the symbol denoting the console varies among computers. This assignment is done by writing OPEN statements in the FORTRAN program; for a CYBER, for example, these statements are

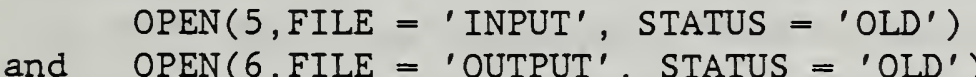

For a PC, 'INPUT' and 'OUTPUT' are replaced by 'CON'; for Perkin-Elmer computers, they are replaced by either 'CON:' or 'C:', depending on the particular P-E computer; and so forth. It is therefore necessary, before one compiles FIRST, to determine whether or not LU5 and 6 must be explicitly assigned. If that is the case, it is easy to do: lines two and three of the program are the ones shown above, but have been "commented" out.

2 More detailed explanations of the various dynamical processes will be given in the documentation (to be published). 
When the program is run, the results of the calculations must be made accessible; in this program, they go to three places: the screen, and two files. The first two questions which appear on the screen, upon running FIRST, are requests for names of these output files. These two files and their names are discussed in section 6.1.

The time required to make a run evidently will depend on the machine used, the run length, and the complexity of the problem which is set up. We will describe the default case which was run for reference: In 1977, Factory Mutual Research Corporation carried out a series of well-instrumented fullscale room fires ( $\operatorname{ref}[12-13]$ ). The basic configuration was a 2.44 by 3.66 by

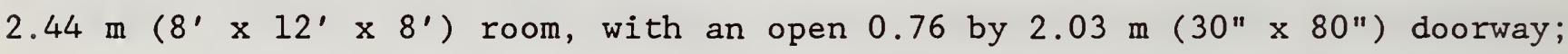
a $1.52 \times 1.52 \mathrm{~m}\left(5^{\prime} \times 5^{\prime}\right)$ slab of polyurethane foam $0.10 \mathrm{~m}$ (4") thick is in one corner, and a $0.30 \times 1.22 \mathrm{~m}\left(1^{\prime} \times 4^{\prime}\right)$ slab of the same material and of like thickness in the facing corner. The first slab was ignited at its center. That is the default case (more details can be found in section 4.1). Incidently, the fire grew and the target object (the second slab) was observed to ignite at about $t=310 \mathrm{sec}$; this growth and the time of ignition are closely approximated by the model.

Finally, the run time required also depends on the convergence criterion which is used. When the convergence criterion is set at $\epsilon=10^{-5}$, it takes over 9 min of CPU time on a Perkin-Elmer 3252 (comparable to a VAX 780) to make a run of 500 simulated seconds. When this criterion is relaxed to $\epsilon=$ $10^{-4}$, the same case takes only $6.5 \mathrm{~min}$ of $\mathrm{CPU}$ time, with no significant difference in the results. If we relax it further, to $\epsilon=3 \times 10^{-4}$, the computing time drops to 6.1 minutes. Use of an optimizing compiler will reduce this figure still further. These times may be compared with the $2 \mathrm{CPU}$ minutes taken by Mark 5 for the same problem.

Some comments on the reliability of the program are appropriate here. First, we must distinguish between the precision and the accuracy of the program. "Precision" concerns the adequacy with which the mathematical equations (which constitute the model) are solved; that involves the fineness of the discretization, truncation errors, the kind of convergence criterion 
that is used, the mathematical techniques used to solve the equations, and other such numerical questions. "Accuracy" refers to the adequacy with which the model represents physical reality.

The accuracy is determined by making validation runs, where predictions are compared with experimental results. This is a very complex problem, for (for example) it is possible that the model might predict one variable - e.g., the hot layer temperature - very accurately (say, within 1\%), but another variable, such as the time at which a target ignites, much less well. Or, it might predict the layer temperature very well over $90 \%$ of the run, but less well over the last $10 \%$. The precision of the calculations is almost invariably far better than their accuracy; hence accuracy is what we must focus on.

Yet another problem, which is not often discussed, is that the experiments themselves have inherent errors of non-negligible magnitude! All of these points are discussed in some detail in references [14-16], for Mark 5. From the results of the validation runs made with Mark 5, it turns out that we can - very crudely - make a single estimate for the accuracy of Mark 5: the simplest estimate is that most calculations are accurate to within 10\%, except for the CO concentration, which is very poorly calculated. Preliminary comparisons with the first FMRC test indicate that calculation with FIRST agrees even better with the experimental results than does calculation with Mark 5. To run the program, the source code (generally available on 9-track tape) must be compiled and linked; ${ }^{3}$ then a few simple control instructions must be given in a short "control" file. Evidently, all of these operations are dependent on the particular computer used, and - more to the point - the particular operating system being used. When the program has been properly installed and is working, a single "word" will bring it up; in the sample run shown in section 4.1 , the word RUNFIRST was used; others would be equally good. The calling word has been omitted in the subsequent examples.

3 It is planned to also have the source code available on disk(s), and an executable version on disk for operation on IBM or IBM-like PC's running with MSDOS and an 8087 chip. 
It is very important to note that not all the variables have been initialized in this program; therefore FIRST should be run with the option to initially zero the memory.

As all other scientific programs do, this one has an INPUT section, a calculation section, and an OUTPUT section. This manual principally describes input and output. For the reader interested in the calculations, reference can be made to [2], the very complete documentation available for version 5 (Mark 5) of the program, most of which is relevant to FIRST. Analogous documentation for FIRST will be prepared.

\section{INPUT}

\subsection{Needed Information}

Geometric and thermophysical data about the room, vents, walls, and various objects must be supplied. The data which the user must supply for a run will now be listed. The superscripts in parenthesis refer to explanatory notes at the end of this subsection. (1) All lengths are in meters.

For the room $(2)$ :

Length in the $\mathrm{x}$ direction ${ }^{(3)}$

Length in the $y$ direction

Height

Ambient temperature $\mathrm{T}_{\mathrm{a}}$ (in degrees Kelvin)

Number of objects ( 4 maximum - - i.e., $\left.0 \leq N_{0} \leq 4\right)^{(4)}$

Is there a photoelectric detector in the room? ( $Y, N)$

Threshold for activation of detector (in meters ${ }^{-1}$ )(5)

Distance of detector below ceiling

For each object, geometrical information:

Is it horizontal or vertical? ${ }^{(8)}$

If vertical, what is the angle between the exposed surface and the $x-z$ plane?

Location of center of exposed surface ( $\mathrm{x}, \mathrm{y}$, height)

Size ( $a \times b$ and its thickness $\theta$, or $R$ and $\theta)^{(6)}$ and $^{(7)} R_{\max }$. For pools and burners, $R=R_{\max }$.

Initial burning radius, $R_{0}$. 
For each object, its chemical and thermophysical properties (20 items):(19)

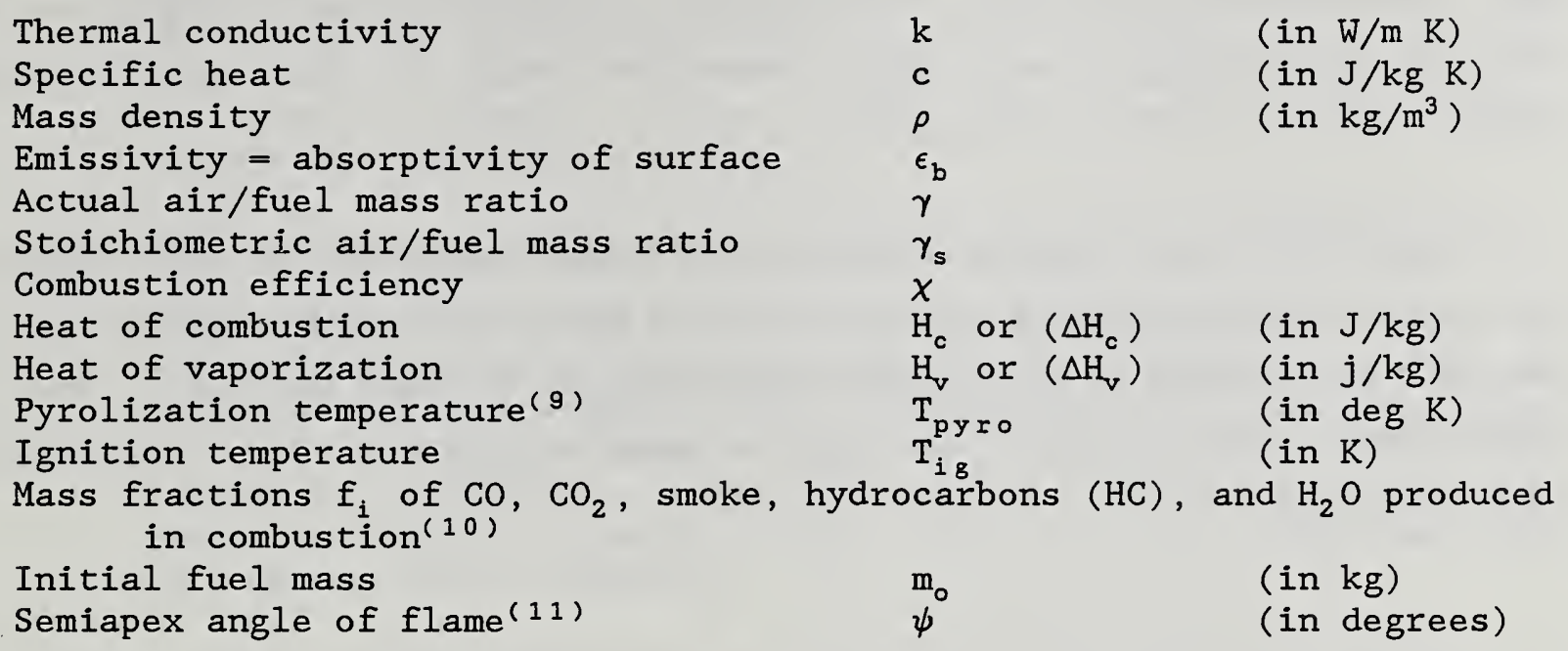

For growing fires, we also need the
Spread rate parameter
Burnout parameter(12)
When it is burning, the absorption
coefficient of its flame,
A
(in $\mathrm{m} / \mathrm{s})(15)$
$t_{b}$
(in seconds)
(in $\mathrm{m}^{-1}$ )
$\kappa_{f}$

We also want to know whether it is flaming initially, or not(13).

Is it, or will it be, a growing fire, a pool fire, or a gas burner fire?

For burner fires, we need the

$$
\text { Gas flow rate }{ }^{(14)} \quad \dot{\mathrm{m}}_{\mathrm{g}}(\mathrm{t}) \quad \text { (in } \mathrm{g} / \mathrm{s} \text { ) }
$$

$\operatorname{Vent}(s)$ : Number of vents $\left(1 \leq \mathrm{N}_{\mathrm{v}} \leq 5\right) \cdot{ }^{4}$

For each vent, its size (height, width) and its vertical location ("transom" height), $h_{t}$

If it is a forced vent, its flow rate $\dot{V}(t)\left(\text { in } \mathrm{m}^{3} / \mathrm{s}\right)^{(16)}$.
Wall: Its thickness
Its material parameters:
$\rho, \mathrm{k}, \mathrm{c}^{(17)}$.
(in $\mathrm{m}$ )

Non-indexed variables $(18)$

Specific heat of air

Ambient temperature outside building

Maximum heat transfer coefficient (walls)

Minimum heat transfer coefficient (walls)

Heat transfer coefficient (for objects)

Plume entrainment coefficient

Vent flow coefficient

$c_{p}$
$T_{a}$
$h_{\text {max }}$
$h_{\text {min }}$
$h^{\alpha}$
$\alpha$
$C_{d}$

(in $\mathrm{J} / \mathrm{kg} \mathrm{K}$ )

(in degrees $\mathrm{K}$ )

(in $\mathrm{W} / \mathrm{m}^{2} \mathrm{~K}$ )

"

4 Also see Appendix B. 
Finally, a number of choices have to be made for the output. We shall defer discussing these until sections 3.5 and 4 have been covered; we will only note here that one must still enter the length of the run (in seconds) and the step size, $\Delta t$, in seconds.

Resall that the maximum number of variables permitted in this version is 100. Hence the user must make sure that $N \leq 100$, where $N$ is given by eq. (1); the input for FIRST is not sophisticated enough to warn the user, should he inadvertently choose a mix involving too many variables -- e.g., four objects and three vents.

\section{Notes:}

(1) If the user does not specify the input values, then a default list will be chosen, corresponding to the standard case (see section 2 and $P U$ foam, in Table 1 ). This is done in sets of information-for example, we might have a problem in which all of the default values except the set for the vent are appropriate. The vent set would have to be modified to the desired values.

(2) The room index $\mathrm{KR}$ (taken to be 1 in the one-room code FIRST) appears in many places in the program. The reason for this is that much of the FIRST software is expected to be useful in future multi-room codes. 
(3) The room is a rectangular paralellepiped with one corner of the floor as the origin of coordinates. If the room has only one door, then the lower left-hand corner of the room (as we face the wall with the door in it, from outside the room) is the origin. The $\mathrm{x}$-axis extends to the right, the y-axis directly away (forward), and the $z$-axis upward.

(4) See, however, the cautionary comments in section 2, under eq. (1).

(5) If the layer is defined to be opaque when the extinction length is $0.30 \mathrm{~m}$ ( $1 \mathrm{ft}$ ), and a detector's sensitivity is designed to be such that the detector responds when the extinction is 18 of this, then the corresponding extinction length is 30 meters (100 ft), and the activation threshold is $0.033 \mathrm{~m}^{-1}$. This is the default value, but the user can (as stated) enter whatever value describes the performance of his detector.

(6) $a$ and $b$ are the dimensions of the (assumed rectangular) object. $R$ is its radius if the object is cylindrical. If it is rectangular, the program internally finds an equivalent radius -- i.e., $\pi \mathrm{R}^{2}=\mathrm{ab}$.

(7) If the object is horizontal and can burn down its sides as well, then the total maximum exposed area includes the area of the sides, as well, and we define --

for a rectangular parallelepiped,

$\pi \mathrm{R}_{\max }^{2}=a b+2(\mathrm{a}+\mathrm{b}) \theta$

for a cylinder,

where $\theta$ is the slab thickness.

$$
\pi \mathrm{R}_{\max }^{2}=\pi \mathrm{R}^{2}+2 \pi \mathrm{R} \theta
$$

(8) It was planned to have inclined objects; the user is therefore asked for the angle of the object to the horizontal. However, that feature has not yet been implemented; hence the question is a bit misleading. At present, if an angle $<45^{\circ}$ is typed in, the program makes the object horizontal $\left(0^{\circ}\right)$; if a value $\geq 45^{\circ}$ is typed in, the object is taken to be vertical $\left(90^{\circ}\right)$. Moreover, even if the object is vertical, it is treated as if it were horizontal.

(9) The temperature at which pyrolysis is supposed to begin is a simplifying concept which is not used in this program. It may be used in future versions, however, and is therefore left in. The user should ignore this value.

(10) Thus, $\mathrm{f}_{\mathrm{CO}}=$ grams of $\mathrm{CO}$ evolved per gram of material consumed. Because of the uptake of $\mathrm{O}_{2}$, the "fractions" of $\mathrm{CO}_{2}$, etc., might be greater than unity. Thus for the P.U. foam, the stoichiometric air/fuel mass ratio is 9.85 ; interpreting $\chi$ as completeness of 
combustion (for the sake of simplicity), then since $\chi=0.65$, we have $\mathrm{m}^{5}\left(\mathrm{O}_{2}\right)=1.48 \mathrm{~m}$, where $\mathrm{m}\left(\mathrm{O}_{2}\right)$ is the mass of oxygen which combines the mass $\mathrm{m}_{\mathrm{v}}$ of fuel vapors. Thus the sum of mass fractions must be 2.48 .

(11) Flames are modeled as cones in this program (see figure 2 at right). The default value of $\psi$ is $30^{\circ}$, although $8-20^{\circ}$ is more realistic. The user can choose any reasonable value he pleases for $\psi$, however. This will then remain constant until burnout is approached or oxygen "starvation" is achieved (see [2], [17]).

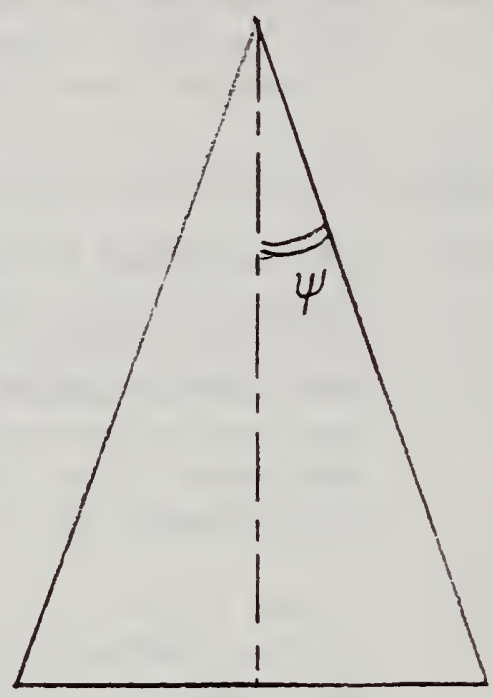

Fig. 2. Schematic of a flame on a horizontal surface.

(12) When a fuel item approaches burnout, geometric and other considerations reduce the burning rate. These effects are simulated by choosing a characteristic time $t_{b}$, in which the burning rate falls by the factor e; thus, we have an exponentially decreasing burning rate towards the end. The default value is 20 sec.

(13) Note that we can start with several independent (simultaneous) fires.

(14) The gas flow rate is input in $\mathrm{g} / \mathrm{s}$, rather than $\mathrm{kg} / \mathrm{s}$, because the former is a much more convenient unit. Any predetermined fire strength or flow rate $\left[\dot{E}_{f}(t)\right.$ or $\left.\dot{m}_{g}(t)\right]$ can be approximated by a series of straight-line segments. Hence provision is made to input up to 30 values of $\dot{m}_{g}\left(t_{i}\right)$ (at the times $t_{i}, i=1-30$ ). A detailed explanation is displayed on the screen, of how to input the values; a copy of that message is shown here:

IN ORDER TO REPRESENT THE BURNER GAS FLOW RATE AS A FUNCTION OF TIME, IT WILL BE APPROXIMATED BY A SERIES OF STRAIGHT LINE SEGMENTS. EACH SEGMENT IS BOUNDED BY A CORRESPONDING GAS FLOW RATE. THE PROGRAM THEN INTERPOLATES FOR TIMES BETWEEN THOSE WHICH ARE INPUT. THE FIRST TIME MAY

$51.48=0.65 \times 9.85 \times 0.232$. 0.232 is the mass fraction of oxygen in air. 
BE 0.0. IN ORDER TO REPRESENT A CONSTANT BURNER RATE THE PROGRAM WILL ASSUME THAT THE FLOW RATE REMAINS CONSTANT FROM THE LAST INPUT VALUE TO THE END OF THE ENTIRE RUN IF THE RUN TIME IS LONGER THAN THE LAST TIME ENTERED.

(Note that the last sentence implies that a single entry suffices, if the flow is constant.) Too high an initial value, however, may produce a discontinuity of such magnitude that the program will not run. An explicit example of how to program the flow is given in section 4.4. There is an internally specified default gas flow rate of $10 \mathrm{~g} / \mathrm{s}$, used to show how the nominal heat release rate is calculated. This can be overwritten, as will be shown in Example 4 , section 4.4 .

(15) When a fire grows exponentially, i.e.,

$R=R_{0} e^{p t}$

due principally to the radiative feedback from the flame to the pyrolyzing surface, we can tie together the spread rate $\dot{R}$ and the radiation flux via

$\dot{\mathrm{R}}=\mathrm{AC}\left[1+\mathrm{C} / 2+\mathrm{C}^{2} / 3\right]$

where $\mathrm{C}=\phi_{\mathrm{rad}} / \sigma \mathrm{T}_{\mathrm{f}}^{4} \quad$ and $\quad \mathrm{A}=4 \mathrm{p} / 3 \kappa$.

In these expressions $\mathrm{T}_{f}$ is the flame temperature, assumed to be $1260 \mathrm{~K}$, and $\phi_{\mathrm{rad}}$ is the radiation flux falling on the surface. The wisdom of choosing the parameter A to describe the growth rate is dubious, but it will be used until the spread-rate problem is addressed in a better way.

(16) The volumetric flow rate must be prescribed by the user, as well as whether it is into the room or out. The flow rate $\dot{v}(t)$ is input in the same way as that of $\dot{\mathrm{m}}_{\mathrm{g}}(t)$ for a burner (see note (14), just above). The instructions given on the screen are reproduced here (also, see example 5 in section 4.5):

IN ORDER TO SIMULATE THE VOLUMETRIC THROUGHPUT AS ANY PRESCRIBED FUNCTION

OF TIME, IT IS APPROXIMATED BY A SERIES OF STRAIGHT-LINE SEGMENTS. EACH

IS BOUNDED BY TWO TIMES, OF COURSE. THE ENTRIES ARE THEREFORE A TIME

AND THE PRESCRIBED VOLUMETRIC THROUGHPUT AT THAT TIME. THE PROGRAM WILL THEN INTERPOLATE LINEARLY BETWEEN THOSE FLOW VALUES, FOR ALL MOMENTS BETWEEN THE GIVEN BOUNDING TIMES. THE INITIAL FLOW MAY BE TAKEN TO BE ZERO, TO ENSURE A GRADUAL TURN-ON OF THE FAN (AND TO AVOID DISCONTINUOUS PHYSICAL PROCESSES!). IN THAT CASE THERE MUST BE AT LEAST TWO SEGMENTS, OF COURSE. 
IN GENERAL THE MINIMUM NUMBER IS 1, THE MAXIMUM NUMBER OF SEGMENTS FOR THE FORCED-VENT-FLOW CURVE IS 20.

(17) Provision has not been made for different wall, ceiling, and floor properties (thickness or material). Hence "wall" here is to be interpreted as "wall, ceiling, and floor". When there are substantial differences in properties, an area-weighted average might be used. Note: Walls are assumed to be thermally thick. If a wall is thermally thin (as is likely to be the case for a metal wall) the wall-heating algorithm will not work properly.

(18) All flames are assumed to have the same temperature $(1260 \mathrm{~K})$. Subsequent versions of the program will permit different flame temperatures for different fuels.

(19) This assumes that each object is a homogeneous fuel with constant, uniform properties. In a situation where there are many objects, the limitation to four objects presents a serious difficulty. Even if there were no such limitation, however, the calculation would become unreasonably slow. A useful simplification, therefore, is to lump several objects into one "effective object." How to achieve this is discussed in item 13, section 8 .

It is appropriate at this point to define, for the user who is not familiar with FORTRAN, the three relevant descriptive modes for numerical input: the first is called "floating-point", and is denoted by the letter F. It merely means that the number is written with a decimal point. Thus, 15. is a floating-point number, while 15 is not. So are .0, 0.0022, .1234, and 567.0; these examples are chosen to indicate that there need not necessarily be a zero before or after the decimal point. But the decimal point must be there. The description is actually more precise: there are two numbers following the F, separated by a period - e.g., F12.4 - for our purposes, it is not necessary to understand the significance of the 12 ; the 4 in this example signifies that only the first four digits after the decimal point will be "read" by the program. Thus, if the number 92.123456 were typed in, the program would read it as 92.1234 . 
The second descriptive mode refers to integers; it is, reasonably enough, denoted by $I$. Here it is necessary to not have a decimal point. However, there is a potential source of difficulty here: the full description has a number following the letter I - e.g., I3. This means that three digits are expected (in this example). Thus if one were to enter (say) "5", this would be an error; what needs to be entered is either "005", or two blanks and then " 5 ". On the other hand, if the number is followed by a comma (as is sometimes called for), then the entry is properly interpreted, even if only one digit is entered.

The third descriptive mode refers to numbers given in exponential notation. Thus, the number $1.2340 \times 10^{-4}$ is written (in FORTRAN) as +0.1234 E-03, and the format description is E11.4; "E" for "exponential", 11 is the number of places required to write the number out, including space for the sign and for the period; and (just as for floating-point numbers), 4 is the number of places appearing after the decimal point. In the above example, if an E13.4 format had been called for, then two blanks should appear to the left of the expression - otherwise the expression is not "right-justified", and would not be accepted. Some examples of these errors will be given in section 4.8 .

Most of the input has a floating-point format -. that is, it must have a decimal point. That is important, for on some systems, if the user forgets to enter a decimal point, the machine will assume one exists (at a place determined by the left-justification of the number), and accept the entry-which will then most likely be off by a few orders of magnitude. For a few items $\left(\mathrm{H}_{c}, \mathrm{H}_{\mathrm{v}}\right)$, it must be in exponential notation -- thus, for example, 0.00094 would have to be entered as 9.4E-04. As has been indicated above, the units are S.I.

\subsection{The Input File}

All of the information described in section 3.1 is stored in a file (except for the default case, which is stored in the program as BLOCK DATA). 
The file name is quite arbitrary, though usually short (eight or fewer characters), with an extension such as .INP or .DAT (for "input" or "data"). 6 When the INPUT section of the program runs, the user can create such input files. Once they are created, they can be named and stored, or discarded. In subsequent runs of the program, a subroutine checks to see whether there are any input files available in the user's account, and lists them. The user can then choose to delete one or more, to use one, to use the default case, and/or to modify one of the available files and then save the modified file under a new name. If an "old" name is used (that is, of one of the preexisting files), then the "old" file is deleted (we cannot have two different files with the same name). It may be the case that the contents of one (or more) of the named input files is not known to the user (or has been forgotten). Therefore, if a file is chosen for use, the user is given the opportunity to examine the file. Then the decision to keep, modify, or delete the file can be easily made.

\subsection{Interactive Input}

An existing file can be modified either by using the computer's text editor (i.e., prior to running the program), or through the "editor" built into the program for just this purpose. Obviously, in order to use the system's text editor to do this, one has to be familiar both with that editor and with the structure of the input file as well. Neither is required if the program itself is used, but access to a terminal is still required, of course. The program can be run in batch mode (see section 5), but creating a new input file without access to a terminal would be very difficult. The input data is entered (or altered) by answering a series of questions which appear on the screen. There also is explanatory text to clarify both the questions and the format in which the answers are to be given.

The input program is very flexible and user-friendly; it makes for quite easy interactive use. The input data can be entered by running through the

6 Except for the CYBER computer, which does not permit a period within the file name. 
questions sequentially - data for the room, followed by the geometry of object 1 , the thermophysical properties of object 1 , the geometry of object 2 , the properties of object 2 , etc. Then information about the vents must be supplied; then about the walls; then some miscellaneous (but important) physical constants. Finally, some information about the desired numerical and output options must be specified. (These will be covered in sections 3.5 and 6, respectively.)

Alternatively, the input can be entered through a menu-driven option. Thus, say a run has been made with input file TEST.INP, and it is desired to make a run with everything unchanged except for (say) the width of a doorway. It would be very tedious to run through the entire sequence in order to change that one datum; instead, when the "menu" is presented, the vent section is chosen, the change is made, and the process terminated. The user is then asked whether he (she) desires to keep this change file (for future use or reference); if this is the case, "Y" (for "yes") is typed in, and then a name is chosen for it. Otherwise, the changed data will be used for the current run, but then it is eliminated. Before the run begins, however, all of the data is recapitulated on the screen (in sequence); and a further opportunity given to change some data in case an error has become apparent during the recapitulation.

Whether the sequential or the menu-driven route is chosen, information for a given category is presented on the screen, and the user may change one or more of the items shown by typing in the item number (an integer), comma, then the new value (in floating-point form, generally; see section 3.4 if this term is not familiar), followed by a carriage return; then the next item number, comma, its new value, etc. We will hereafter use the symbol <RET> to mean "carriage return". When all the changes which are desired have been made, an extra $<$ RET $>$ will go to the next display.

There is one other set of options not yet described: to use some alternative physics subroutines (also see section 4.6). This appears as the very first question when running through sequentially, or as choice (1) "select physics subroutines", in the menu-driven option. It refers to three 
areas of calculation where alternative calculational procedures can be used. The first is in finding the surface temperature of an object (subroutines TMPO). Alternative \#1 is a simple approximation which is generally not recommended (there was insufficient to remove it in this version). Alternative \#2 is a numerical integration of the partial differential equation describing the one-dimensional diffusion of heat in a slab. It is rather more elaborate but much more accurate; moreover, it does not in fact take a great deal of time to carry out, and is therefore the default option.

The second set of alternatives concerns the calculation of the absorption coefficient $\kappa$ of the hot layer (via subroutines ABSRB). The first choice here is to just use the soot concentration of the layer (calculated elsewhere) to find $\kappa$; it works well for fuels where soot is the principal absorber; this is the default option. The second choice uses a much more elaborate calculation which takes the $\mathrm{CO}_{2}$ and $\mathrm{H}_{2} \mathrm{O}$ molecular absorption bands into account, as well. It evidently should be used for non-luminous fuels, such as $\mathrm{H}_{2}$, $\mathrm{CO}$, or $\mathrm{CH}_{4}$.

The third set of alternatives related to the expressions to be used for the mass and energy fluxes carried into the upper layer by the thermal plume above the fire. In Mark 5, the calculation assumed that there is an equivalent virtual point source beneath the fire surface (see ref. [2, 17]). This is the default choice. Some experiments have shown, however (see [18-19]) that real plumes are better simulated by taking the point source at the surface; this, therefore, is the second choice which is made available. There exist, moreover, several other good plume models, based on other correlations and/or analyses; there is no one definitive "correct" (or even "best"!) choice to be made among them at present, however. Therefore, four additional new choices (see [19-22]) have been made available for the knowledgeable user who may prefer to use one of them. They are discussed in detail in ref. [22a]. In most cases, the results of using one of these will not differ very markedly from those found using either of the first two plume models. This is especially true when the burning object is a complex combination of many items. 


\subsection{Errors}

In typing in data, it is inevitable that errors will be made. These are of two kinds: erroneous choices (say, two vents instead of three) and errors of syntax. The program is very forgiving of syntactical errors: with very few exceptions, if such an error is made, the question is merely reasked. The most common such errors involve omitting a decimal point where one belongs, or typing in a single digit where three are asked for.

Besides the syntactical errors, errors of choice or of entries (which are syntactically correct) can be made; in order to catch these right away, once one has made whatever changes are desired on a given display and has (therefore) typed an extra $\langle$ RET $\rangle$, the display is repeated, with the altered values now shown, and a new opportunity is given to effect whatever changes are wanted.

At the very end of the entire procedure, when all desired changes have been made, the entire set of data can be displayed yet again, if desired (via subroutine RECAP), and yet another opportunity to make last-minute changes is given. If there are none, then another <RET> permits one to go on with the actual calculation.

\subsection{Numerical Options}

We will not describe the numerical techniques used in solving the equations (the interested reader is again referred to Mitler and Emmons [2]). Suffice it to say here that an iterative scheme is used; if the number of iterations needed to converge to a solution exceeds a certain number, the message "NOT CONVERGED" appears on the screen. Then the time step $\Delta t$ is halved, and the procedure restarted. The halving will proceed (if necessary) until the time increment is $\Delta t$ (initial)/2048; for the default $\Delta t$ (initial) $=2$ $\mathrm{sec}$, the smallest time step is approximately $1 \mathrm{~ms}\left(10^{-3} \mathrm{sec}\right)$; if it still fails to converge, the message "YOU ARE IN TROUBLE" appears on the screen and the options then are: (1) to stop the run, (2) to proceed, or (3) to invoke the debugger (see section 7 ). 
The covergence criterion used in these calculations is that, for each of a certain subset of the variables, the fractional difference $\left|\frac{\Delta x}{x}\right|$ between two successive iterations be less than a predetermined constant, TOLER. In Mark 5 , the default value of TOLER was taken to be $3 \times 10^{-4}$ but could be changed to any desired value by the user, before any run. For FIRST, this default value has been reduced to $10^{-4}$. As pointed out in section 8 (item 11), if a calculation runs into difficulties at some point, rerunning with TOLER changed to some other value will often give almost exactly the same results, and succeed in going through the troublesome region, as well. The number of iterations carried out before halving the time interval was fixed at 35 in Mark 5. In FIRST, this value has been increased to 100 , but it can be changed to any other desired value by the user, before a run.

Finally, the default time increment $\Delta t$ is 2 seconds; however, this can be changed to any other value before a run, if desired.

\subsection{Materials Handbook}

One of the more tedious aspects of running the program is to input the chemical and thermophysical values for the various inert and flammable materials involved in the particular problem. Still worse is finding the appropriate data, which is often scattered in various handbooks and in the literature, and - worse - is sometimes unpublished. Both of these difficulties are avoided for a number of fuels, by the introduction of a separate data-base-management program, MASBANK, which sets up a file of the thermophysical data which is needed. The program is designed to access this data file, and this permits the user to choose a particular material (if it's one of those in the data bank, that is) by name.

Even more troublesome is finding data for real burning objects (upholstered chairs; beds; trash baskets); data on product generation rates; data applicable to situations to be modeled. Many of the inputs are not fundamental properties or "constants", e.g., mass fractions, combustion efficiency, burnout parameter, spread rate parameter, absorption coefficient, etc. 
If one can get a consistent set of values which succeeds in simulating such a complex item, therefore, it will be very useful to use MASBANK to store it.

MASBANK sets up two files, MASNAM and MASDAT; the first is merely a list of the names of the materials which are included, with a short comment for each. The second file contains the actual data. The user of MASBANK can add as many new materials as he (she) pleases (up to a present limit of 50), with accompanying names. He can also delete any item, and rename any material. Moreover, the list can be alphabetized (by choosing the "SORT" option). Also, the existing data for a material can be modified. Finally, even though there are only 20 pieces of thermophysical information for each material right now, room has been made for up to 40 items per material. (For example, one might want the transverse and parallel thermal conductivities for anisotropic materials such as wood, in the future. However, some (small) changes must be made in the program itself in order to expand the list beyond 20.)

It is as undesirable to have most users of the program be able to modify the data bank, as it would be for someone to be able to modify a value in a handbook. It was therefore decided to have MASBANK as a separate program, rather than to incorporate it as a subroutine in FIRST. It can thus be kept in a master account, accessible only to the program custodian. MASDAT, then, should be a protected $\mathrm{file}^{7}$ in the master account, inaccessible to users except to copy it as is - i.e., to be used as "reference standards" which may be copied into a user's account when required. The user can then change the data via the program for his own purposes, but the master file remains inviolate.

The procedure in running MASBANK is completely analogous to that for running FIRST - that is, a control file (.CSS, .CON, or whatever) is set up if necessary, so that keypunching MASBANK (or any other plausible name) starts the program. A sample session is given in example 9, section 4.9. A discussion of the available data is given in the next section (3.7).

7 Protected against any change or deletion by anyone other than the program custodian. 


\subsection{Data Available at Present}

It is appropriate to begin with an important caveat: the information supplied with this program has been obtained from reliable sources, but may not be entirely correct. What is more important, it will not be applicable to all samples and all situations.

There are a number of basic problems involved:

(1) It is possible to give pretty unambiguous chemical and thermophysical data for pure simple substances such as water and methane; however, many more substances come in a number of similar but not identical forms - such as different isomers of hydrocarbons. Still others come as mixtures (such as gasoline) which are not unique. For such substances there is no one value which is correct, for any of the properties.

(2) A little less obvious are substances such as PMMA (polymethyl methacrylate), which can have different additives which change its properties significantly. Or which can be in different states, all of them appearing the same.

(3) Still other substances are strongly influenced by ambient humidity, as they absorb water readily. This is true, for example, for wood, gypsum and concrete.

(4) Some properties - such as thermal conductivity and specific heatare functions (sometimes complex) of temperature. The present version of the model, however, does not take this into account. Hence, we must choose some representative temperature at which to list these values. The simplest choice is $25^{\circ} \mathrm{C}$ (although some mean value might possibly be better).

(5) Ignition. For our ignition criterion, we use an "ignition temperature", $\mathrm{T}_{\mathrm{ig}}$. This is already an inaccurate description of reality. Moreover, there are at least two values for it: piloted ignition temperature and auto-ignition temperature. We assume that in a room fire, the appropriate one is the pilot ignition temperature.

(6) Wood. Not only does wood have characteristics which vary with relative humidity and with temperature, but it is an anisotropic substance. Since lumber is cut along the grain, the proper value to use for thermal conductivity is the transverse value, $k_{\perp}$. Moreover, wood chars and a description for that process is not yet in the program.

(7) Many substances "age" - oxidation, cross-linking, decomposition, devolatilization, and other processes occur which change the material properties - often in unknown ways. 
(8) Similar phenomena as described in (7) typically take place during burning.

(9) Flame emissivity. A real flam is turbulent, inhomogenous, and anisotropic. It is modeled here as a uniform, isotropic, homogenous cone of "grey" gas of uniform temperature. The appropriate emissivity to use for it, therefore, is not immediately apparent, even when good experimental data exists. The value to be used in the model must be consistent with the flame temperature assumed (1260 K, at present), and with the radiative losses as well as radition back to the pyrolyzing surface.

(10) Perhaps even larger uncertainties appear because of disagreements in measurements made by various experiments.

(11) Finally, real combustibles often are composites which may generate combustion products not in direct proportion to their mass or area, when burning.

For all of these reasons (and others), it has been decided to include only a small set of materials. The data sources are listed in the reference section. Within the next year or so a report will appear with a larger data base.

The materials which are covered are methane $\left(\mathrm{CH}_{4}\right)$, heptane $\left(\mathrm{C}_{7} \mathrm{H}_{16}\right)$, polymethylmethacrylate (PMMA; $\mathrm{C}_{5} \mathrm{H}_{8} \mathrm{O}_{2}$ ), and flexible polyurethane foam (PU; $\left.\mathrm{CH}_{1.91} \mathrm{O}_{0.263} \mathrm{~N}_{0.055}\right)$. These are shown in Table 1 . For many of the values, there are several references. The references listed in square brackets after the value itself is the one which is probably best, in the author's opinion.

Values are also given in Table 1 for $\mathrm{T}_{\mathrm{pyro}}, \mathrm{A}, \psi$, and $\mathrm{t}_{\mathrm{b}}$ which require some discussion: The temperature at which pyrolysis is supposed to begin, $\mathrm{T}_{\text {pyro }}$, is discussed in note $(10)$, section 3.1. Any value can be used for it since it is not used at present. The spread rate parameter $A$ is also discussed in section 3.1 (see note (9) there). There is no data for A except for PU foam; hence values have been estimated for it for materials other than $\mathrm{PU}$ foam, from the relative burning rates of those materials. That is, it is assumed that

$$
A_{i} \cong\left(\dot{m}_{i}^{\prime \prime} / \dot{m}_{p}^{\prime \prime}\right) A_{p}
$$


where the subscript "p" here stands for "polyurethane", and $\dot{m}_{i}^{\prime \prime}$ is the pyrolysis rate (in $\mathrm{gm} / \mathrm{m}^{2} \mathrm{sec}$ ) for material $i$. The data for $\dot{\mathrm{m}}_{i}^{\prime \prime}$ are taken from Table II of reference [23]. What to use for $\psi$ and $t_{b}$ are discussed in notes (12) and (13), respectively, section 3.1 .

Finally, consider $\gamma$. In a turbulent flame, the eddies of air which are pulled into the combustion zone may contain more oxygen than is required to oxidize the fuel; that is, the actual air/fuel mass ratio in the flame may exceed the stiochiometric value. Although in most cases $\gamma$ will be approximately $\gamma_{s}$, the possibility is therefore left open to take it to be larger than $\gamma_{s}$. An estimate of the actual values of $\gamma$ for a flame can be obtained from the mean flame temperature: if it falls below the value it would have if energy were lost from the region via radiation only, then $\gamma>\gamma_{s}$.

\section{SAMPLE SESSIONS AT THE TERMINAL: OPERATING IN INTERACTIVE MODE}

In this subsection, several sample sessions at the keyboard will be illustrated, with some supplementary notes. First, some general notes:

(a) Evidently, the first thing that must be done is to sign on (i.e., log on). The procedure to be described here is specific to the operating system OS 32 , for Perkin-Elmer computers; if you have another computer, consult your manual or your system operator for the appropriate procedures - they are all generically similar, but usually differ in details.

Initially, a system "prompt" is visible (it is an asterisk, for OS 32). We then type in something like:

S NAME, 100, SECRET

The $S$ is shorthand for "sign on"; NAME is your identifying label (for convenience); 100 is your account number, and SECRET is the current password for account 100 (NAME, 100, and SECRET are, of course, arbitrary labels chosen for this example). For many systems, the password (SECRET, in this case) will not "echo"that is, it will not appear on the screen, even though it has been properly typed in. This is done for security reasons.

(b) After signing on, the user must call up the program. This is done by typing in some label; we have used RUNFIRE (some computers may require typing in several lines: the control file, briefly discussed in section 5 .) 
(c) $\angle R E T>$ is the symbol we use to refer to a "carriage return".

(d) User responses ( $\mathrm{Y}, \mathrm{N}$, or a number) appear in column 1, while all the text generated internally appears in cols. 2-80. Since the responses show up in the margin, we do not need to use a prompt to indicate where a user response is required (and given). There are some exceptions, especially when a $\langle$ RET $>$ is called for.

(e) In the examples, the character "N" has been typed in (for "NO"), wherever it is the appropriate answer. However, the program is so written that $\angle R E T>$ is generally accepted instead of $\mathrm{N}$; $\mathrm{N}$ has been used in these illustrative samples nevertheless, because a carriage return does not show up on the printed page. ${ }^{8}$

(f) Whenever running interactively, the third question must always be answered No.

\subsection{Example 1. Default Run}

The shortest session requires precisely eight responses (two file names and $\operatorname{six} \mathrm{N}^{\prime} \mathrm{s}$, in this case), and that results in running the default case. The names requested are for the output files; they are discussed in section 6.1; FIROUT and PLOTUT are just sample names. The request for file names is displayed explicitly only in this example; it is omitted in subsequent examples.

The run can be labeled any way one chooses, as we can see from the last line shown on the next page: "Programmer-Run Number = ". (The reason for the form of this label is that more than one programmer had access to the program, during its development. It should, by rights, be changed to read "User ...".)

8 However, some machines (such as the CYBER 855) will interpret this as an "end of file" and cease "reading" what is being typed in. To avoid that, one can type a blank (i.e., hit the space bar) before $\langle$ CR $>$. 
RUNFIRE

ENTER A NAME FOR THE OUTPUT FILE

FILE NAME MAY BE A MAXIMUM OF 14 CHARACTERS

LENGTH OF FILE NAME IS LIMITED BY YOUR COMPUTER

FIROUT

ENTER A NAME FOR THE OUTPUT PLOT FILE

FILE NAME MAY BE A MAXIMUM OF 14 CHARACTERS

LENGTH OF FILE NAME IS LIMITED BY YOUR COMPUTER PLOTUT

WILL THIS BE USED FOR FURTHER BATCH RUNS? ( $\mathrm{Y} / \mathrm{N})$ :

$\mathrm{N}$

WELCOME TO THE INPUT PORTION OF THE PROGRAM. THIS SECTION ALLOWS YOU

TO INITIALIZE YOUR VARIABLES EITHER BY BLOCK DATA OR BY A PREEXISTING INPUT FILE. IT THEN ALLOWS YOU TO MAKE ANY CHANGES TO YOUR INPUT DATA AND GIVES you THE OPTION TO SAVE THESE CHANGES IN A FILE (NAMED BY YOU).

YOU HAVE A TOTAL OF 3 INPUT FILE(S)

AVAILABLE FOR USE

DAN2. INP

HENRI. INP

LEN. INP

BEFORE CONTINUING, WOULD YOU LIKE ANY OF THESE INPUT FILES DELETED? (Y/N): $\mathrm{N}$

WOULD YOU LIKE ONE OF THESE INPUT DATA FILES TO BE READ IN AND INITIALIZE THE INPUT VARIABLES? ( $\mathrm{Y} / \mathrm{N})$ : $\mathrm{N}$

YOUR INPUT DATA WILL BE BASED ON THE PROGRAM BLOCK-DATA DEFAULTS

WOULD YOU LIKE YOUR INPUT DATA DISPLAYED TO LET YOU SEE WHAT THE VARIABLES HAVE BEEN INITIALIZED TO? ( $\mathrm{Y} / \mathrm{N})$ : N

WOULD YOU LIKE TO MAKE ANY CHANGES TO THE INPUT DATA? ( $\mathrm{Y} / \mathrm{N})$ : $\mathrm{N}$

WOULD YOU LIKE TO SAVE YOUR INPUT DATA IN A FILE? (Y/N): N

ENTER USER-GENERATED DOCLMENTATION FOR THIS RUN:

PROGRAMMER-RUN NUMBER = 


\subsection{Example 2. Serial Input}

For our second example, we run through the entire input sequence serially, making only one change in the input data: the air/fuel mass ratio for the burning object is changed (from the present default value, to the stoichiometric value). Note that the order in which data is requested is as it is in section 3.1. A few remarks about this are in order: The program first checks a file which lists the available input files; it counts their number, prints it out, and then prints out their names.

Concerning the first table below (for ROOM NUMBER 1), item \#4: note that even though the number of objects in the room is an integer, it should still be entered with a decimal point.

The second table, on the same page, and subsequent tables: the values are given in exponential notation - even if they are entered in floating-point form. At the end of each of these tables, there is an instruction to enter the information in I4 format, comma, then F12.4 format. In fact, as soon as the comma is inserted, the program interprets the integer correctly, even if it is not entered in I4 format. This is seen at the top of p. 31, where 5 is entered (rather than 0005); similarly, the 9.85 is not entered in F12.4 format, but is correctly interpreted.

Near the end of the examples, the question "DO YOU WANT TO USE THE DEBUGGER?" was answered with a carriage return <RET>, rather than with $N$; this was inadvertent, but illustrates another feature: a <RET> is equivalent to a "No" answer in this program (see comment (e), p. 25). The debugger should only be used after you have become familiar with its capabilities, and then only after your fire has been run once and it has been found that there are difficulties that need analysis.

Note: in Example 1, there were three input files available. Input files can be created by anyone using the program; when Example 2 was run, it was found that 6 input files now existed. Also note that the physical values listed here (for PU foam) differ from the updated values shown in Table 1 , at the end of this report. 
WILL THIS BE USED FOR FURTHER BATCH RUNS? ( $\mathrm{Y} / \mathrm{N})$ :

$\mathrm{N}$

WELCOME TO THE INPUT PORTION OF THE PROGRAM. THIS SECTION ALLOWS YOU

TO INITIALIZE YOUR VARIABLES EITHER BY BLOCK DATA OR BY A PREEXISTING INPUT FILE. IT THEN ALLOWS YOU TO MAKE ANY CHANGES TO YOUR INPUT DATA AND GIVES YOU THE OPTION TO SAVE THESE CHANGES IN A FILE (NAMED BY YOU).

YOU HAVE A TOTAL OF 6 INPUT FILE(S)

AVAILABLE FOR USE

DAN2 . INP

HENRI. INP

LEN. INP

TEST.DAT

JAR . TEM

PU.INP

BEFORE CONTINUING, WOULD YOU LIKE ANY OF THESE INPUT FILES DELETED? (Y/N): $\mathrm{N}$

WOULD YOU LIKE ONE OF THESE INPUT DATA FILES TO BE READ IN AND INITIALIZE THE INPUT VARIABLES? ( $\mathrm{Y} / \mathrm{N})$ :

$\mathrm{N}$

YOUR INPUT DATA WILL BE BASED ON THE PROGRAM BLOCK-DATA DEFAULTS

WOULD YOU LIKE YOUR INPUT DATA DISPLAYED TO LET YOU SEE WHAT THE VARIABLES HAVE BEEN INITIALIZED TO? ( $\mathrm{Y} / \mathrm{N})$ :

$\mathrm{N}$

WOULD YOU LIKE TO MAKE ANY CHANGES TO THE INPUT DATA? (Y/N): Y

IN THE INPUT SEQUENCE TO FOLLOW, NOTE THAT AN INPUT ERROR

-- E.G. TYPING A LETTER WHERE A DIGIT IS REQUIRED --

CAUSES THE QUESTION TO BE REASKED.

THE SYMBOL 〈RET> STANDS FOR CARRIAGE RETURN, OR NEWLINE, OR WHATEVER KEY ON THE TERMINAL IS USED TO ENTER DATA.

HIT 〈RET> TO CONTINUE

YOU HAVE 2 OPTIONS FOR CHANGING THE DATA:

1) A MENU FOR SELECTING YOUR AREAS OF CHANGE

2) RUN THROUGH THE WHOLE INPUT SEQUENCE, START TO FINISH

NOTE: IF YOU ARE NOT FANILIAR WITH THE INPUT PROGRAM, IT IS BEST TO MAKE CHOICE 非 2 IN ORDER TO FAMILIARIZE YOURSELF WITH THE DIFFERENT SECTIONS.

PLEASE ENTER THE ITEM NUMBER OF YOUR CHOICE

2

CHANGE FROM STANDARD PHYSICS SUBROUTINES? ( $\mathrm{Y} / \mathrm{N})$ : $\mathrm{N}$ 
Y

CHANGE FROM STANDARD GEOMETRIC AND PHYSICAL PARAMETERS? ( $\mathrm{Y} / \mathrm{N})$ :

WOULD YOU LIKE TO USE THE MENU INSTEAD OF RUNNING THROUGH EACH SCREEN? (Y/N): $\mathrm{N}$

WHEN ENTERING THE ROOM GEOMETRY BELOW, NOTE THAT THE CARTESIAN COORDINATE SYSTEM WE USE IS: FACING THE FRONT OF THE BUILDING, THE ORIGIN IS AT THE BOTTOM OF THE GROUND FLOOR, EXTREME LEFT-HAND SIDE, FRONT. FOR A SINGLE ROOM WITH A SINGLE DOOR, "THE FRONT" IS DEFINED AS THE WALL WITH THE DOOR IN IT. IF THERE IS MORE THAN ONE DOOR, THE DEFINITION IS UP TO THE USER.

THE X-, Y-, AND Z- COORDINATES GIVE DISTANCES TO THE RIGHT, REAR, AND TOP OF THE ROOM, THUS CONSTITUTING A STANDARD RIGHT-HANDED COORDINATE SYSTEM.

HIT 〈RET〉 TO CONTINUE.

IN EACH TABLE BELOW, IF ALL THE VALUES ARE SATISFACTORY, THEN AS INDICATED, ENTER ITEM $O$ AND 〈RET〉. IN ORDER TO CHANGE ANY (OR ALL) OF THE VALUES, TYPE IN THE APPROPRIATE ITEM NUMBER IN I3 FORMAT, THEN A COMMA, AND THEN THE RELEVANT DATA VALUE IN F12.4 OR E12.4, FOLLOWED BY 〈RET >. REPEAT FOR AS MANY ITEMS AS DESIRED, ENDING

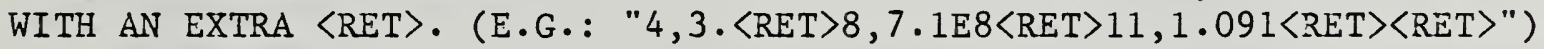

ROOM NUMBER 1:

0) CHANGE NOTHING (CONTINUE)

1) LENGTH ALONG X (METERS):

2) LENGTH ALONG Y (METERS):

3) HEIGHT (METERS):

4) 非 OF OBJECTS:

5) INITIAL ROOM TEMPERATURE (K): 300.000

6) PHOTOELECTIC SMOKE DETECTOR ( $1.0=$ PRESENT, $0.0=$ ABSENT $): 1.0$

7) DETECTOR ABSORPTION COEFFICIENT THRESHOLD ( $1 / \mathrm{M}): 0.3300 E-01$

8) POSITION OF DETECTOR INPUT PORT (METERS BELOW CEILING): 0.2000E-01 100) COPY ALL ABOVE DATA FROM ANOTHER ROOM TO CHANGE ITEMS, ENTER "ITEM, VALUE〈RET〉" (I4,F12.4); END WITH AN EXTRA 〈RET〉:

UNLESS THERE IS A COMPELLING REASON TO CHOOSE OTHERWISE, THE LOCATION OF AN OBJECT IS THE POINT AT THE GEOMETRICAL CENTER OF THE PRINCIPAL EXPOSED SURFACE OF THE OBJECT.

ROOM NUMBER 1, OBJECT NUMBER 1 (OBJ KO = 1) - GEOMETRIC PROPERTIES:

0) CHANGE NOTHING (CONTINUE)

1) X-COORDINATE (METERS): $\quad 0.8400 E+00$

2) Y-COORDINATE (METERS): $\quad 0.2818 E+01$

3) HEIGHT (METERS): $\quad 0.6100 E+00$

4) ANGLE WITH HORIZONTAL (IN DEGREES): $0.0000 E+00$

5) IF SURFACE IS VERTICAL, ANGLE WITH XZ-PLANE: $0.0000 E+00$

6) THICKNESS (METERS): $\quad 0.1000 E+00$

7) INITIAL BURNING RADIUS (METERS): $\quad 0.3700 \mathrm{E}-01$ 
8) OBJECT RADIUS (METERS): $\quad 0.8598 \mathrm{E}+00$

9) MAXIMUM BURNING RADIUS (METERS): $0.9677 \mathrm{E}+00$

10) INSTEAD OF ITEMS $8 \& 9$, ENTER DIMENSIONS OF RECTANGULAR OBJECT (ITEM NO., LENGTH AND WIDTH VALUES ALL ON ONE LINE (METERS): E.G., "10,1.5,3.85")

100) COPY ALL ABOVE DATA FROM ANOTHER OBJECT - ENTER "100,OBJECT非" (SAME FORMAT TO CHANGE ITEMS, ENTER "ITEM, VALUE〈RET〉" (I4,F12.4); END WITH AN EXTRA 〈RET〉:

THE OBJECT'S CURRENT COORDINATES PLACE PART OF THE OBJECT OUTSIDE OF THE ROOM, ASSUMING THAT THOSE COORDINATES ARE THE GEOMETRIC CENTER OF THE OBJECT. UNLESS YOU INTEND FOR THE OBJECT'S COORDINATES TO BE SOMETHING OTHER THAN THE GEOMETRIC CENTER OF THE OBJECT, THE FOLLOWING CHANGES ARE INDICATED:

A NEW X-COORDINATE FOR THE OBJECT IN THE RANGE [ 8.5980000E-01, 1.5786000E+00] A NEW Y-COORDINATE FOR THE OBJECT IN THE RANGE [ 8.5980000E-01, 2.7978000E+00] DO YOU WISH TO MAKE SUCH CHANGES? (TYPE Y/N)

$\mathrm{N}$

Properties of selected materials are now available

from a data bank. Do you wish to use this feature? $(\mathrm{Y} / \mathrm{N})$

$\mathrm{N}$

ROOM NUMBER 1 , OBJECT NUMBER 1 (OBJ KO = 1) - PHYSICAL PROPERTIES:

IS THE OBJECT BURNING? ( $Y / N)$ :

$\mathrm{Y}$

When burning, object 1 will be a

1) GROWING FIRE

2) POOL FIRE

3) GAS BURNER

4) SPECIAL FIRE (User must supply the algorithm)

5) WALL FIRE (Not currently available)

1

Enter number: 1 - 5 (FORMAT Il)

Is this object away from walls: (0)

close to a wall: (1)

in a corner : (2)

0

Object 1 is Growing fire

It is away from all walls

1) THERMAL CONDUCTIVITY (W/M DEG K): $0.5400 E-01$

2) SPECIFIC HEAT ( $/ \mathrm{Kg}$ DEG K):

$0.1900 \mathrm{E}+04$

3) DENSITY (Kg/CUBIC METERS):

4) EMISSIVITY/ABSORPTIVITY OF SURFACE:

$0.4800 E+02$

5) AIR/FUEL MASS RATIO IN FREE BURN:

$0.9800 \mathrm{E}+00$

6) STOICHIOMETRIC MASS RATIO:

$0.1445 \mathrm{E}+02$

$0.9850 \mathrm{E}+01$

7) FRACTION OF HEAT OF COMBUSTION RELEASED: $0.6500 E+00$

8) HEAT OF COMBUSTION $(\mathrm{J} / \mathrm{Kg})$ :

$0.2870 \mathrm{E}+08$

9) HEAT OF VAPORIZATION $(\mathrm{J} / \mathrm{Kg})$ :

$0.2054 \mathrm{E}+07$

10) INITIAL FUEL MASS $(\mathrm{Kg})$ :

$0.6852 \mathrm{E}+01$

11) TEMPERATURE OF IGNITION (K):

$0.7270 \mathrm{E}+03$

12) TEMPERATURE OF ONSET OF PYROLIZATION (K): $0.6000 E+03$

13) CO2 MASS EVOLVED/FUEL MASS:

$0.1504 \mathrm{E}+01$

14) CO MASS EVOLVED/FUEL MASS:

$0.1330 \mathrm{E}-01$

15) SMOKE MASS EVOLVED/FUEL MASS:

$0.2410 \mathrm{E}+00$

16) WATER MASS EVOLVED/FUEL MASS:

$0.7135 \mathrm{E}+00$

17) SEMIAPEX ANGLE OF FLAME (IN DEGREES):

$0.3000 \mathrm{E}+02$

* Note: 14.45 is the default value; it is to be changed for this calculation. 
18) FIRE SPREAD PARAMETER (M/SEC):

$0.1090 E-01$

19) BURNOUT PARAMETER (IN SECONDS):

20.00

20) Flame Extinction Coef. $(1 / M)$ :

1.550

100) COPY ALL ABOVE DATA FROM ANOTHER OBJECT - ENTER '100,OBJECT非' (SAME FORMAT

TO CHANGE ITEMS, ENTER "I'TEM,VALUE〈RET>" (I4,F12.4); END WITH AN EXTRA 〈RET〉:

$5,9.85$

ROOM NUMBER 1, OBJECT NUMBER 1 (OBJ KO = 1) - PHYSICAL PROPERTIES:

Object 1 is Growing fire

It is away from all walls

1) THERMAL CONDUCTIVITY (W/M DEG K): $0.5400 E-01$

2) SPECIFIC HEAT ( J/Kg DEG K): $0.1900 E+04$

3) DENSITY (Kg/CUBIC METERS): $0.4800 \mathrm{E}+02$

4) EMISSIVITY/ABSORPTIVITY OF SURFACE: $0.9800 E+00$

5) AIR/FUEL MASS RATIO IN FREE BURN:

6) STOICHIOMETRIC MASS RATIO:

$0.9850 \mathrm{E}+01$

$0.9850 \mathrm{E}+01$

7) FRACTION OF HEAT OF COMBUSTION RELEASED: $0.6500 E+00$

8) HEAT OF COMBUSTION ( $\mathrm{J} / \mathrm{Kg})$ :

$0.2870 \mathrm{E}+08$

9) HEAT OF VAPORIZATION $(\mathrm{J} / \mathrm{Kg})$ :

$0.2054 \mathrm{E}+07$

10) INITIAL FUEL MASS $(\mathrm{Kg})$ :

$0.6852 \mathrm{E}+01$

11) TEMPERATURE OF IGNITION (K):

$0.7270 \mathrm{E}+03$

12) TEMPERATURE OF ONSET OF PYROLIZATION (K):

$0.6000 \mathrm{E}+03$

13) CO2 MASS EVOLVED/FUEL MASS:

$0.1504 E+01$

14) CO MASS EVOLVED/FUEL MASS:

$0.1330 \mathrm{E}-01$

15) SMOKE MASS EVOLVED/FUEL MASS :

$0.2410 \mathrm{E}+00$

16) WATER MASS EVOLVED/FUEL MASS :

$0.7135 \mathrm{E}+00$

17) SEMIAPEX ANGLE OF FLAME (IN DEGREES):

$0.3000 \mathrm{E}+02$

18) FIRE SPREAD PARAMETER (M/SEC):

19) BURNOUT PARAMETER (IN SECONDS):

$0.1090 \mathrm{E}-01$

20) Flame Extinction Coef. ( $1 / M)$ :

20.00

1.550

100) COPY ALL ABOVE DATA FROM ANOTHER OBJECT - ENTER '100,OBJECT非' (SAME FORMAT DO YOU WANT TO CHANGE YOUR INPUT? ( $\mathrm{Y} / \mathrm{N})$ :

$\mathrm{N}$

UNLESS THERE IS A COMPELLING REASON TO CHOOSE OTHERWISE, THE LOCATION OF AN OBJECT IS THE POINT AT THE GEOMETRICAL CENTER OF THE PRINCIPAL EXPOSED SURFACE OF THE OBJECT.

ROOM NUMBER 1, OBJECT NUMBER 2 (OBJ KO = 2) - GEOMETRIC PROPERTIES:

0) CHANGE NOTHING (CONTINUE)

1) X-COORDINATE (METERS):

$0.2080 \mathrm{E}+01$

2) Y-COORDINATE (METERS):

$0.2818 \mathrm{E}+01$

3) HEIGHT (METERS) :

$0.8640 \mathrm{E}+00$

4) ANGLE WITH HORIZONTAL (IN DEGREES):

$0.0000 \mathrm{E}+00$

5) IF SURFACE IS VERTICAL, ANGLE WITH XZ-PLANE:

$0.0000 \mathrm{E}+00$

6) THICKNESS (METERS) :

7) INITIAL BURNING RADIUS (METERS):

$0.1000 \mathrm{E}+00$

8) OBJECT RADIUS (METERS):

$0.3700 \mathrm{E}-01$

9) MAXIMUM BURNING RADIUS (METERS):

$0.3439 \mathrm{E}+00$

10) INSTEAD OF ITEMS $8 \& 9$, ENTER DIMENSIONS OF RECTANGULAR OBJECT (ITEM NO., LENGTH AND WIDTH VALUES ALL ON ONE LINE (METERS): E.G., "10,1.5,3.85")

100) COPY ALL ABOVE DATA FROM ANOTHER OBJECT - ENTER "100,OBJECT 非" (SAME FORMAT TO CHANGE ITEMS, ENTER "ITEM,VALUE〈RET〉" (I4,F12.4); END WITH AN EXTRA 〈RET〉:

* Note that the keyboard input has made items 5 and 6 identical in value, as verified in this second display of the table. 


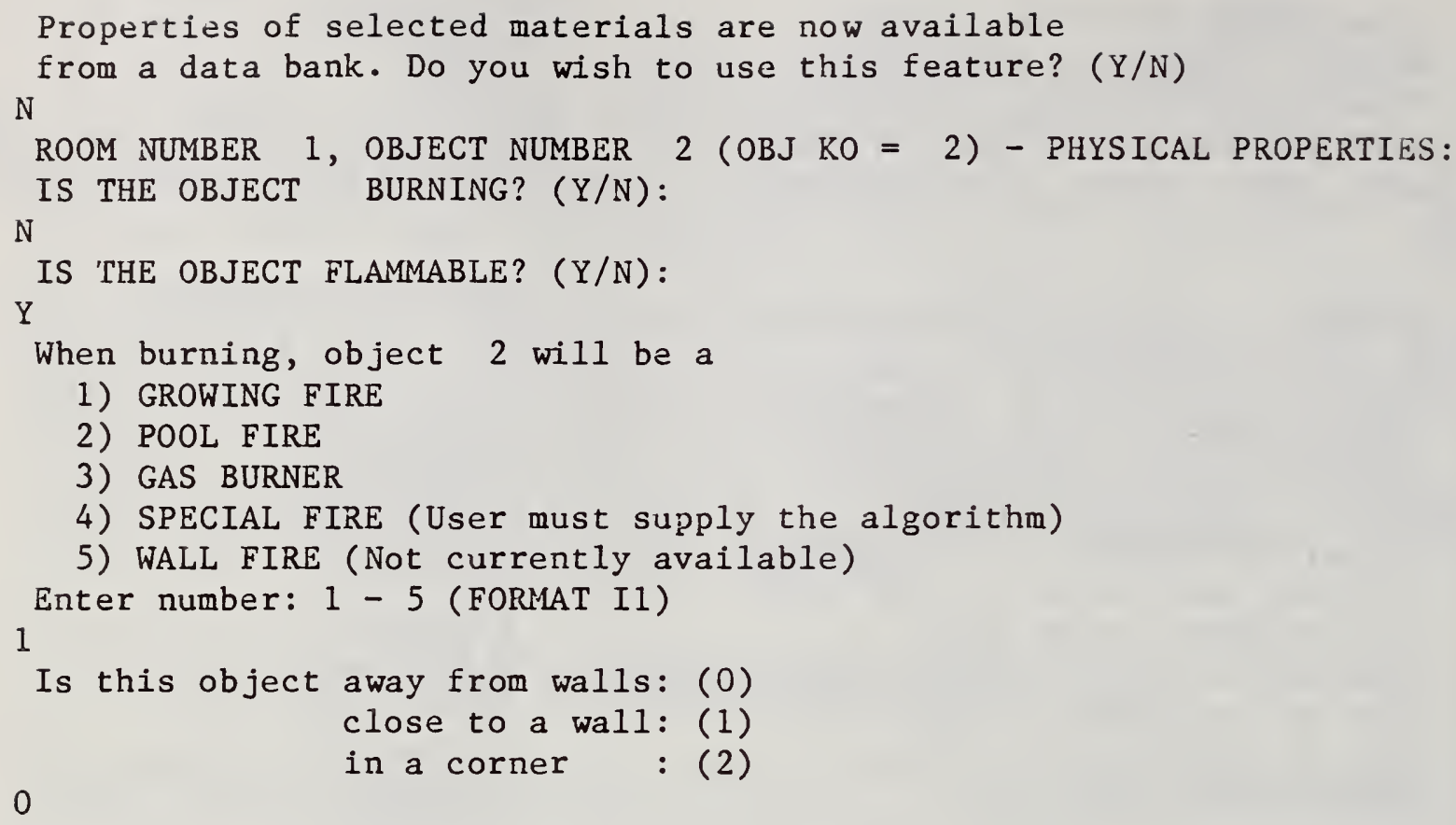

1) THERMAL CONDUCTIVITY (W/M DEG K): $0.5400 \mathrm{E}-01$

2) SPECIFIC HEAT ( J/Kg DEG K): $1900 \mathrm{E}+04$

3) DENSITY ( $\mathrm{Kg} /$ CUBIC METERS): $0.4800 \mathrm{E}+02$

4) EMISSIVITY/ABSORPTIVITY OF SURFACE: $0.9800 \mathrm{E}+00$

5) AIR/FUEL MASS RATIO IN FREE BURN: $0.1445 E+02$

6) STOICHIOMETRIC MASS RATIO: $0.9850 \mathrm{E}+01$

7) FRACTION OF HEAT OF COMBUSTION RELEASED: $0.6500 E+00$

8) HEAT OF COMBUSTION $(\mathrm{J} / \mathrm{Kg}): \quad 0.2870 \mathrm{E}+08$

9) HEAT OF VAPORIZATION $(\mathrm{J} / \mathrm{Kg})$ : $\quad 0.2054 \mathrm{E}+07$

10) INITIAL FUEL MASS $(\mathrm{Kg}): \quad 0.1096 \mathrm{E}+01$

11) TEMPERATURE OF IGNITION (K): $0.7400 \mathrm{E}+03$

12) TEMPERATURE OF ONSET OF PYROLIZATION (K): $0.6000 E+03$

13) CO2 MASS EVOLVED/FUEL MASS: $0.1504 E+01$

14) CO MASS EVOLVED/FUEL MASS: $0.1330 \mathrm{E}-01$

15) SMOKE MASS EVOLVED/FUEL MASS: $0.2410 E+00$

16) WATER MASS EVOLVED/FUEL MASS: $0.7135 E+00$

17) SEMIAPEX ANGLE OF FLAME (IN DEGREES): $0.3000 E+02$

18) FIRE SPREAD PARAMETER (M/SEC): $0.1090 E-01$

19) BURNOUT PARAMETER (IN SECONDS): 20.00

20) Flame Extinction Coef. (1/M): 1.550

100) COPY ALL ABOVE DATA FROM ANOTHER OBJECT - ENTER '100, OBJECT非' (SAME FORMAT TO CHANGE ITEMS, ENTER "ITEM, VALUE〈RET〉" (I4,F12.4); END WITH AN EXTRA 〈RET〉:

$* *$

DESIRED NUMBER OF VENTS (DEFAULT $=1, \operatorname{MAX}=5$ ):

VENT NUMBER 1

0) CHANGE NOTHING (CONTINUE)

1) WIDTH (METERS): $\quad 0.7620 E+00$

2) HEIGHT (METERS): $\quad 0.2032 E+01$

** Note that omitting an entry has the effect of giving the default value ( 1 , in this case). 
3) TRANSOM DEPTH (METERS): $0.4064 E+00$

4) SIDE 1 IS IN ROOM: 1

5) SIDE 2 IS IN ROOM: 0

6) THIS VENT IS INITIALLY OPEN

100) COPY ALL ABOVE DATA FROM ANOTHER VENT - ENTER "100, VENT非" (SAME FORMAT) TO CHANGE ITEMS, ENTER "ITEM,VALUE〈RET>" (I4,F12.4); END WITH AN EXTRA 〈RET〉:

VENT NUMBER 1

FORCED VENTILATION $(T=$ PRESENT, $F=$ ABSENT $): \quad F$

TO CHANGE THE STATUS ENTER " $T$ " OR " $F$ " ONLY

HIT 〈RET〉 TO CONTINUE

WALL NUMBER 1 (SIDE 1 IN ROOM 1; SIDE 2 IN 0 )

0) CHANGE NOTHING (CONTINUE)

1) THICKNESS (METERS): $0.2540 E-01$

2) THERMAL CONDUCTIVITY (W/M DEG K): $0.1340 E+00$

3) SPECIFIC HEAT ( J/Kg DEG K): $0.1062 \mathrm{E}+04$

4) DENSITY (Kg/CUBIC METERS): $0.8000 E+03$

100) COPY ALL ABOVE DATA FROM ANOTHER WALL - ENTER "100, WALL\#" (SAME FORMAT) TO CHANGE ITEMS, ENTER "ITEM, VALUE〈RET>" (I4,F12.4); END WITH AN EXTRA 〈RET〉:

NON-INDEXED VARIABLES:

0) CHANGE NOTHING (CONTINUE)

1) SPECIFIC HEAT OF AIR (J/Kg DEG C): $\quad 0.1004 E+04$

3) AMBIENT TEMP. OUTSIDE BUILDING (K): $0.3000 E+03$

4) MAX. HEAT TRANSFER COEF. (WALLS)(W/SQ. METERS DEG C): $0.5000 E+02$

5) MIN. HEAT TRANSFER COEF. (WALLS)(W/SQ. METERS DEG C): $0.5000 E+01$

6) HEAT TRANSFER COEF . (OBJECTS)(W/SQ - METERS DEG C): $\quad 0.1000 E+02$

7) PLUME ENTRAINMENT COEFFICIENT: $\quad 0.1000 \mathrm{E}+00$

8) VENT FLOW COEFFICIENT: $\quad 0.6300 \mathrm{E}+00$

TO CHANGE ITEMS, ENTER "ITEM, VALUE〈RET>" (I4,F12.4); END WITH AN EXTRA 〈RET〉:

YOU ARE DONE CHANGING THE GEOMETRIC AND PHYSICAL PARAMETERS. WOULD YOU LIKE TO GO BACK AND MAKE ANY FURTHER CHANGES? ( $\mathrm{Y} / \mathrm{N})$ :

$\mathrm{N}$

DO YOU WANT OUTPUT IN COLUMNAR SHORT FORM (REQUIRES LINE PRINTER) INSTEAD OF (DEFAULT) TABULAR LONG FORM? ( $\mathrm{Y} / \mathrm{N})$ :

N

DO YOU WANT THE TERMINAL OUTPUT IN GRAPHICAL FORM INSTEAD OF (OR IN ADDITION TO THE DEFAULT) TABULAR FORM? ( $\mathrm{Y} / \mathrm{N})$ : N 


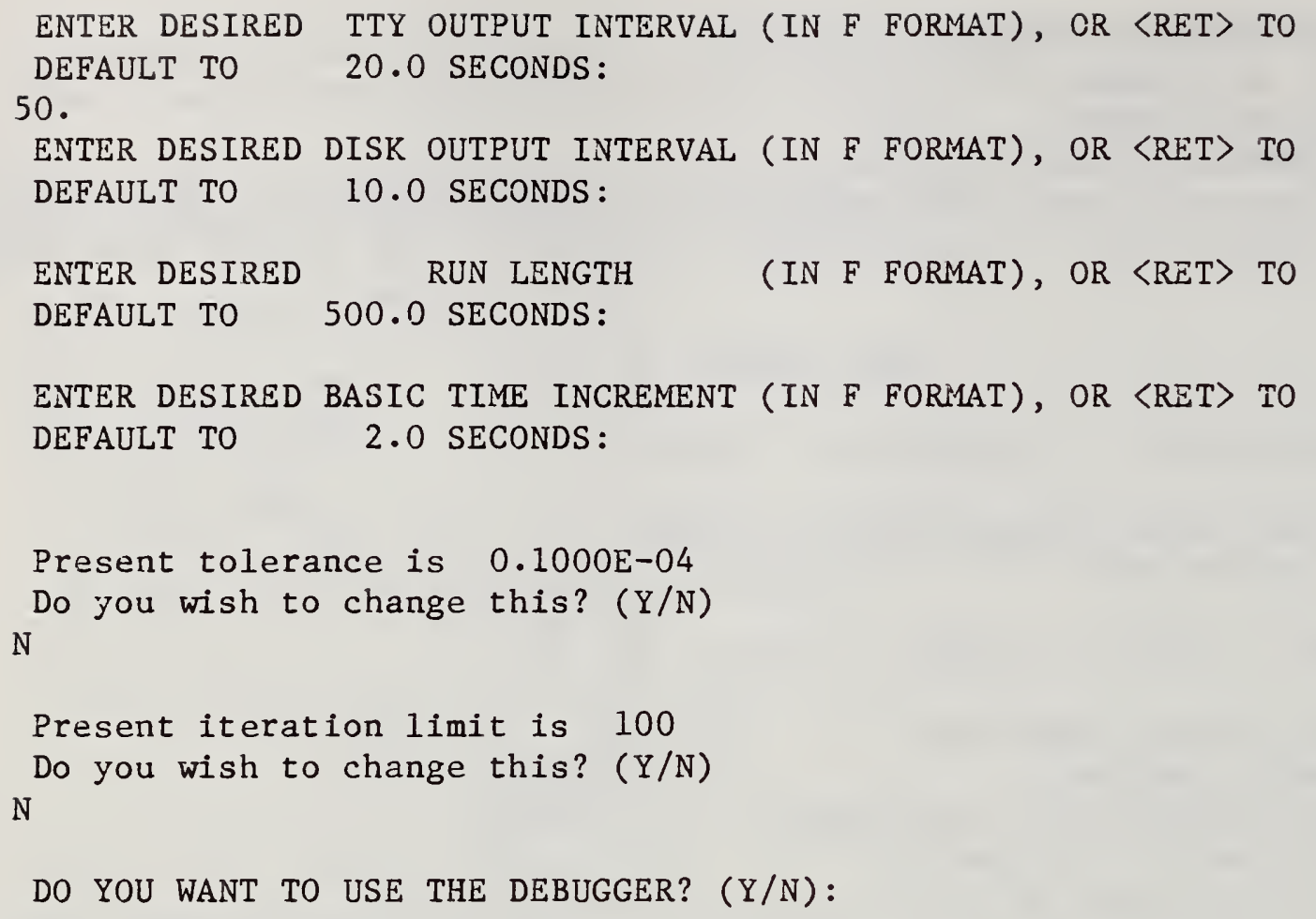

TYPE IN COMMENT LINES FOR LABEL, ENDING WITH AN EXTRA 〈RET>. NO COMMENTS AT THIS TIME

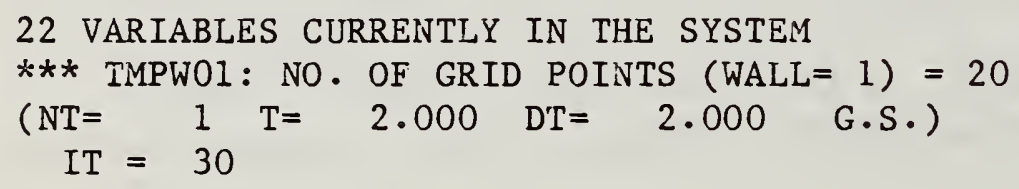

The calculation has begun, and we can stop the example here. ** To understand the absence of an " $\mathrm{N}$ " here, see comment at beginning of section 4.2 


\subsection{Example 3. Menu-Driven Input}

This is exactly the same as example 2, except that the change is made via the menu-driven option; the procedure can be seen to be quite a bit more succinct. Warning: see Section 4.9 before choosing option (10) in the menu!

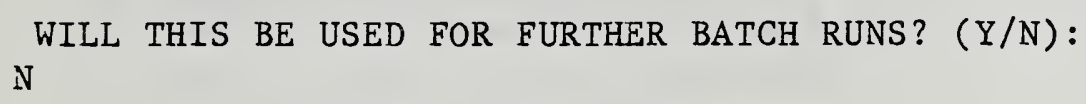

WELCOME TO THE INPUT PORTION OF THE PROGRAM. THIS SECTION ALLOWS YOU TO INITIALIZE YOUR VARIABLES EITHER BY BLOCK DATA OR BY A PREEXISTING INPUT FILE. IT THEN ALLOWS YOU TO MAKE ANY CHANGES TO YOUR INPUT DATA AND GIVES YOU THE OPTION TO SAVE THESE CHANGES IN A FILE (NAMED BY YOU).

YOU HAVE A TOTAL OF 6 INPUT FILE(S)

AVAILABLE FOR USE

DAN2. INP

HENRI . INP

LEN . INP

TEST.DAT

JAR . TEM

PU. INP

BEFORE CONTINUING, WOULD YOU LIKE ANY OF THESE INPUT FILES DELETED? (Y/N): $\mathrm{N}$

WOULD YOU LIKE ONE OF THESE INPUT DATA FILES TO BE READ IN AND INITIALIZE THE INPUT VARIABLES? ( $\mathrm{Y} / \mathrm{N})$ :

$\mathrm{N}$

YOUR INPUT DATA WILL BE BASED ON THE PROGRAM BLOCK-DATA DEFAULTS

WOULD YOU LIKE YOUR INPUT DATA DISPLAYED TO LET YOU SEE WHAT THE VARIABLES HAVE BEEN INITIALIZED TO? ( $\mathrm{Y} / \mathrm{N})$ :

$\mathrm{N}$

WOULD YOU LIKE TO MAKE ANY CHANGES TO THE INPUT DATA? ( $\mathrm{Y} / \mathrm{N})$ : $\mathrm{Y}$

IN THE INPUT SEQUENCE TO FOLLOW, NOTE THAT AN INPUT ERROR

-- E.G. TYPING A LETTER WHERE A DIGIT IS REQUIRED --

CAUSES THE QUESTION TO BE REASKED.

THE SYMBOL 〈RET> STANDS FOR CARRIAGE RETURN, OR NEWLINE, OR WHATEVER KEY ON THE TERMINAL IS USED TO ENTER DATA.

HIT 〈RET〉 TO CONTINUE

YOU HAVE 2 OPTIONS FOR CHANGING THE DATA:

1) A MENU FOR SELECTING YOUR AREAS OF CHANGE

2) RUN THROUGH THE WHOLE INPUT SEQUENCE, START TO FINISH 
NOTE: IF YOU ARE NOT FAMILIAR WITH THE INPUT PROGRAM, IT IS BEST TO MAKE CHOICE 非 2 IN ORDER TO FAMILIARIZE YOURSELF WITH THE DIFFERENT SECTIONS.

1

PLEASE ENTER THE ITEM NUMBER OF YOUR CHOICE

THE FOLLOWING LIST IS A BREAKUP OF THE MAIN SECTIONS OF THE PROGRAIA. TO CHANGE THE DAT $L_{L}$ IN ANY ONE OF THESE SECTIONS, ENTER THE ITEM NUMBER OF YOUR CHOICE.

0) NO MORE CHANGES

1) SELECT PHYSICS SUBROUTINES

2) CHANGE GEOMETRIC AND/OR PHYSICAL PARAMETERS

3) CHANGE OUTPUT OPTIONS

2

WOULD YOU LIKE TO USE THE MENU INSTEAD OF RUNNING THROUGH EACH SCREEN? ( $Y / N$ ): Y

THE FOLLOWING MENU ALLOWS YOU TO MAKE SPECIFIC CHANGES TO THE INPUT

VALUES WITHOUT GOING THROUGH THE WHOLE INPUT PROGRAM. TO MAKE A CHANGE, ENTER THE ITEM NUMBER AND FOLLOW THE INSTRUCTIONS. ONCE YOU ARE DONE, THIS MENU WILL REAPPEAR FOR FUTHER CHANGES TO BE MADE (IF ANY).

NOTE: CHANGING THE NUMBER OF OBJECTS IN A ROOM MAY BE DONE BY ENTERING "GEOMETRIC PROPERTIES FOR ROOM".

HIT 〈RET〉 TO CONTINUE

MENU FOR SPECIFIC CHANGES

0) NO MORE CHANGES

1) GEOMETRIC PARAMETERS FOR ROOM

2) GEOMETRIC PARAMETERS FOR OBJECT

3) PHYSICAL PARAMETERS FOR OBJECT

4) VENT PARAMETERS

5) WALL PROPERTIES

7) NON-INDEXED VARIABLES

8) $\mathrm{ADD} A$ VENT

9) DELETE A VENT

10) SELECT OBJECT MATERIAL 3

PLEASE ENTER THE NUMBER OF THE SECTION TO BE CHANGED.

PLEASE ENTER THE OBJECT NUMBER

1

ROOM NUMBER 1 , OBJECT NUMBER 1 (OBJ KO = 1) - PHYSICAL PROPERTIES: IS THE OBJECT BURNING? ( $\mathrm{Y} / \mathrm{N})$ :

$Y$

When burning, object 1 will be a

1) GROWING FIRE

2) POOL FIRE

3) GAS BURNER

4) SPECIAL FIRE (User must supply the algorithm)

5) WALL FIRE (Not currently available)

Enter number: 1 - 5 (FORMAT I1)

1 
Is this object away from walls: (0) close to a wal1: (1)

in a corner :

0

Object 1 is Growing fire

It is away from all walls

1) THERMAL CONDUCTIVITY (W/M DEG K): $0.5400 E-01$

2) SPECIFIC HEAT (J/Kg DEG K): $0.1900 \mathrm{E}+04$

3) DENSITY (Kg/CUBIC METERS): $0.4800 E+02$

4) EMISSIVITY/ABSORPTIVITY OF SURFACE: $0.9800 E+00$

5) AIR/FUEL MASS RATIO IN FREE BURN: $0.1445 E+02$

6) STOICHIOMETRIC MASS RATIO: $0.9850 E+01$

7) FRACTION OF HEAT OF COMBUSTION RELEASED: $0.6500 E+00$

8) HEAT OF COMBUSTION ( $\mathrm{J} / \mathrm{Kg})$ :

9) HEAT OF VAPORIZATION $(\mathrm{J} / \mathrm{Kg}):-0.2054 \mathrm{E}+07$

10) INITIAL FUEL MASS ( $\mathrm{Kg}):-0.6852 \mathrm{E}+01$

11) TEMPERATURE OF IGNITION (K): $0.7270 E+03$

12) TEMPERATURE OF ONSET OF PYROLIZATION (K): $0.6000 E+03$

13) CO2 MASS EVOLVED/FUEL MASS: $0.1504 E+01$

14) CO MASS EVOLVED/FUEL MASS: $0.1330 \mathrm{E}-01$

15) SMOKE MASS EVOLVED/FUEL MASS: $0.2410 E+00$

16) WATER MASS EVOLVED/FUEL MASS: $0.7135 \mathrm{E}+00$

17) SEMIAPEX ANGLE OF FLAME (IN DEGREES): $0.3000 E+02$

13) FIRE SPREAD PARAMETER (M/SEC): $0.1090 E-01$

19) BURNOUT PARAMETER (IN SECONDS): 20.00

20) Flame Extinction Coef. (1/M): 1.550

100) COPY ALL ABOVE DATA FROM ANOTHER OBJECT - ENTER '100, OBJECT非' (SAME FORMAT TO CHANGE ITEMS, ENTER "ITEM,VALUE〈RET〉" (I4,F12.4); END WITH AN EXTRA 〈RET〉: $5,9.85$

ROOM NUMBER 1 , OBJECT NUMBER 1 (OBJ KO = 1) - PHYSICAL PROPERTIES: Object 1 is Growing fire

It is away from all walls

1) THERMAL CONDUCTIVITY (W/M DEG K): $0.5400 E-01$

2) SPECIFIC HEAT (J/Kg DEG K): $0.1900 E+04$

3) DENSITY ( $\mathrm{Kg} /$ CUBIC METERS): $0.4800 \mathrm{E}+02$

4) EMISSIVITY/ABSORPTIVITY OF SURFACE: $0.9800 E+00$

5) AIR/FUEL MASS RATIO IN FREE BURN: $0.9850 E+01$

6) STOICHIOMETRIC MASS RATIO: $0.9850 \mathrm{E}+01$

7) FRACTION OF HEAT OF COMBUSTION RELEASED: $0.6500 E+00$

8) HEAT OF COMBUSTION $(\mathrm{J} / \mathrm{Kg}): \quad 0.2870 \mathrm{E}+08$

9) HEAT OF VAPORIZATION $(\mathrm{J} / \mathrm{Kg}): \quad 0.2054 \mathrm{E}+07$

10) INITIAL FUEL MASS ( $\mathrm{Kg}): \quad 0.6852 \mathrm{E}+01$

11) TEMPERATURE OF IGNITION (K): $0.7270 E+03$

12) TEMPERATURE OF ONSET OF PYROLIZATION (K): $0.6000 E+03$

13) CO2 MASS EVOLVED/FUEL MASS: $0.1504 \mathrm{E}+01$

14) CO MASS EVOLVED/FUEL MASS: $0.1330 \mathrm{E}-01$

15) SMOKE MASS EVOLVED/FUEL MASS: $0.2410 E+00$

16) WATER MASS EVOLVED/FUEL MASS: $0.7135 \mathrm{E}+00$

17) SEMIAPEX ANGLE OF FLAME (IN DEGREES): $0.3000 E+02$

18) FIRE SPREAD PARAMETER (M/SEC): $0.1090 E-01$

19) BURNOUT PARAMETER (IN SECONDS): 20.00 
20) Flame Extinction Coef. (I/M):

1.550

100) COPY ALL ABOVE DATA FROM ANOTHER OBJECT - ENTER '100,OBJEC'S非' (SAME FORMAT DO YOU WANT TO CHANGE YOUR INPUT? $(\mathrm{Y} / \mathrm{N})$ : $\mathrm{N}$

MENU FOR SPECIFIC CHANGES

0) NO MORE CHANGES

1) GEOMETRIC PARAMETERS FOR ROOM

2) GEOMETRIC PARAMETERS FOR OBJECT

3) PHYSICAL PARAMETERS FOR OBJECT

4) VENT PARAMETERS

5) WALL PROPERTIES

7) NON-INDEXED VARIABLES

8) $A D D$ A VENT

9) DELETE A VENT

10) SELECT OBJECT MATERIAL 0

PLEASE ENTER THE NUMBER OF THE SECTION TO BE CHANGED.

THE FOLLOWING LIST IS A BREAKUP OF THE MAIN SECTIONS OF THE PROGRAM. TO CHANGE THE DATA IN ANY ONE OF THESE SECTIONS, ENTER THE ITEM NUMBER OF YOUR CHOICE.

0) NO MORE CHANGES

1) SELECT PHYSICS SUBROUTINES

2) CHANGE GEOMETRIC AND/OR PHYSICAL PARAMETERS

3) CHANGE OUTPUT OPTIONS

0

WOULD YOU LIKE YOUR INPUT DATA DISPLAYED TO LET YOU SEE WHAT THE VARIABLES HAVE BEEN INITIALIZED TO? ( $\mathrm{Y} / \mathrm{N})$ :

$\mathrm{N}$

WOULD YOU LIKE TO GO BACK AND MAKE ANY FURTHER CHANGES BEFORE RUNNING THE SIMULATION? ( $\mathrm{Y} / \mathrm{N})$ :

$\mathrm{N}$

WOULD YOU LIKE TO SAVE YOUR INPUT DATA IN A FILE? ( $\mathrm{Y} / \mathrm{N})$ : $\mathrm{N}$

ENTER USER-GENERATED DOCUMENTATION FOR THIS RUN:

PROGRAMMER-RUN NUMBER = MIT 2

TYPE IN COMMENT LINES FOR LABEL, ENDING WITH AN EXTRA 〈RET〉. FOOLS RUSH IN .... 


\subsection{Example 4. A Variable-Flow Gas Burner Fire}

The variable gas-burner option is invoked in order to produce a specified fire. (Note that if we went ahead and ran this case, we would automatically have a burner with the default radius, i.e., almost one meter!) A table is built up of the values $\dot{m}_{g}\left(t_{i}\right)$ of mass flow rate at times $t_{i}, i=1$, $\ldots, n(n \leq 20)$. There is also a fourth column, marked "nominal heat release rate $(\mathrm{kW}) "$; this is what the heat release rate would be if all the heating value inherent in the gas (i.e., $\Delta \mathrm{H}_{\mathrm{c}} \mathrm{J} / \mathrm{kg}$ ) were released, yielding 1000 $\dot{\mathrm{m}}_{\mathrm{g}}\left(t_{\mathrm{i}}\right) \Delta \mathrm{H}_{\mathrm{c}}$ watts. This is calculated internally, with the user-specified (or default) value of $\Delta \mathrm{H}_{\mathrm{c}}$. The actual heat release will be $\chi \Delta \mathrm{H}_{\mathrm{c}} \mathrm{J} / \mathrm{kg}$, unless oxygen starvation limits the output even further.

Some of the thermal chemical/physical data for materials which is listed in section 3.1 , is not needed when we have a gas burner - for example, the burnout parameter $t_{b}$, the fire spread parameter $A$. Indeed, items 9-12 and 1819 from that list have been omitted in the list which appears on page 42, for that reason. Items $1-4$ should also have been omitted, but appear nevertheless; do not be confused by this programming lapse: these items are irrelevant, and should simply be ignored. (Indeed, they are not used in the burner algorithm; the values which appear for items 1-4 could therefore be quite arbitrary.)

The problem we will solve in the following example is a gas burner yielding a fire which increases to an initial peak at $40 \mathrm{sec}$, a second peak at $50 \mathrm{sec}$, and then declines rapidly to zero at $300 \mathrm{sec}$. Note that the fuel used is user-chosen (if not, it will emit gaseous PU foam!) 
WILL THIS BE USED FOR FURTHER BATCH RUNS? ( $Y / N)$ :

$\mathrm{N}$

WELCOME TO THE INPUT PORTION OF THE PROGRAM. THIS SECTION ALLOWS YOU

TO INITIALIZE YOUR VARIABLES EITHER BY BLOCK DATA OR BY A PREEXISTING INPUT FILE. IT THEN ALLOWS YOU TO MAKE ANY CHANGES TO YOUR INPUT DATA AND GIVES YOU THE OPTION TO SAVE THESE CHANGES IN A FILE (NAMED BY YOU).

YOU HAVE A TOTAL OF 6 INPUT FILE(S)

AVAILABLE FOR USE

DAN2 . INP

HENRI . INP

LEN . INP

TEST.DAT

JAR . TEM

PU. INP

BEFORE CONTINUING, WOULD YOU LIKE ANY OF THESE INPUT FILES DELETED? (Y/N): $\mathrm{N}$

WOULD YOU LIKE ONE OF THESE INPUT DATA FILES TO BE READ IN AND INITIALIZE THE INPUT VARIABLES? ( $\mathrm{Y} / \mathrm{N})$ :

$\mathrm{N}$

YOUR INPUT DATA WILL BE BASED ON THE PROGRAM BLOCK-DATA DEFAULTS

WOULD YOU LIKE YOUR INPUT DATA DISPLAYED TO LET YOU SEE WHAT THE VARIABLES HAVE BEEN INITIALIZED TO? ( $\mathrm{Y} / \mathrm{N})$ :

$\mathrm{N}$

WOULD YOU LIKE TO MAKE ANY CHANGES TO THE INPUT DATA? ( $Y / N)$ :

Y

IN THE INPUT SEQUENCE TO FOLLOW, NOTE THAT AN INPUT ERROR

-- E.G. TYPING A LETTER WHERE A DIGIT IS REQUIRED --

CAUSES THE QUESTION TO BE REASKED.

THE SYMBOL 〈RET> STANDS FOR CARRIAGE RETURN, OR NEWLINE, OR

WHATEVER KEY ON THE TERMINAL IS USED TO ENTER DATA.

HIT 〈RET〉 TO CONTINUE

YOU HAVE 2 OPTIONS FOR CHANGING THE DATA:

1) A MENU FOR SELECTING YOUR AREAS OF CHANGE

2) RUN THROUGH THE WHOLE INPUT SEQUENCE, START TO FINISH

NOTE: IF YOU ARE NOT FAMILIAR WITH THE INPUT PROGRAM, IT IS BEST TO MAKE CHOICE 非 IN ORDER TO FAMILIARIZE YOURSELF WITH THE DIFFERENT SECTIONS.

PLEASE ENTER THE ITEM NUMBER OF YOUR CHOICE 1

THE FOLLOWING LIST IS A BREAKUP OF THE MAIN SECTIONS OF THE PROGRAM. TO CHANGE THE DATA IN ANY ONE OF THESE SECTIONS, ENTER THE ITEM NUMBER OF YOUR CHOICE. 
0) NO MORE CHANGES

1) SELECT PHYSICS SUBROUTINES

2) CHANGE GEOMETRIC AND/OR PHYSICAL PARAMETERS

3) CHANGE OUTPUT OPTIONS

2

WOULD YOU LIKE TO USE THE MENU INSTEAD OF RUNNING THROUGH EACH SCREEN? (Y/N): $Y$

THE FOLLOWING MENU ALLOWS YOU TO MAKE SPECIFIC CHANGES TO THE INPUT VALUES WITHOUT GOING THROUGH THE WHOLE INPUT PROGRAM. TO MAKE A CHANGE, ENTER THE ITEM NUMBER AND FOLLOW THE INSTRUCTIONS. ONCE YOU ARE DONE, THIS MENU WILL REAPPEAR FOR FUTHER CHANGES TO BE MADE (IF ANY). NOTE: CHANGING THE NUMBER OF OBJECTS IN A ROOM MAY BE DONE BY ENTERING "GEOMETRIC PROPERTIES FOR ROOM".

HIT 〈RET〉 TO CONTINUE

MENU FOR SPECIFIC CHANGES

0) NO MORE CHANGES

1) GEOMETRIC PARAMETERS FOR ROOM

2) GEOMETRIC PARAMETERS FOR OBJECT

3) PHYSICAL PARAMETERS FOR OBJECT

4) VENT PARAMETERS

5) WALL PROPERTIES

7) NON-INDEXED VARIABLES

8) $\mathrm{ADD}$ A VENT

9) DELETE A VENT

10) SELECT OBJECT MATERIAL

3

PLEASE ENTER THE NUMBER OF THE SECTION TO BE CHANGED.

PLEASE ENTER THE OBJECT NUMBER

1

ROOM NUMBER 1 , OBJECT NUMBER 1 (OBJ KO = 1) - PHYSICAL PROPERTIES:

IS THE OBJECT BURNING? ( $\mathrm{Y} / \mathrm{N})$ : Y

When burning, object 1 will be a

1) GROWING FIRE

2) POOL FIRE

3) GAS BURNER

4) SPECIAL FIRE (User must supply the algorithm)

5) WALL FIRE (Not currently available)

3

Enter number: 1 - 5 (FORMAT II)

Is this object away from walls: (0)

close to a wall: (1)

0 in a corner : (2)

Object 1 is Gas burner

It is away from all walls

1) THERMAL CONDUCTIVITY (W/M DEG K):

2) SPECIFIC HEAT ( $\mathrm{J} / \mathrm{Kg}$ DEG K): $0.1900 \mathrm{E}+04$ 
3) DENSITY ( $\mathrm{Kg} /$ CUBIC METERS):

4) EMISSIVITY/ABSORPTIVITY OF SURFACE:

5) AIR/FUEL MASS RATIO IN FREE BURN:

6) STOICHIOMETRIC MASS RATIO:

7) FRACTION OF HEAT OF COMBUSTION RELEASED:

8) HEAT OF COMBUSTION ( $\mathrm{J} / \mathrm{Kg})$ :

13) CO2 MASS EVOLVED/FUEL MASS:

14) CO MASS EVOLVED/FUEL MASS:

15) SHOKE MASS EVOLVED/FUEL MASS:

16) WATER MASS EVOLVED/FUEL MASS:

17) SEMIAPEX ANGLE OF FLAME (IN DEGREES):

20) Flame Extinction Coef. (1/M):
$0.4800 \mathrm{E}+02$

$0.9800 \mathrm{E}+00$

$0.1445 \mathrm{E}+02$

$0.9850 \mathrm{E}+01$

$0.6500 \mathrm{E}+00$

$0.2870 \mathrm{E}+08$

$0.1504 \mathrm{E}+01$

$0.1330 \mathrm{E}-01$

$0.2410 \mathrm{E}+00$

$0.7135 \mathrm{E}+00$

$0.3000 \mathrm{E}+02$

1.550

100) COPY ALL ABOVE DATA FROM ANOTHER OBJECT - ENTER '100, OBJECT 非' (SAME FORMAT TO CHANGE ITEMS, ENTER "ITEM, VALUE〈RET>" (I4,F12.4); END WITH AN EXTRA 〈RET>:

IN ORDER TO REPRESENT THE BURNER GAS FLOW RATE AS A FUNCTION OF TIME, IT WILL BE APROXIMATED BY A SERIES OF STRIAGHT LINE SEGMENTS. EACH SEGMENT IS BOUNDED BY A CORRESPONDING GAS FLOW RATE. THE PROGRAM THEN INTERPOLATES FOR TIMES BETWEEN THOSE WHICH ARE INPUT. THE FIRST TIME MAY BE 0.0. IN ORDER TO REPRESENT A CONSTANT BURNER RATE THE PROGRAM WILL ASSUME THAT THE FLOW RATE REMAINS CONSTANT FROM THE LAST INPUT VALUE TO THE END OF THE ENTIRE RUN IF THE RUN TIME IS LONGER THAN THE LAST TIME ENTERED.

\section{BURNER GAS FLOW RATE}

\begin{tabular}{cccc} 
I & T(I) & $\begin{array}{l}\text { GAS FLOW } \\
\text { RATE(G/SEC) }\end{array}$ & $\begin{array}{c}\text { "NOMINAL" HEAT } \\
\text { RELEASE RATE(KW) }\end{array}$ \\
\hline 1 & 0.0 & 10.000 & 287.000 \\
2 & 40.0 & 10.000 & 287.000
\end{tabular}

Y

DO YOU WANT TO CHANGE YOUR INPUT? (Y/N):

WHAT TYPE OF CHANGE?

(0) NO MORE CHANGES

(1) DELETE OLD POINT(S)

(2) ADD NEW POINT(S)

(3) ALTER A POINT(S)

BURNER GAS FLOW RATE

\begin{tabular}{cccc} 
I & T(I) & $\begin{array}{l}\text { GAS FLOW } \\
\text { RATE (G/SEC) }\end{array}$ & $\begin{array}{c}\text { "NOMINAL" HEAT } \\
\text { RELEASE RATE (KW) }\end{array}$ \\
\hline 1 & 0.0 & 10.000 & 287.000 \\
2 & 40.0 & 10.000 & 287.000
\end{tabular}

ENTER THE \# OF THE POINT TO BE CHANGED, ENTER A ZERO(O) TO RETURN TO THE MENU. 1

PLEASE ENTER THE NEW TIME(SEC) AND THE NEW FLOW RATE(GRAMS/SEC)

SEPARATED BY A COMMA. DON'T FORGET THE DECIMAL PT!

$0.0,0$. 


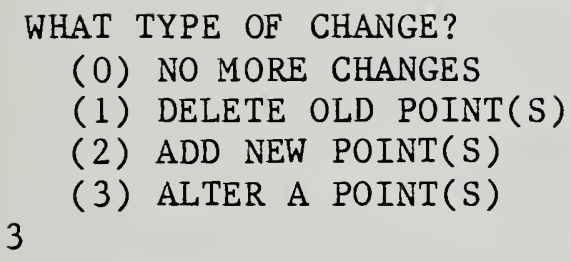

(1) DELETE OLD POINT(S)

(2) ADD NEW POINT(S)

(3) ALTER A POINT(S)

BURNER GAS FLOW RATE

\begin{tabular}{cccc} 
& & GAS FLOW & "NOM INAL" HEAT \\
I & T(I) & RATE (G/SEC) & RELEASE RATE (KW) \\
\hline 1 & 0.0 & 0.000 & 0.000 \\
2 & 40.0 & 10.000 & 287.000
\end{tabular}

ENTER THE 非 OF THE POINT TO BE CHANGED, ENTER A ZERO(0) TO RETURN TO THE MENU. 2

PLEASE ENTER THE NEW TTME(SEC) AND THE NEW FLOW RATE(GRAMS/SEC)

SEPARATED BY A COMMA. DON'T FORGET THE DECIMAL PT!

\section{0., 1 .}

WHAT TYPE OF CHANGE?

(0) NO MORE CHANGES

(1) DELETE OLD POINT(S)

(2) ADD NEW POINT(S)

(3) ALTER A POINT(S)

BURNER GAS FLOW RATE

\begin{tabular}{cccc} 
& & GAS FLOW & "NAM INAL" HEAT \\
I & T(I) & RATE (G/SEC) & RELEASE RATE $(\mathrm{KW})$ \\
\hline 1 & 0.0 & 0.000 & 0.000 \\
2 & 10.0 & 1.000 & 28.700
\end{tabular}

ENTER THE TIME(SEC) AND THE FLOW RATE(GRAMS/SEC) SEPARATED BY A COMMA (ENTER "9999." TO RETURN TO THE MENU)

DON'T FORGET THE DECIMAL PT.!

$30 ., 11$.

BURNER GAS FLOW RATE

\begin{tabular}{cccc} 
& & GAS FLOW & "NOM INAL" HEAT \\
I & T(I) & RATE $(G /$ SEC $)$ & RELEASE RATE (KW ) \\
\hline 1 & 0.0 & 0.000 & 0.000 \\
3 & 10.0 & 1.000 & 28.700 \\
& 30.0 & 11.000 & 315.700
\end{tabular}

ENTER THE TIME(SEC) AND THE FLOW RATE(GRAMS/SEC) SEPARATED BY A COMMA (ENTER "9999." TO RETURN TO THE MENU) 
DON'T FORGET THE DEC IMAL PT.!

40., 30 .

BURNER GAS FLOW RATE

\begin{tabular}{cccc} 
& & GAS FLOW & "NOM INAL" HEAT \\
I & T(I) & RATE $($ G/SEC $)$ & RELEASE RATE $($ KW $)$ \\
\hline 1 & 0.0 & 0.000 & 0.000 \\
2 & 10.0 & 1.000 & 28.700 \\
3 & 30.0 & 11.000 & 315.700 \\
4 & 40.0 & 30.000 & 861.000
\end{tabular}

ENTER THE TIME(SEC) AND THE FLOW RATE(GRAMS/SEC) SEPARATED BY A COMMA (ENTER "9999." TO RETURN TO THE MENU)

DON'T FORGET THE DECIMAL PT.!

45.,25.

BURNER GAS FLOW RATE

\begin{tabular}{cccc} 
& & GAS FLOW & "NOMINAL" HEAT \\
I & T(I) & RATE $($ G/SEC $)$ & RELEASE RATE $(\mathrm{KW})$ \\
\hline 1 & 0.0 & 0.000 & 0.000 \\
2 & 10.0 & 1.000 & 28.700 \\
3 & 30.0 & 11.000 & 315.700 \\
4 & 40.0 & 30.000 & 861.000 \\
5 & 45.0 & 25.000 & 717.500
\end{tabular}

ENTER THE TIME(SEC) AND THE FLOW RATE(GRAMS/SEC) SEPARATED BY A COMMA (ENTER "9999." TO RETURN TO THE MENU)

DON'T FORGET THE DECIMAL PT.!

$50,, 39$.

BURNER GAS FLOW RATE

\begin{tabular}{cccc} 
& & GAS FLOW & "NOM INAL" HEAT \\
I & T(I) & RATE $(G /$ SEC $)$ & RELEASE RATE $(\mathrm{KW})$ \\
\hline 1 & 0.0 & 0.000 & 0.000 \\
2 & 10.0 & 1.000 & 28.700 \\
3 & 30.0 & 11.000 & 315.700 \\
4 & 40.0 & 30.000 & 861.000 \\
5 & 45.0 & 25.000 & 717.500 \\
6 & 50.0 & 39.000 & 1119.300
\end{tabular}

ENTER THE TIME(SEC) AND THE FLOW RATE(GRAMS/SEC) SEPARATED BY A COMMA (ENTER "9999." TO RETURN TO THE MENU)

DON'T FORGET THE DECIMAL PT.!

$60 ., 35$. 


\section{BURNER GAS FLOW RATE}

$\begin{array}{cccc} & & \text { GAS FLOW } & \text { "NOMINAL" HEAT } \\ \text { RELEASE RATE }(\mathrm{KW})\end{array}$

ENTER THE TIME(SEC) AND THE FLOW RATE(GRAMS/SEC) SEPARATED BY A COMMA (ENTER "9999." TO RETURN TO THE MENU)

DON'T FORGET THE DECIMAL PT.!

120,0 .

BURNER GAS FLOW RATE

$\begin{array}{cccc}\text { I } & \text { T(I) } & \text { GAS FLOW } & \text { "NOM INAL" HEAT } \\ 1 & 0.0 & 0.000 & \text { RELEASE RATE(KW) } \\ 2 & 10.0 & 1.000 & 0.000 \\ 3 & 30.0 & 11.000 & 28.700 \\ 4 & 40.0 & 30.000 & 315.700 \\ 5 & 45.0 & 25.000 & 861.000 \\ 6 & 50.0 & 39.000 & 717.500 \\ 7 & 60.0 & 35.000 & 1119.300 \\ 8 & 120.0 & 6.000 & 1004.500 \\ \end{array}$

ENTER THE TIME(SEC) AND THE FLOW RATE(GRAMS/SEC) SEPARATED BY A COMMA (ENTER "9999." TO RETURN TO THE MENU)

DON'T FORGET THE DECIMAL PT.!

300., 0 .

BURNER GAS FLOW RATE

\begin{tabular}{cccc} 
& & GAS FLOW & "NOM INAL" HEAT \\
I & T(I) & RATE $($ G/SEC $)$ & RELEASE RATE $(\mathrm{KW})$ \\
\hline 1 & 0.0 & 0.000 & 0.000 \\
2 & 10.0 & 1.000 & 28.700 \\
3 & 30.0 & 11.000 & 315.700 \\
4 & 40.0 & 30.000 & 861.000 \\
5 & 45.0 & 25.000 & 717.500 \\
6 & 50.0 & 39.000 & 1119.300 \\
7 & 60.0 & 35.000 & 1004.500 \\
8 & 120.0 & 6.000 & 172.200 \\
9 & 300.0 & 0.000 & 0.000
\end{tabular}


ENTER THE TIME(SEC) AND THE FLOW RATE(GRAMS/SEC) SEPARATED BY A COMMA (ENTER "9999." TO RETURN TO THE MENU)

DON'T FORGET THE DECIMAL PT.!

9999.

WHAT TYPE OF CHANGE?

(0) NO MORE CHANGES

(1) DELETE OLD POINT(S)

(2) ADD NEW POINT(S)

(3) ALTER A POINT(S)

0

BURNER GAS FLOW RATE

\begin{tabular}{cccc} 
& & GAS FLOW & "NOM INAL" HEAT \\
I & T(I) & RATE $($ G/SEC $)$ & RELEASE RATE $(\mathrm{KW})$ \\
\hline 1 & 0.0 & 0.000 & 0.000 \\
2 & 10.0 & 1.000 & 28.700 \\
3 & 30.0 & 11.000 & 315.700 \\
4 & 40.0 & 30.000 & 861.000 \\
5 & 45.0 & 25.000 & 717.500 \\
6 & 50.0 & 39.000 & 1119.300 \\
7 & 60.0 & 35.000 & 1004.500 \\
8 & 120.0 & 6.000 & 172.200 \\
9 & 300.0 & 0.000 & 0.000
\end{tabular}

DO YOU WANT TO CHANGE YOUR INPUT? ( $\mathrm{Y} / \mathrm{N})$ :

$\mathrm{N}$

MENU FOR SPECIF IC CHANGES

0) NO MORE CHANGES

1) GEOMETRIC PARAMETERS FOR ROOM

2) GEOMETRIC PARAMETERS FOR OBJECT

3) PHYSICAL PARAMETERS FOR OBJECT

4) VENT PARAMETERS

5) WALL PROPERTIES

7) NON-INDEXED VARIABLES

8) $\mathrm{ADD}$ A VENT

9) DELETE A VENT

10) SELECT OBJECT MATERIAL 0

PLEASE ENTER THE NUMBER OF THE SECTION TO BE CHANGED.

THE FOLLOWING LIST IS A BREAKUP OF THE MAIN SECTIONS OF THE PROGRAM. TO CHANGE THE DATA IN ANY ONE OF THESE SECTIONS, ENTER THE ITEM NUMBER OF YOUR CHOICE.

0) NO MORE CHANGES

1) SELECT PHYSICS SUBROUTINES

2) CHANGE GEOMETRIC AND/OR PHYSICAL PARAMETERS 
3) CHANGE OUTPUT OPTIONS

WOULD YOU LIKE YOUR INPUT DATA DISPLAYED TO LET YOU SEE WHAT THE VARIABLES HAVE BEEN INITIALIZED TO? ( $\mathrm{Y} / \mathrm{N})$ :

N

WOULD YOU LIKE TO GO BACK AND MAKE ANY FURTHER CHANGES BEFORE RUNNING THE STMULATION? ( $\mathrm{Y} / \mathrm{N})$ :

N

WOULD YOU LIKE TO SAVE YOUR INPUT DATA IN A FILE? (Y/N):

N

ENTER USER-GENERATED DOCLMENTATION FOR THIS RUN:

PROGRAMMER-RUN NUMBER = $\operatorname{MIT} 3$

TYPE IN COMMENT LINES FOR LABEL, ENDING WITH AN EXTRA 〈RET>. ... WHERE WISE MEN ... 


\subsection{Example 5. Forced Flow Venting}

The forced-flow option is demonstrated; note that we have two vents because we must have at least one free vent (see the discussion in section 2). Note that the option to make the vent (非, in this case) a forced vent is giver after the dimensions are specified.

\footnotetext{
WILL THIS BE USED FOR FURTHER BATCH RUNS? ( $\mathrm{Y} / \mathrm{N})$ :

$\mathrm{N}$
}

WELCOME TO THE INPUT PORTION OF THE PROGRAM. THIS SECTION ALLOWS YOU

TO INITIALIZE YOUR VARIABLES EITHER BY BLOCK DATA OR BY A PREEXISTING INPUT FILE. IT THEN ALLOWS YOU TO MAKE ANY CHANGES TO YOUR INPUT DATA AND GIVES YOU THE OPTION TO SAVE THESE CHANGES IN A FILE (NAMED BY YOU).

YOU HAVE A TOTAL OF 3 INPUT FILE(S)

AVAILABLE FOR USE

DAN2. INP

HENRI. INP

LEN. INP

BEFORE CONTINUING, WOULD YOU LIKE ANY OF THESE INPUT FILES DELETED? (Y/N): $\mathrm{N}$

WOULD YOU LIKE ONE OF THESE INPUT DATA FILES TO BE READ IN AND INITIALIZE THE INPUT VARIABLES? ( $\mathrm{Y} / \mathrm{N})$ :

$\mathrm{N}$

YOUR INPUT DATA WILL BE BASED ON THE PROGRAM BLOCK-DATA DEFAULTS

WOULD YOU LIKE YOUR INPUT DATA DISPLAYED TO LET YOU SEE WHAT THE VARIABLES HAVE BEEN INITIALIZED TO? ( $\mathrm{Y} / \mathrm{N})$ :

$\mathrm{N}$

WOULD YOU LIKE TO MAKE ANY CHANGES TO THE INPUT DATA? ( $\mathrm{Y} / \mathrm{N})$ : Y

IN THE INPUT SEQUENCE TO FOLLOW, NOTE THAT AN INPUT ERROR

-- E.G. TYPING A LETTER WHERE A DIGIT IS REQUIRED --

CAUSES THE QUESTION TO BE REASKED.

THE SYMBOL 〈RET> STANDS FOR CARRIAGE RETURN, OR NEWLINE, OR WHATEVER KEY ON THE TERMINAL IS USED TO ENTER DATA. HIT 〈RET> TO CONTINUE

YOU HAVE 2 OPTIONS FOR CHANGING THE DATA:

1) A MENU FOR SELECTING YOUR AREAS OF CHANGE

2) RUN THROUGH THE WHOLE INPUT SEQUENCE, START TO FINISH 
NOTE: IF YOU ARE NOT FAMILIAR WITH THE INPUT PROGRAM, IT IS BEST TO MAKE CHOICE 非 2 IN ORDER TO FAMILIARIZE YOURSELF WITH THE DIFFERENT SECTIONS.

PLEASE ENTER THE ITEM NUMBER OF YOUR CHOICE 1

THE FOLLOWING LIST IS A BREAKUP OF THE MAIN SECTIONS OF THE PROGRAM. TO CHANGE THE DATA IN ANY ONE OF THESE SECTIONS, ENTER THE ITEM NUMBER OF YOUR CHOICE.

0) NO MORE CHANGES

1) SELECT PHYSICS SUBROUTINES

2) CHANGE GEOMETRIC AND/OR PHYSICAL PARAMETERS

3) CHANGE OUTPUT OPTIONS

2

WOULD YOU LIKE TO USE THE MENU INSTEAD OF RUNNING THROUGH EACH SCREEN? ( $\mathrm{Y} / \mathrm{N})$ : Y

THE FOLLOWING MENU ALLOWS YOU TO MAKE SPECIF IC CHANGES TO THE INPUT VALUES WITHOUT GOING THROUGH THE WHOLE INPUT PROGRAM. TO MAKE A CHANGE, ENTER THE ITEM NUMBER AND FOLLOW THE INSTRUCTIONS. ONCE YOU ARE DONE, THIS MENU WILL REAPPEAR FOR FUTHER CHANGES TO BE MADE (IF ANY). NOTE: CHANGING THE NUMBER OF OBJECTS IN A ROOM MAY BE DONE BY ENTERING "GEOMETRIC PROPERTIES FOR ROOM". HIT 〈RET〉 TO CONTINUE

MENU FOR SPECIFIC CHANGES

0) NO MORE CHANGES

1) GEOMETRIC PARAMETERS FOR ROOM

2) GEOMETRIC PARAMETERS FOR OBJECT

3) PHYSICAL PARAMETERS FOR OBJECT

4) VENT PARAMETERS

5) WALL PROPERTIES

7) NON-INDEXED VARIABLES

8) ADD A VENT

9) DELETE A VENT

10) SELECT OBJECT MATERIAL 8

PLEASE ENTER THE NUMBER OF THE SECTION TO BE CHANGED.

VENT NUMBER 2

0) CHANGE NOTHING (CONTINUE)

1) WIDTH (METERS): $0.7620 E+00$

2) HEIGHT (METERS): $0.2032 E+01$

3) TRANSOM DEPTH (METERS): $0.4064 \mathrm{E}+00$

4) SIDE 1 IS IN ROOM: 1

5) SIDE 2 IS IN ROOM: 0

100) COPY ALL ABOVE DATA FROM ANOTHER VENT - ENTER "100,VENT非" (SAME FORMAT) TO CHANGE ITEMS, ENTER "ITEM, VALUE〈RET>" (I4,F12.4); END WITH AN EXTRA 〈RET〉: $1, .4$

$2, .3$

$3, .1$ 
0) CHANGE NOTHING (CONTINUE)

1) WIDTH (METERS): $\quad 0.4000 E+00$

2) HEIGHT (METERS): $\quad 0.3000 E+00$

3) TRANSOM DEPTH (METERS): $0.1000 E+00$

4) SIDE 1 IS IN ROOM: 1

5) SIDE 2 IS IN ROOM: 0

100) COPY ALL ABOVE DATA FROM ANOTHER VENT - ENTER "100,VENT非" (SAME FORMAT) DO YOU WANT TO CHANGE YOUR INPUT? ( $\mathrm{Y} / \mathrm{N})$ : $\mathrm{N}$

VENT NUMBER 2

FORCED VENTILATION $(\mathrm{T}=$ PRESENT, $\mathrm{F}=\mathrm{ABSENT}): \mathrm{F}$

TO CHANGE THE STATUS ENTER "T" OR "F" ONLY

HIT 〈RET〉 TO CONTINUE

$\mathrm{T}$

IN ORDER TO SIMULATE THE VOLUMETRIC THROUGHPUT AS ANY PRESCRIBED FUNCTION OF TIME, IT IS APPROXIMATED BY A SERIES OF STRAIGHT-LINE SEGMNTS. EACH SEGMENT IS BOUNDED BY TWO TIMES, OF COURSE. THE ENTRIES ARE THEREFORE A TIME AND THE PRESCRIBED VOLUMETRIC THROUGHPUT AT THAT TIME. THE PROGRAM WILL THEN INTERPOLATE LINEARLY BETWEEN THOSE FLOW VALUES, FOR ALL MOMENTS BETWEEN THE GIVEN BOUNDING TIMES. THE INITIAL FLOW MAY BE TAKEN TO BE ZERO, TO ENSURE A GRADUAL TURN-ON OF THE FAN (AND TO AVOID DISCONTINUOUS PHYSICAL PROCESSES!). IN THAT CASE THERE MUST BE AT LEAST TWO SEGMENTS, OF COURSE.

IN GENERAL THE MINIMUM NUMBER IS 1, THE MAXIMUM NUMBER OF SEGIENTS FOR THE FORCED-VENT-F LOW CURVE IS 20.

HIT 〈RETURN> TO CONTINUE

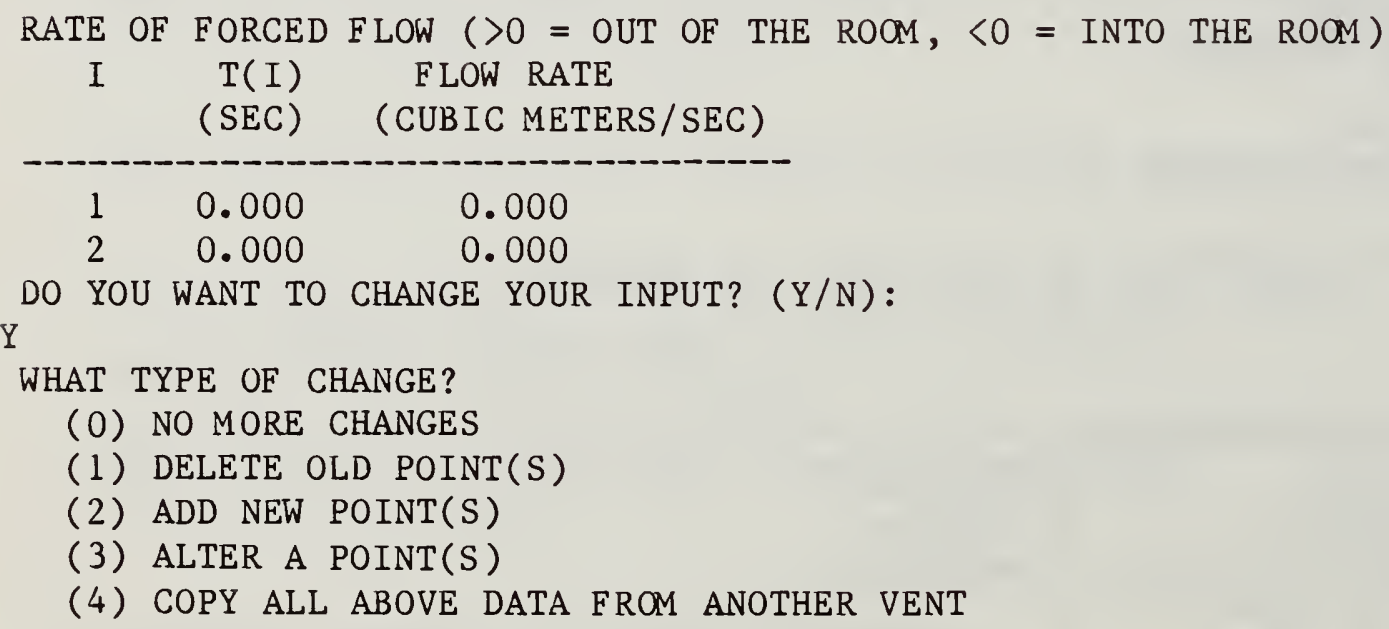

(0) NO MORE CHANGES

(1) DELETE OLD POINT(S)

(2) ADD NEW POINT(S)

(3) ALTER A POINT(S)

(4) COPY ALL ABOVE DATA FROM ANOTHER VENT 
RATE OF FORCED FLOW ( $>0=$ OUT OF THE ROOM, $<0=$ INTO THE ROOM)

I $\mathrm{T}(\mathrm{I})$ FLOW RATE (SEC) (CUBIC METERS/SEC)

$\begin{array}{lll}1 & 0.000 & 0.000 \\ 2 & 0.000 & 0.000\end{array}$

ENTER THE \# OF THE POINT TO BE CHANGED,

2

WHAT IS THE NEW TIME(SEC) AND THE NEW FLOW RATE(CUBIC METERS/SEC)

SEPARATED BY A COMMA. DON'T FORGET THE DECTMAL PT!

$10 ., .1$

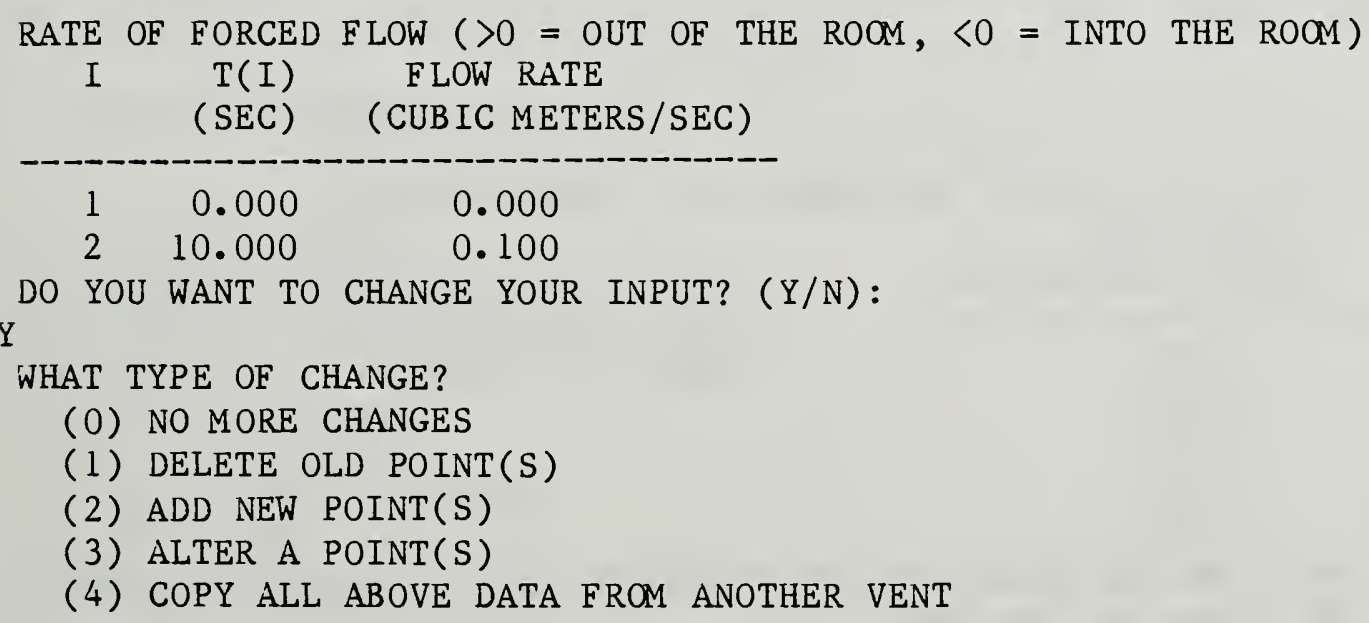

(0) NO MORE CHANGES

(1) DELETE OLD POINT(S)

(2) ADD NEW POINT(S)

(3) ALTER A POINT(S)

(4) COPY ALL ABOVE DATA FROM ANOTHER VENT

2

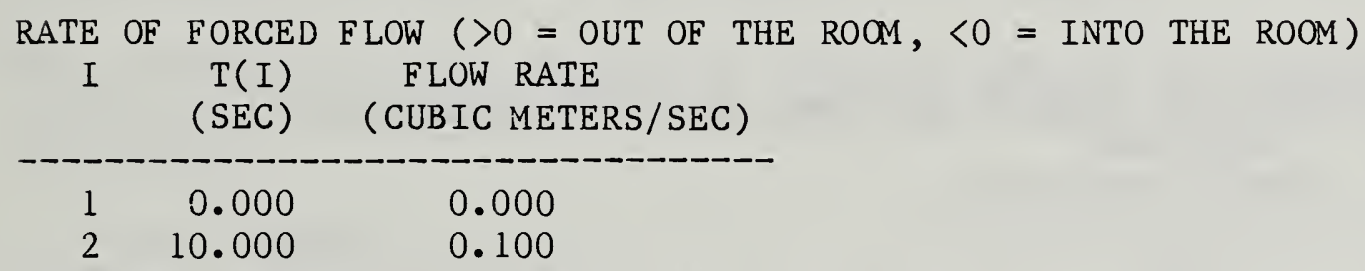

ENTER THE TIME(SEC) AND THE FLOW RATE(CUBIC METERS/SEC) SEPARATED BY A COMMA (ENTER "9999." TO RETURN TO THE MENU)

DON'T FORGET THE DECIMAL PT.!

$30 ., .5$

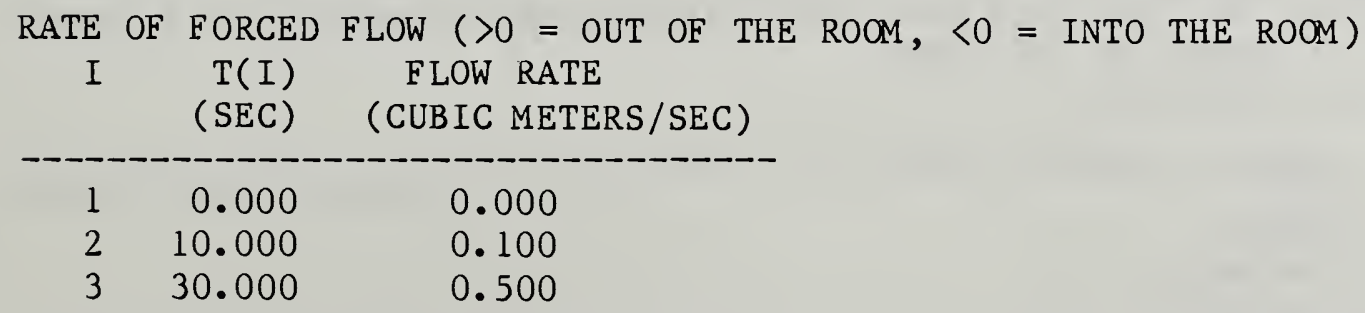

ENTER THE TIME(SEC) AND THE FLOW RATE(CUBIC METERS/SEC) SEPARATED BY A COMMA (ENTER "9999." TO RETURN TO THE MENU) 
DON'T FORGET THE DECIMAL PT.!

$120 ., .25$

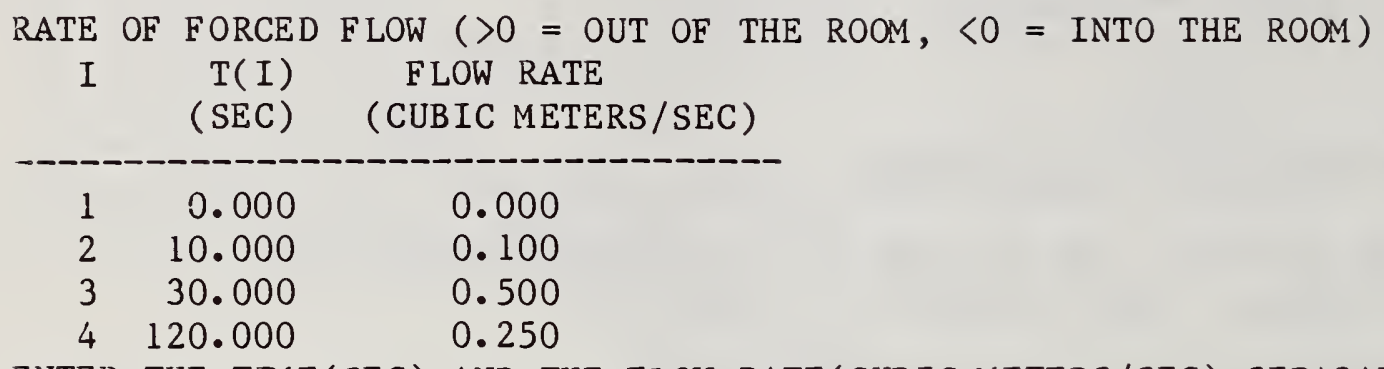

$\begin{array}{rrr}1 & 0.000 & 0.000 \\ 2 & 10.000 & 0.100 \\ 3 & 30.000 & 0.500 \\ 4 & 120.000 & 0.250\end{array}$

ENTER THE TIME(SEC) AND THE FLOW RATE(CUBIC METERS/SEC) SEPARATED BY A COMMA (ENTER "9999." TO RETURN TO THE MENU)

DON'T FORGET THE DECIMAL PT.!

$130 ., .45$

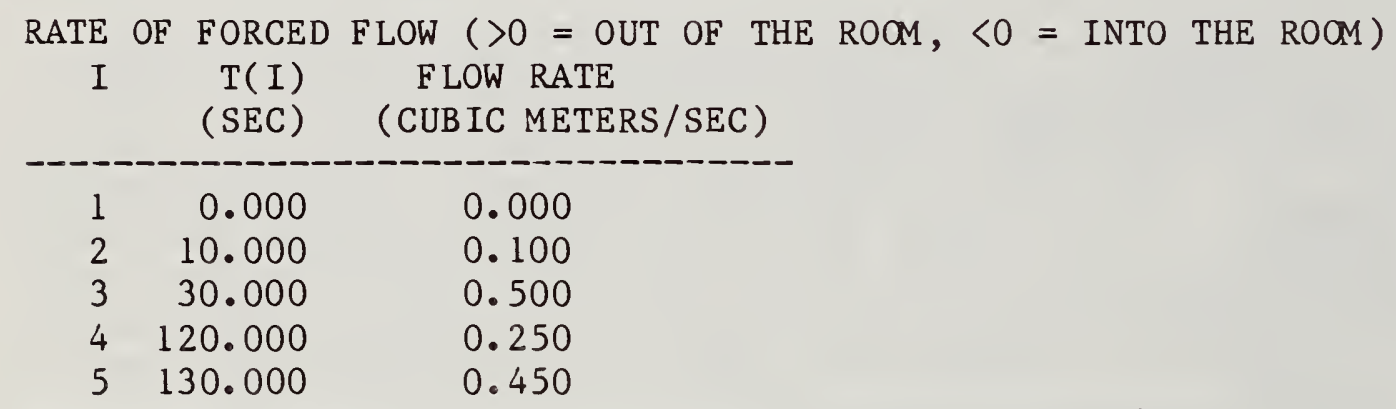

ENTER THE TIME(SEC) AND THE FLOW RATE(CUBIC METERS/SEC) SEPARATED BY A COMMA (ENTER "9999." TO RETURN TO THE MENU)

DON'T FORGET THE DECIMAL PT.!

$600 ., .2$

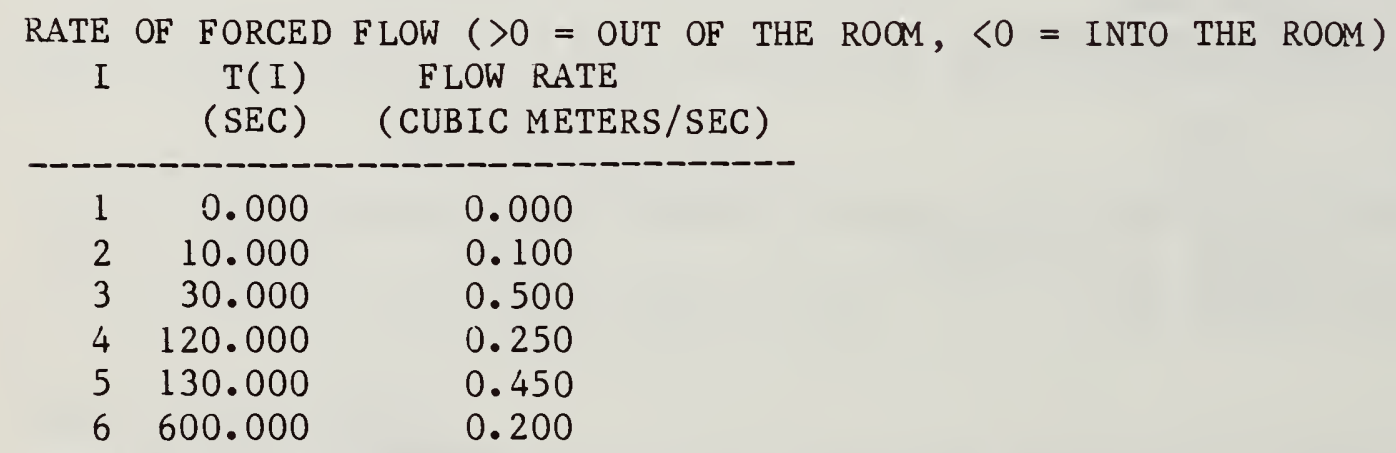

ENTER THE TIME(SEC) AND THE FLOW RATE(CUBIC METERS/SEC) SEPARATED BY A COMMA (ENTER "9999." TO RETURN TO THE MENU)

DON'T FORGET THE DECIMAL PT.!

9999.

WHAT TYPE OF CHANGE?

(0) NO MORE CHANGES

(1) DELETE OLD POINT(S)

(2) ADD NEW POINT(S)

(3) ALTER A POINT(S) 
(4) COPY ALL ABOVE DATA FROM ANOTHER VENT

RATE OF FORCED FLOW ( $>0=$ OUT OF THE ROOM, $<0=$ INTO THE ROOM)

I $\mathrm{T}(\mathrm{I})$ FLOW RATE

(SEC) (CUBIC METERS/SEC)

$\begin{array}{rrr}1 & 0.000 & 0.000 \\ 2 & 10.000 & 0.100 \\ 3 & 30.000 & 0.500 \\ 4 & 120.000 & 0.250 \\ 5 & 130.000 & 0.450 \\ 6 & 600.000 & 0.200\end{array}$

$\mathrm{N}$

MENU FOR SPECIFIC CHANGES

0) NO MORE CHANGES

1) GEOMETRIC PARAMETERS FOR ROOM

2) GEOMETRIC PARAMETERS FOR OBJECT

3) PHYSICAL PARAMETERS FOR OBJECT

4) VENT PARAMETERS

5) WALI PROPERTIES

7) NON-INDEXED VARIABLES

8) ADD A VENT

9) DELETE A VENT

10) SELECT OBJECT MATERIAL

0

PLEASE ENTER THE NUMBER OF THE SECTION TO BE CHANGED.

THE FOLLOWING LIST IS A BREAKUP OF THE MAIN SECTIONS OF THE PROGRAM. TO CHANGE THE DATA IN ANY ONE OF THESE SECTIONS, ENTER THE ITEM NUMBER OF YOUR CHOICE.

0) NO MORE CHANGES

1) SELECT PHYSICS SUBROUTINES

2) CHANGE GEOMETRIC AND/OR PHYSICAL PARAMETERS

3) CHANGE OUTPUT OPTIONS

0

WOULD YOU LIKE YOUR INPUT DATA DISPLAYED TO LET YOU SEE WHAT THE VARIABLES HAVE BEEN INITIALIZED TO? ( $\mathrm{Y} / \mathrm{N})$ :

$\mathrm{N}$

WOULD YOU LIKE TO GO BACK AND MAKE ANY FURTHER CHANGES BEFORE RUNNING THE SIMULATION? ( $\mathrm{Y} / \mathrm{N}$ ):

$\mathrm{N}$ 
WOULD YOU LIKE TO SAVE YOUR INPUT DATA IN A FILE? (Y/N):

$\mathrm{N}$

ENTER USER-GENERATED DOCLMENTATION FOR THIS RUN:

PROGRAMMER-RUN NUMBER =

MIT 4

TYPE IN COMMENT LINES FOR LABEL, ENDING WITH AN EXTRA 〈RET>.

....FEAR TO TREAD. 


\subsection{Example 6. Alternative Algorithms for Physics}

This illustrates the choices available for different physics subroutines. The input sequence is not run through to the end because that is not necessary for our present purposes. The user is again urged to make the default choice if he is not familiar with the literature. For the different plume models, see ref. [22a].

WILL THIS BE USED FOR FURTHER BATCH RUNS? ( $\mathrm{Y} / \mathrm{N})$ :

$\mathrm{N}$

WELCOME TO THE INPUT PORTION OF THE PROGRAM. THIS SECTION ALLOWS YOU

TO INITIALIZE YOUR VARIABLES EITHER BY BLOCK DATA OR BY A PREEXISTING INPUT FILE. IT THEN ALLOWS YOU TO MAKE ANY CHANGES TO YOUR INPUT DATA AND GIVES YOU THE OPTION TO SAVE THESE CHANGES IN A FILE (NAMED BY YOU).

YOU HAVE A TOTAL OF 3 INPUT FILE(S)

AVAILABLE FOR USE

DAN2. INP

HENRI. INP

LEN. INP

BEFORE CONTINUING, WOULD YOU LIKE ANY OF THESE INPUT FILES DELETED? (Y/N): iN

WOULD YOU LIKE ONE OF THESE INPUT DATA FILES TO BE READ IN AND INITIALIZE THE INPUT VARIABLES? ( $\mathrm{Y} / \mathrm{N})$ :

$\mathrm{N}$

YOUR INPUT DATA WILL BE BASED ON THE PROGRAM BLOCK-DATA DEFAULTS

WOULD YOU LIKE YOUR INPUT DATA DISPLAYED TO LET YOU SEE WHAT THE VARIABLES HAVE BEEN INITIALIZED TO? ( $\mathrm{Y} / \mathrm{N})$ :

N

WOULD YOU LIKE TO MAKE ANY CHANGES TO THE INPUT DATA? ( $\mathrm{Y} / \mathrm{N}$ ): Y

IN THE INPUT SEQUENCE TO FOLLOW, NOTE THAT AN INPUT ERROR

-- E.G. TYPING A LETTER WHERE A DIGIT IS REQUIRED --

CAUSES THE QUESTION TO BE REASKED.

THE SYMBOL 〈RET> STANDS FOR CARRIAGE RETURN, OR NEWLINE, OR

WHATEVER KEY ON THE TERM INAL IS USED TO ENTER DATA.

HIT 〈RET〉 TO CONTINUE

YOU HAVE 2 OPTIONS FOR CHANGING THE DATA:

1) A MENU FOR SELECTING YOUR AREAS OF CHANGE

2) RUN THROUGH THE WHOLE INPUT SEQUENCE, START TO FINISH 
NOTE: IF YOU ARE NOT FAMILIAR WITH THE INPUT PROGRAM, IT IS BEST TO MAKE CHOICE \#2 IN ORDER TO FAMILIARIZE YOURSELF WITH THE DIFFERENT SECTIONS .

PLEASE ENTER THE ITEM NUMBER OF YOUR CHOICE

1

THE FOLLOWING LIST IS A BREAKUP OE THE MAIN SECTIONS OF THE PROGRAM. TO CHANGE THE DATA IN ANY ONE OF THESE SECTIONS, ENTER THE ITEM NUMBER OF YOUR CHOICE.

0) NO MORE CHANGES

1) SELECT PHYSICS SUBROUTINES

2) CHANGE GEOMETRIC AND/OR PHYSICAL PARAMETERS

3) CHANGE OUTPUT OPTIONS

1

TMPO1: SIMPLE ANALYTIC APPROXIMATION TO SURFACE TEMPERATURE OF OBJECT BEING HEATED

TMPO2: "EXACT" ONE-DIMENSIONAL NUMERICAL CALCULATION OF SURFACE TEMPERATURE OF OBJECT BEING HEATED

WHICH VERSION OF TMPO DO YOU WANT, 1 OR 2? DEFAULT IS TMPO2:

2

ABSRB2: ABSORPTION COEFFICIENT OF LAYER CALCULATED ASSUMING SOOT IS ONLY CONTRIBUTOR

ABSRB3: MORE PRECISE CALCULATION, TAKING CO2 AND H2O INTO ACCOUNT

WHICH VERSION OF ABSRB DO YOU WANT, 2 OR 3?

DEFAULT IS ABSRB2:

2

PLUM1 : AREA-SOURCE MORTON-TAYLOR-TURNER PLUME (VIRTUAL POINT SOURCE BELOW FIRE BASE)

PLUM2: SAME PLUME AS \#1, BUT POINT SOURCE IS AT FIRE BASE

Plume3: McCaffrey (empirical data fit)

Plume4: Zukoski, Kubota, Cetegen (empirical data fit)

Plume 5: Delichatsios/FM (empirical data fit - low turbulence data)

Plume6: Tokunaga, Sakai, Kawagoe, Tanaka \& Hasemi (empirical data fit, near field same as McCaffrey)

WHICH VERSION OF PLUM DO YOU WANT, 1 - 6 ?

DEFAULT IS PLUMI:

2

THE FOLLOWING LIST IS A BREAKUP OF THE MAIN SECTIONS OF THE PROGRAM. TO CHANGE THE DATA IN ANY ONE OF THESE SECTIONS, ENTER THE ITEM NUMBER OF YOUR CHOICE.

0) NO MORE CHANGES

1) SELECT PHYSICS SUBROUTINES

2) CHAINGE GEOMETRIC AND/OR PHYSICAL PARAMETERS

3) CHANGE OUTPUT OPTIONS

0

WOULD YOU LIKE YOUR INPUT DATA DISPLAYED TO LET YOU SEE WHAT THE VARIABLES $\mathrm{N}$ HAVE BEEN INITLALIZED TO? ( $/ / N$ ):

and so on.... 


\subsection{Example 7. Use of Input Files and Data Bank}

In this example, one of the available input files is chosen for use. Normally, one would examine this file (unless you were very familiar with it); that is done here. In order to kill two birds with one stone, we also illustrate here how to use the materials data bank to choose a different material for object \#1. We then check the data to make sure that the correct information (for heptane) was indeed substituted for whatever was there before; the example is not pursued beyond that point.*

WELCOME TO THE INPUT PORTION OF THE PROGRAM. THIS SECTION ALLOWS YOU TO INITIALIZE YOUR VARIABLES EITHER BY BLOCK DATA OR BY A PREEXISTING INPUT FILE. IT THEN ALLOWS YOU TO MAKE ANY CHANGES TO YOUR INPUT DATA AND GIVES YOU THE OPTION TO SAVE THESE CHANGES IN A FILE (NAMED BY YOU).

\section{YOU HAVE A TOTAL OF 3 INPUT FILE(S)}

AVAILABLE FOR USE

DAN2. INP

HENRI. INP

LEN. INP

BEFORE CONTINUING, WOULD YOU LIKE ANY OF THESE INPUT FILES DELETED? (Y/N): $\mathrm{N}$

WOULD YOU LIKE ONE OF THESE INPUT DATA FILES TO BE READ IN AND INITIALIZE THE INPUT VARIABLES? ( $\mathrm{Y} / \mathrm{N})$ :

$\mathrm{Y}$

PLEASE ENTER THE NAME OF THE FILE TO BE USED HENRI. INP

PLEASE WAIT WHILE YOUR FILE IS BEING READ IN

WOULD YOU LIKE YOUR INPUT DATA DISPLAYED TO LET YOU SEE WHAT THE VARIABLES HAVE BEEN INITIALIZED TO? ( $\mathrm{Y} / \mathrm{N})$ :

Y

ROOM NUMBER 1:

$\operatorname{DIMENSIONS}(X, Y, Z)=\left(\begin{array}{lll}(3.4380 & 2.4380\end{array}\right)$

$\begin{array}{lc}\text { AMBIENT TEMPERATURE }= & 300.0 \\ \text { A PHOTOELECTRIC SMOKE DETECTOR IS PRESENT IN THE ROOM : }\end{array}$

ABSORPTION COEEFICIENT THRESHOLD FOR ALARM $=0.033001 / \mathrm{M}$

LOCATION OF DETECTOR INPUT PORT(METERS BELOW CEILING) $=0.020$

TYPE 〈RET〉 TO CONTINUE

* Warning: do not make choice $\#_{10}$ in the main program menu (as is done here) unless files MASNAM and MASDAT exist in your account. If they do not, then at least one entry must be made in the materials data bank, using MASBANK, so as to generate those files. See Section 4.9. 
OBJECT NUMBER $1(I D=1)$ :

\begin{tabular}{|c|c|c|c|c|}
\hline \multicolumn{5}{|c|}{ It is Flaming a Growing Fire } \\
\hline \multicolumn{5}{|c|}{$\begin{array}{lllll}\text { It } \text { is Flaming } & \text { a Growing Fire } & \text { Away from Walls } & \\
\text { COORDINATES }(X, Y, Z)= & (c 0.6100) & 0.8400 & 2.8000 & 0.6\end{array}$} \\
\hline \multirow{2}{*}{\multicolumn{5}{|c|}{ ANGLE WITH HORIZONTAL $=0.00$ ANGLE WITH XZ-PLANE $=\quad 0.00$}} \\
\hline THICKNESS= & & & & 48.00 \\
\hline INITIAL MASS= & 6.852 & \multicolumn{2}{|c|}{ INITIAL RADIUS= } & 0.037 \\
\hline MAXIMUM RADIUS= & 0.968 & \multicolumn{2}{|c|}{ OBJECT RADIUS= } & 0.860 \\
\hline SPECIFIC HEAT = & 1900. & \multicolumn{2}{|c|}{ THERMAL CONDUCTIVITY= } & 0.0540 \\
\hline EMISSIVITY= & 0.98 & \multicolumn{2}{|c|}{ CHI(FRACTION OF HEAT } & )$=0.65$ \\
\hline HEAT OF COMBUSTION = & $2.870 E+07$ & \multicolumn{2}{|c|}{ HEAT OF VAPORIZATION = } & $2.054 \mathrm{E}+06$ \\
\hline PYROLIZATION TEMP= & $600 \cdot 0$ & \multicolumn{2}{|c|}{ IGNITION TEMP= } & 727.0 \\
\hline AIR/FUEL MASS RATIO= & 14.45 & \multicolumn{2}{|c|}{ STOICHIOMETRIC MASS RATID= } & 9.85 \\
\hline FCO2(CO2 MASS/FUEL MA & $=1.504$ & \multicolumn{2}{|c|}{ FCO $($ CO MASS $/$ FUEL MASS $)=$} & 0.013 \\
\hline FS(SMOKE MASS/FUEL MA & $=0.241$ & \multicolumn{2}{|c|}{ FH2O(H2O MASS/FUEL MASS $)=$} & 0.714 \\
\hline FHC (TOTAL HC/FUEL MA & $=0.002$ & \multicolumn{2}{|c|}{ Flame cone angle (deg) $=$} & $30 \cdot 0$ \\
\hline A(FIRE SPREAD PARAMETE & )$=0.0109$ & \multicolumn{2}{|c|}{ BURNOUT PARAMETER $($ SEC) $=$} & 20.00 \\
\hline
\end{tabular}

TYPE 〈RET〉 TO CONTINUE

OBJECT NUMBER $2(I D=2)$ :

\begin{tabular}{|c|c|c|c|c|}
\hline It is Non Flaming & Growing & Away & from Walls & \\
\hline $\operatorname{COORDINATES}(X, Y, Z)$ & $=$ & 1.2200 & 1.8300 & \\
\hline ANGLE WITH HORIZONT & 0.00 & ANGLE WITH & $\mathrm{XZ}-\mathrm{PLANE}=$ & 0.00 \\
\hline THI CKNESS= & 0.100 & DENSITY= & & 48.00 \\
\hline INITIAL MASS= & 1.096 & INITIAL RA & DIUS $=$ & 0.037 \\
\hline MAXIMUM RADIUS= & 0.466 & OBJECT RAD & IUS $=$ & 0.344 \\
\hline SPECIFIC HEAT $=$ & 1900. & THERMAL CO & NDUCT IVITY= & 0.0540 \\
\hline EMISSIVITY= & 0.98 & CHI (FRACTI & ON OF HEAT RELEAS & D) $=0.65$ \\
\hline HEAT OF COMBUSTION & $2.870 E+07$ & HEAT OF VA & PORIZATION = & $2.054 E+06$ \\
\hline PYROLIZATION TEMP= & 600.0 & IGNITION T & $\mathrm{EMP}=$ & 3000.0 \\
\hline AIR/FUEL MASS RATIO & 14.45 & STOICHIOME & TRIC MASS RATIO= & 9.85 \\
\hline FCO2(CO2 MASS/FUEL & )$=1.504$ & FCO (CO MAS & S/FUEL MASS $)=$ & 0.013 \\
\hline FS(SMOKE MASS/FUEL & MASS $)=0.241$ & $\mathrm{FH} 2 \mathrm{O}(\mathrm{H} 2 \mathrm{O} \mathrm{M}$ & ASS /FUEL MASS) $=$ & 0.714 \\
\hline FHC（TOTAL HC/FUEL & MASS $)=0.002$ & Flame cone & angle $(\operatorname{deg})=$ & 30.0 \\
\hline A(FIRE SPREAD PARAM & (ETER) $=0.0109$ & BURNOUT PA & RAMETER $($ SEC $)=$ & 20.00 \\
\hline
\end{tabular}

TYPE 〈RET〉 TO CONTINUE

VENT NUMBER 1:

$($ WIDTH, HEIGHT, DEPTH $)=\left(\begin{array}{lll}0.7620 & 2.0320 & 0.4064\end{array}\right)$

TYPE 〈RET〉 TO CONTINUE

WALL NUMBER 1:

THICKNESS=

0.0254 DENSITY $=$

800.00

SPECIFIC HEAT=

1062 .

THERMAL CONDUCTIVITY=

0.1340

PHYSICAL CONSTANTS :

SPECIFIC HEAT OF AIR $=1004$.

FOR AIR :

HEAT TRANSFER COEFF $=\quad 10.00$ PLUME ENTRAINNENT COEFF=

0.10

FOR LAYER GASES:

MAX. HEAT TRANSFER COEFF $=50.00$ MIN. HEAT TRANSFER COEFF=

5.00 FOR VENTS:

FLOW COEFFICIENT $=\quad 0.68$ 
Iteration 1imit: 140 Tolerance: 1.0E-05

Max time step: 2.00 Min time step: 0.00098

WOULD YOU LIKE TO MAKE ANY CHANGES TO THE INPUT DATA? (Y/N): Y

IN THE INPUT SEQUENCE TO FOLLOW, NOTE THAT AN INPUT ERROR

-- E.G. TYPING A LETTER WHERE A DIGIT IS REQUIRED --

CAUSES THE QUESTION TO BE REASKED.

THE SYMBOL 〈RET> STANDS FOR CARRIAGE RETURN, OR NEWLINE, OR

WHATEVER KEY ON THE TERM INAL IS USED TO ENTER DATA.

HIT 〈RET〉 TO CONTINUE

YOU HAVE 2 OPTIONS FOR CHANGING THE DATA:

1) A MENU FOR SELECTING YOUR AREAS OF CHANGE

2) RUN THROUGH THE WHOLE INPUT SEQUENCE, START TO FINISH

NOTE: IF YOU ARE NOT FAMILIAR WITH THE INPUT PROGRAM, IT IS BEST TO MAKE CHOICE 非 2 IN ORDER TO FAMILIARIZE YOURSELF WITH THE DIFFERENT SECTIONS.

PLEASE ENTER THE ITEM NUMBER OF YOUR CHOICE

1

THE FOLLOWING LIST IS A BREAKUP OF THE MAIN SECTIONS OF THE PROGRAM. TO CHANGE THE DATA IN ANY ONE OF THESE SECTIONS, ENTER THE ITEM NUMBER OF YOUR CHOICE.

0) NO MORE CHANGES

1) SELECT PHYSICS SUBROUTINES

2) CHANGE GEOMETRIC AND/OR PHYSICAL PARAMETERS

3) CHANGE OUTPUT OPTIONS

2

WOULD YOU LIKE TO USE THE MENU INSTEAD OF RUNNING THROUGH EACH SCREEN? ( $\mathrm{Y} / \mathrm{N})$ : Y

THE FOLLOWING MENU ALLOWS YOU TO MAKE SPECIF IC CHANGES TO THE INPUT VALUES WITHOUT GOING THROUGH THE WHOLE INPUT PROGRAM. TO MAKE A CHANGE, ENTER THE ITEM NLMBER AND FOLLOW THE INSTRUCTIONS. ONCE YOU ARE DONE, THIS MENU WILL REAPPEAR FOR FUTHER CHANGES TO BE MADE (IF ANY). NOTE: CHANGING THE NLMBER OF OBJECTS IN A ROOM MAY BE DONE BY ENTERING "GEOMETRIC PROPERTIES FOR ROOM".

HIT 〈RET〉 TO CONTINUE

MENU FOR SPECIFIC CHANGES

0) NO MORE CHANGES

1) GEOMETRIC PARAMETERS FOR ROOM

2) GEOMETRIC PARAMETERS FOR OBJECT

3) PHYSICAL PARAMETERS FOR OBJECT

4) VENT PARAMETERS

5) WALL PROPERTIES

7) NON-INDEXED VARIABLES

8) $\mathrm{ADD}$ A VENT 
9) DELETE A VENT

10) SELECT OBJECT MATERIAL

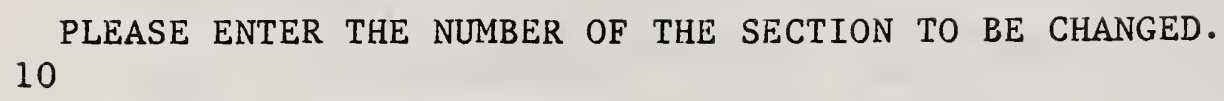

0) NO MORE CHANGES

1) GEOMETRIC PARAMETERS FOR ROOM

2) GEOMETRIC PARAMETERS FOR OBJECT

3) PHYSICAL PARAMETERS FOR OBJECT

4) VENT PARAMETERS

5) WALL PROPERTIES

7) NON-INDEXED VARIABLES

8) $\mathrm{ADD}$ A VENT

9) DELETE A VENT

10) SELECT OBJECT MATERIAL 0

PLEASE ENTER THE NUMBER OF THE SECTION TO BE CHANGED.

THE FOLLOWING LIST IS A BREAKUP OF THE MAIN SECTIONS OF THE PROGRAM. TO CHANGE THE DATA IN ANY ONE OF THESE SECTIONS, ENTER THE ITEM NUMBER OF YOUR CHOICE.

0) NO MORE CHANGES

1) SELECT PHYSICS SUBROUTINES

2) CHANGE GEOMETRIC AND/OR PHYSICAL PARAMETERS

3) CHANGE OUTPUT OPTIONS 0

*Note: These 8 items are here for illustrative purposes only; at present there are only four materials in the databank. What will appear on the screen will be just what actually is included in the databank at that time (up to 50 material that is). 
WOULD YOU LIKE YOUR INPUT DATA DISPLAYED TO LET YOU SEE WHAT THE VARIABLES HAVE BEEN INITIALIZED TO? ( $\mathrm{Y} / \mathrm{N})$ :

Y

RECAPITULATION OF INPUT FOR THIS RUN:

ROOM NUMBER 1:

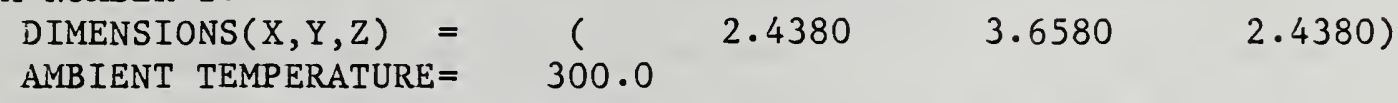

A PHOTOELECTRIC SMOKE DETECTOR IS PRESENT IN THE ROOM:

ABSORPTION COEEFICIENT THRESHOLD FOR ALARM $=0.033001 / \mathrm{M}$

LOCATION OF DETECTOR INPUT PORT(METERS BELOW CEILING) $=0.020$

TYPE 〈RET〉 TO CONTINUE

OBJECT NUMBER $1(I D=1)$ :

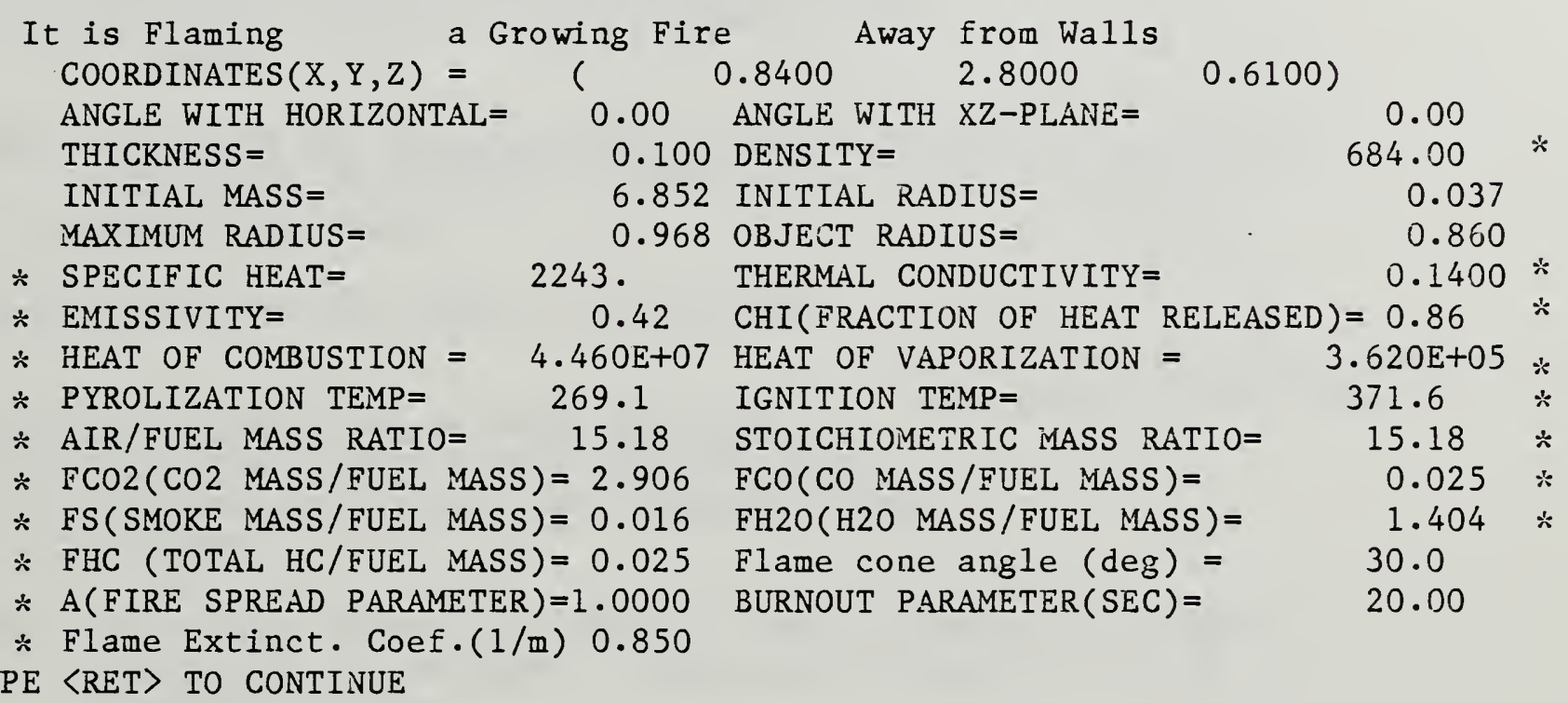

* Note: the parameters which have been changed (to those corresponding to heptane) are items 6-15 in the first column and items 2 and 5-11 in the second column. They have been starred for emphasis. 


\subsection{Example 8. Errors}

In this example, a number of errors are purposely made in the process of entering the input data, to demonstrate how the program handles them. Generally, the question is merely reasked; this is done on this and the next page. The program may stall not be completely forgiving of syntactical errors made by the user during input, however. Response errors were made in the lines preceded by an asterisk. Any comment following an exclamation mark, in the following pages, is a comment made here, and does not appear on the screen. 
WOULD YOU LIKE TO MAKE ANY CHANGES TO THE INPUT DATA? ( $\mathrm{Y} / \mathrm{N})$ :

PERHAPS

WOULD YOU LIKE TO MAKE ANY CHANGES TO THE INPUT DATA? ( $\mathrm{Y} / \mathrm{N})$ :

$\mathrm{Y}$

IN THE INPUT SEQUENCE TO FOLLOW, NOTE THAT AN INPUT ERROR

-- E.G. TYPING A LETTER WHERE A DIGIT IS REQUIRED --

CAUSES THE QUESTION TO BE REASKED.

THE SYMBOL 〈RET〉 STANDS FOR CARRIAGE RETURN, OR NEWLINE, OR WHATEVER KEY ON THE TERMINAL IS USED TO ENTER DATA.

HIT 〈RET〉 TO CONTINUE

YOU HAVE 2 OPTIONS FOR CHANGING THE DATA:

1) A MENU FOR SELECTING YOUR AREAS OF CHANGE

2) RUN THROUGH THE WHOLE INPUT SEQUENCE, START TO FINISH

NOTE: IF YOU ARE NOT FAMILIAR WITH THE INPUT PROGRAM, IT IS BEST TO MAKE CHOICE 非 2 IN ORDER TO FAMILIARIZE YOURSELF WITH THE DIFFERENT SECTIONS.

PLEASE ENTER THE ITEM NUMBER OF YOUR CHOICE $* 8$

YOU HAVE 2 OPTIONS FOR CHANGING THE DATA:

: 1 or 2 are the only permitted options.

: The question is reasked.

1) A MENU FOR SELECTING YOUR AREAS OF CHANGE

2) RUN THROUGH THE WHOLE INPUT SEQUENCE, START

TO FINISH

NOTE: IF YOU ARE NOT FAMILIAR WITH THE INPUT PROGRAM, IT IS BEST TO MAKE CHOICE \#2 IN ORDER TO FAMILIARIZE YOURSELF WITH THE DIFFERENT SECTIONS.

PLEASE ENTER THE ITEM NUMBER OF YOUR CHOICE

1

THE FOLLOWING LIST IS A BREAKUP OF THE MAIN SECTIONS OF THE PROGRAM. TO CHANGE THE DATA IN ANY ONE OF THESE SECTIONS, ENTER THE ITEM NUMBER OF YOUR CHOICE.

0) NO MORE CHANGES

1) SELECT PHYSICS SUBROUTINES

2) CHANGE GEOMETRIC AND/OR PHYSICAL PARAMETERS

3) CHANGE OUTPUT OPTIONS

$* 7$

THE FOLLOWING LIST IS A BREAKUP OF THE MAIN SECTIONS OF THE PROGRAM. TO CHANGE THE DATA IN ANY ONE OF THESE SECTIONS, ENTER THE ITEM NUMBER OF YOUR CHOICE.

0) NO MORE CHANGES

1) SELECT PHYSICS SUBROUTINES

2) CHANGE GEOMETRIC AND/OR PHYSICAL PARAMETERS

3) CHANIGE OUTPUT OPTIONS 
WOULD YOU LIKE TO USE THE MENU INSTEAD OF RUNNING THROUGH EACH SCREEN? (Y/N): * MAYBE

WOULD YOU LIKE TO USE THE MENU INSTEAD OF RUNNING THROUGH EACH SCREEN? (Y/N): * OK

WOULD YOU LIKE TO USE THE MENU INSTEAD OF RUNNING THROUGH EACH SCREEN? (Y/N): $\mathrm{Y}$

THE FOLLOWING MENU ALLOWS YOU TO MAKE SPECIFIC CHANGES TO THE INPUT VALUES WITHOUT GOING THROUGH THE WHOLE INPUT PROGRAM. TO MAKE A CHANGE, ENTER THE ITEM NUMBER AND FOLLOW THE INSTRUCTIONS. ONCE YOU ARE DONE, THIS MENU WILL REAPPEAR FOR FUTHER CHANGES TO BE MADE (IF ANY). NOTE: CHANGING THE NUMBER OF OBJECTS IN A ROOM MAY BE DONE BY ENTERING "GEOMETRIC PROPERTIES FOR ROOM".

HIT 〈RET〉 TO CONTINUE

MENU FOR SPECIFIC CHANGES

0) NO MORE CHANGES

1) GEOMETRIC PARAMETERS FOR ROOM

2) GEOMETRIC PARAMETERS FOR OBJECT

3) PHYSICAL PARAMETERS FOR OBJECT

4) VENT PARAMETERS

5) WALL PROPERTIES

7) NON-INDEXED VARIABLES

8) ADD A VENT

9) DELETE A VENT

10) SELECT OBJECT MATERIAL $* 11$

PLEASE ENTER THE NUMBER OF THE SECTION TO BE CHANGED.

MENU FOR SPECIFIC CHANGES

0) NO MORE CHANGES

1) GEOMETRIC PARAMETERS FOR ROOM

2) GEOMETRIC PARAMETERS FOR OBJECT

3) PHYSICAL PARAMETERS FOR OBJECT

4) VENT PARAMETERS

5) WALL PROPERTIES

7) NON-INDEXED VARIABLES

8) ADD A VENT

9) DELETE A VENT

10) SELECT OBJECT MATERIAL 0

PLEASE ENTER THE NUMBER OF THE SECTION TO BE CHANGED.

THE FOLLOWING LIST IS A BREAKUP OF THE MAIN SECTIONS OF THE PROGRAM. TO CHANGE THE DATA IN ANY ONE OF THESE SECTIONS, ENTER THE ITEM NUMBER OF YOUR CHOICE.

0) NO MORE CHANGES

1) SELECT PHYSICS SUBROUTINES

2) CHANGE GEOMETRIC AND/OR PHYSICAL PARAMETERS

3) CHANGE OUTPUT OPTIONS 
WOULD YOU LIKE YOUR INPUT DATA DISPLAYED TO LET YOU SEE WHAT THE VARIABLES HAVE BEEN INITIALIZED TO? ( $\mathrm{Y} / \mathrm{N})$ :

*WHO WANTS TO KNOW?

WOULD YOU LIKE YOUR INPUT DATA DISPLAYED TO LET YOU SEE WHAT THE VARIABLES HAVE BEEN INITIALIZED TO? ( $\mathrm{Y} / \mathrm{N})$ : $\because$ GO AWAY!

WOULD YOU LIKE YOUR INPUT DATA DISPLAYED TO LET YOU SEE WHAT THE VARIABLES HAVE BEEN INITIALIZED TO? ( $\mathrm{Y} / \mathrm{N})$ : $\mathrm{N}$

WOULD YOU LIKE TO GO BACK AND MAKE ANY FURTHER CHANGES BEFORE RUNNING THE SIMULATION? ( $\mathrm{Y} / \mathrm{N})$ :

$\mathrm{N}$

WOULD YOU LIKE TO SAVE YOUR INPUT DATA IN A FILE? ( $\mathrm{Y} / \mathrm{N})$ : $* \mathrm{~N}$

ENTER USER-GENERATED DOCUMENTATION FOR THIS RUN:

PROGRAMMER-RUN NUMBER = MIT 5 


\subsection{Example 9. Running MASBANK}

The following pages show what happens upon loading MASBANK into the computer, and running it (the commands for loading and starting are machinedependent; for the Perken-Elmer computer, for example, the commands are LOAD MASBANK and START).

The ten fuel items in the list on the next page are only illustrative: they are not the ones currently in the data bank. ${ }^{9}$ When a new material is introduced into the data bank (as is done in this example), the data values have to be inserted. This is done here without any preliminary instructions,

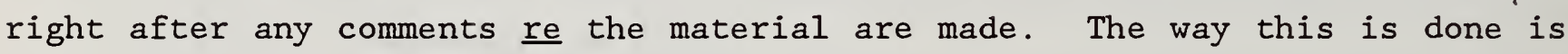
for the current (generally zero) value of property to be listed, with a request for a value to be entered. When this is done, that (new) value is displayed, and the next item on the list requested.

As soon as all the data has been entered, the entire list of new data is displayed. (Incidently, the format requested is F15.5 (i.e., floating-point format); in fact, however, any format is acceptable.) After the new data has been displayed, the "correction" (C) option is exercised (in this example), and then the "alphabetize" (S) option. Finally, ARBITRARY is deleted (it was only a fake material anyway).

The user who wishes to enter the thermophysical data displayed in Table 1 (or any other data) by just typing in the name of the material, as in example 4.7, must first use MASBANK to place those data into the input file MASDAT. MASDAT will contain as much information as is typed in by the user (and it will be in the form required by subroutine DBANK in FIRST).

9 In example 7, there were eight illustrative items; the ten items here are just as arbitrary, and (again) meant only as illustration. This program is actually being distributed with only the data for PMMA (as given in Table 1) in file MASDAT. 
THIS PROGRAM CREATES AND MAINTAINS A DATA BASE OF MATERIALS AND THEIR FIRE PROPERTIES FOR USE BY THE NBS/HARVARD FIRE SIMULATION PROGRAMS.

THERE ARE THO FILES:

MASNAM HOLDS THE NAMES OF THE MATERIALS WHOSE PROPERTIES ARE STORED.

MASDAT HOIDS THE STORED DATA.

PRESS "RETURN" <CR> TO CONTINUE

MATERIAL NAMES CURRENTLY IN THE DATA BANE (JOT DOWN THE NUMBER(S) OF ITEM

TO BE CHANGED):

! See footnote, previous page

1 GASOLINE

4 METHANE

7 POLYURETHANE

10 RED OAK

PRESS "RETURN" <CR, TO CONTINUE

THIS PROGRAM HAS SIX USE OPTIONS:

A) ADD A MATERIAL TO THE DATA BANK

C) CHANGE MATERIAL DATA ALREADY IN THE BANK

D) DELETE A MATERIAL

E) EXIT PROGRAM; WRITE DATA BASE TO DISE FILE

S) SORT (ALPHABETIZE) THE DATA BANK

V) VIEW A MATERIAI IN THE BANK

ENTER YOUR CHOICE: A, C, D, E, S OR V

A

ENTER NAME OF THE NEW MATERIAL: THE NAME SHOUID START IN COLUMN 1.

\section{ARBITRARY}

THE NEW MATERIAL NAME IS

11 ARBITRARY

IS THIS CORRECT? ( $Y / N)$

$Y$

ENTER NEW COMMENTS ( 75 CHARACTRS MAX)

CURRENT MATERIAL COMMENT IS

$\mathrm{N}$

IS THIS CORRECT? ( $\mathrm{Y} / \mathrm{N}$ )

ENTER NEW COMMENTS ( 75 CHARACTRS MAX)

FARE MATERIAL CURRENT MATERIAL COMMENT IS

FABE MATERIAL

IS THIS CORRECT? ( $Y / N)$ $Y$

1 ZJOZZ .00000D+00 THERMAL CONDUCTIVITY (W/M DEG K) 
WHAT VALUE DO YOU WANT FOR THE THERMAL CONDUCTIVITY (W/M DEG K)

THE FORMAT IS F 15.5

1 .

1 ZJOZZ .10000D+01 THERMAL CONDUCTIVITY (W/M DEG R)

$2 \mathrm{ZCOZZ} .00000 \mathrm{D}+00$ SPECIFIC HEAT (J/KG DEG)

WHAT VALUE DO YOU WANT FOR THE SPECIFIC HEAT (J/KG DEG)

THE FORMAT IS F 15.5

2 .

$22 \mathrm{COZZ}$.20000D+01 SPECIFIC HEAT ( $J / K G$ DEG)

3 VMOZZ .00000D+00 DENSITY (KG/M3)

WHAT VALUE DO YOU WANT FOR THE DENSITY (KG/M3)

THE FORMAT IS F15.5

3.

3 VMOZZ . 30000D+01 DENSITY (KG/M3)

4 EB $\quad .00000 D+00$ EMISSIVITY/ABSORPTIVITY OF SURFACE

WHAT VALUE DO YOU WANT FOR THE EMISSIVITY/ABSORPTIVITY OF SURFACE

THE FORMAT IS F15.5

4.

4 EB $\quad .40000 D+01$ EMISSIVITY/ABSORPTIVITY OF SURFACE

5 XGAMMA . OOOOOD+00 AIR/FUEL MASS RATIO

WHAT VALUE DO YOU WANT FOR THE AIR/FUEL MASS RATIO

THE FORMAT IS F15.5

5 .

6 XGAMAS .0OOOOD+00 STOICHIOMETRIC AIR/FUEL MASS RATIO

WHAT VALUE DO YOU WANT FOR THE STOICHIOMETRIC AIR/FUEL MASS RATIO

THE FORMAT IS F15.5

6.

6 XGAMAS .60000D+01 STOICHIOMETRIC AIR/FUEL MASS RATIO

7 CHI . OOOOOD+OO COMBUSTION ENERGY, FRACTION RELEASED

WHAT VALUE DO YOU WANT FOR THE COMBUSTION ENERGY, FRACTION RELEASED ? THE FORMAT IS F15.5

7.

7 CHI .70000D+01 COMBUSTION ENERGY, FRACTION RELEASED

8 QF . OOOOOD+OO HEAT OF COMBUSTION (JOULES/KG)

WHAT VALUE DO YOU WANT FOR THE HEAT OF COMBUSTION(JOULES/KG)

THE FORMAT IS F15.5

8.

8 QF $\quad .80000 D+01$ HEAT OF COMBUSTION (JOULES/KG)

9 QVAP . OOOOOD+OO HEAT OF VAPORIZATION (JOULES/KG)

WHAT VALUE DO YOU WANT FOR THE HEAT OF VAPORIZATION(JOULES/KG)

THE FORMAT IS F 15.5

9 .

9 QVAP .9000OD+OI HEAT OF VAPORIZATION(JOULES/KG) 
10 ZKOPY .0000OD+00 TEMPERATURE OF PYROLYSIS

WHAT VALUE DO YOU WANT FOR THE TEMPERATURE OF PYROLYSIS

THE FORMAT IS F15.5

10 .

10 ZKOPY .1000OD+02 TEMPERATURE OF PYROLYSIS

11 FCO2 .0OOOOD+O0 MASS FRACTION EVOLVED AS CO2

WHAT VALUE DO YOU WANT FOR THE MASS FRACTION EVOLVED AS CO2?

THE FORMAT IS F15.5

1

11 FCO2 .10000D+00 MASS FRACTION EVOLVED AS CO2

12 FCO $\quad$ OOOOOD+OO MASS FRACTION EVOLVED AS CO

WHAT VALUE DO YOU WANT FOR THE MASS FRACTION EVOLVED AS CO?

THE FORMAT IS F15.5

.2

12 FCO .20000D+OO MASS FRACTION EVOLVED AS CO

13 FS .OOOOOD+OO MASS FRACTION EVOLVED AS SMOKE

WHAT VALUE DO YOU WANT FOR THE MASS FRACTION EVOLVED AS SMOEE? THE FORMAT IS F15.5

.3

13 FS $\quad 30000 D+00$ MASS FRACTION EVOLVED AS SMOKE

14 FHC .OOOOOD+OO MASS FRACTION EVOLVED AS HYDROCARBONS

WHAT VALUE DO YOU WANT FOR THE MASS FRACTION EVOLVED AS HYDROCARBONS?

THE FORMAT IS F15.5

4

14 FHC .4000OD+OO MASS FRACTION EVOLVED AS HYDROCARBONS

15 FH2O .0000OD+OO MASS FRACTION EVOLVED AS H2O

WHAT VALUE DO YOU WANT FOR THE MASS FRACTION EVOLVED AS H2O

THE FORMAT IS F15.5

.5

15 FH2O .50000D+00 MASS FRACTION EVOLVED AS H2O

16 AFIRE . OOOOOD+00 FIRE SPREAD PARAMETER

WHAT VALUE DO YOU WANT FOR THE FIRE SPREAD PARAMETER

THE FORMAT IS F15.5

6

16 AFIRE $.60000 D+00$ FIRE SPREAD PARAMETER

17 ZKOIG .OOOOOD+00 TEMPERATURE OF IGNITION(DEG $\mathrm{K}$ )

WHAT VALUE DO YOU WANT FOR THE TEMPERATURE OF IGNITION(DEG $K$ )

THE FORMAT IS F15.5

.7

17 ZKOIG .70000D+00 TEMPERATURE OF IGNITION(DEG K)

18 PSI .00000D+00 SEMIAPEX ANGLE OF FLAME

WHAT VALUE DO YOU WANT FOR THE SEMIAPEX ANGLE OF FLAME

THE FORMAT IS F15.5 

18 PSI
$.80000 D+00$
SEMIAPEX ANGLE OF FLAME
19 TBURN
$.00000 D+00$
BURNOUT TIME (SEC)

WHAT VALUE DO YOU WANT FOR THE BURNOUT TIME (SEC)

THE FORMAT IS F 15.5

.9

19 TBURN

$90000 D+00$

BURNOUT TIME (SEC)

20 ZUFZZ

OOOOOD+OO

FLAME EXTINCTION COEF. ( $1 / \mathrm{M})$

WHAT VALUE DO YOU WANT FOR THE FLAME EXTINCTION COEF. ( $1 / M)$

THE FORMAT IS F15.5

1.1

20 ZUFZZ .1100OD+01 FLAME EXTINCTION COEF. ( $1 / \mathrm{M})$

RECAPITULATION OF DATA FOR THIS MATERIAL !DATA APPEARS IN SLIGHTLY

! DIFFERENT ORDER FROM

!WHAT IT IS IN SECTIONS

!3. 1 AND 4.2 .

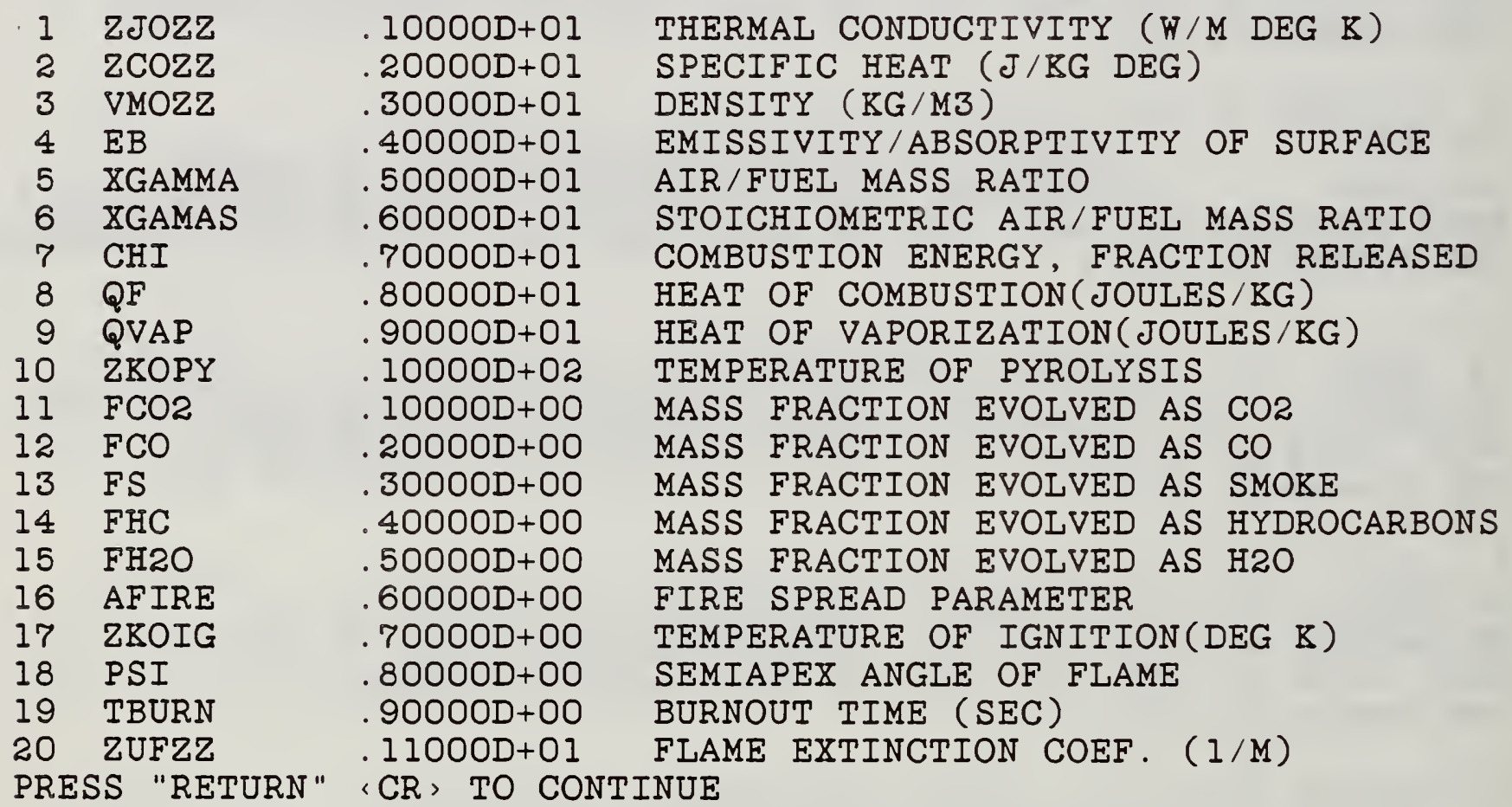

N

ANY CORRECTIONS? ANS $(Y / N)$

MATERIAL NAMES CURRENTLY IN THE DATA BANK (JOT DOWN THE NUMBER(S) OF ITEM TO BE CHANGED):
1 GASOLINE
2 HEPTANE
3 KEROSENE
4 METHANE
5 PMMA
7 POLYURETHANE
8 PROPANE
6 POLYSTYRENE
9 PU FOAM

10 RED OAK

10 RED

11 ARBITRARY

PRESS "RETURN" <CR > TO CONTINUE 
THIS PROGRAM HAS SIX USE OPTIONS:

A) ADD A MATERIAL TO THE DATA BANK

C) CHANGE MATERIAL DATA ALREADY IN THE BANK

D) DELETE A MATERIAL

E) EXIT PROGRAM; WRITE DATA BASE TO DISK FILE

S) SORT (ALPHABETIZE) THE DATA BANK

V) VIEW A MATERIAL IN THE BANK

ENTER YOUR CHOICE:. A, C, D, E, S OR V

C

ENTER THE NUMBER OF THE MATERIAL WHOSE DATA IS TO BE CHANGED. 11

11 ARBITRARY

DO YOU WANT TO CHANGE THE NAME OF THE MATERIAL? IF SO, ENTER "Y" N

CURRENT MATERIAL COMMENT IS

FAKE MATERIAL

IS THIS CORRECT? ( $Y / N)$

$Y$

CURRENT DATA FOR ARBITRARY

1 ZJOZZ . IOOOOD+01

$2 \mathrm{ZCOZZ} \quad .20000 D+01$

3 VMOZZ .3000OD+01

4 EB $40000 D+01$

5 XGAMMA .50000D+01

6 IGAMAS $.60000 D+01$

7 CHI $\quad .70000 D+01$

8 QF $\quad .80000 D+01$

9 QVAP $\quad .90000 D+01$

10 ZKOPY .10000D+02

11 FCO2 .10000D+00

12 FCO .20000D +00

13 FS .30000D+00

14 FHC .40000D+00

15 FH2O $.50000 D+00$

16 AFIRE .60000D+00

17 ZKOIG .7000OD+00

18 PSI $\quad .80000 D+00$

19 TBURN .90000D+00

20 ZUFZZ .I1000D+01

PRESS "RETURN" 〈CR > TO CONTINUE

THERMAL CONDUCTIVITY ( $W / M$ DEG $K$ )

SPECIFIC HEAT ( $J / B G$ DEG)

DENSITY ( $\mathrm{KG} / \mathrm{M3})$

EMISSIVITY/ABSORPTIVITY OF SURFACE

AIR/FUEL MASS RATIO

STOICHIOMETRIC AIR/FUEL MASS RATIO

COMBUSTION ENERGY, FRACTION RELEASED

HEAT OF COMBUSTION (JOULES/KG)

HEAT OF VAPORIZATION (JOULES/KG)

TEMPERATURE OF PYROLYSIS

MASS FRACTION EVOLVED AS CO2

MASS FRACTION EVOLVED AS CO

MASS FRACTION EVOLVED AS SMORE

MASS FRACTION EVOLVED AS HYDROCARBONS

MASS FRACTION EVOLVED AS H2O

FIRE SPREAD PARAMETER

TEMPERATURE OF IGNITION(DEG $\mathrm{K}$ )

SEMIAPEX ANGLE OF FLAME

BURNOUT TIME (SEC)

FLAME EXTINCTION COEF. ( $I / M)$

ENTER INDEX NUMBER OF ITEM TO BE CHANGED FOLLOWED BY A COMMA, FOLLOWED BY THE NEW VALUE (FI5.5). ENTER 0,0 TO END CHANGES.

$20,8.205$

$15, .0075$

$10,798.65$

0,0

$\begin{array}{lll}1 & \text { ZJOZZ } & .10000 D+01 \\ 2 & \text { ZCOZZ } & .20000 D+01 \\ 3 & \text { VMOZZ } & .30000 D+01 \\ 4 & \text { EB } & .40000 D+01\end{array}$

THERMAL CONDUCTIVITY ( $W / M$ DEG $\mathrm{K}$ )

SPECIFIC HEAT (J/KG DEG)

DENSITY (KG/M3)

EMISSIVITY/ABSORPTIVITY OF SURFACE 


\begin{tabular}{|c|c|c|c|}
\hline 5 & XGAMMA & $50000 D+01$ & AIR/FUEL MASS RATIO \\
\hline 6 & XGAMAS & $60000 D+01$ & STOICHIOMETRIC AIR/FUEL MASS RATIO \\
\hline 7 & CHI & $70000 D+01$ & COMBUSTION ENERGY, FRACTION RELEASED \\
\hline 8 & QF & $.80000 D+01$ & HEAT OF COMBUSTION (JOULES/KG) \\
\hline 9 & QVAP & $.90000 D+01$ & HEAT OF VAPORIZATION (JOULES/KG) \\
\hline 10 & ZROPY & $.79865 \mathrm{D}+03$ & TEMPERATURE OF PYROLYSIS \\
\hline 11 & $\mathrm{FCO} 2$ & $.10000 D+00$ & MASS FRACTION EVOLVED AS CO2 \\
\hline 12 & FCO & $.20000 D+00$ & MASS FRACTION EVOLVED AS CO \\
\hline 13 & FS & $.30000 D+00$ & MASS FRACTION EVOLVED AS SMOKE \\
\hline 14 & FHC & $.40000 D+00$ & MASS FRACTION EVOLVED AS HYDROCARBONS \\
\hline 15 & FH2O & $.75000 D-02$ & MASS FRACTION EVOLVED AS H2O \\
\hline 16 & AFIRE & $.60000 D+00$ & FIRE SPREAD PARAMETER \\
\hline 17 & ZKOIG & $.70000 D+00$ & TEMPERATURE OF IGNITION(DEG $\mathrm{K}$ ) \\
\hline 18 & PSI & $.80000 D+00$ & SEMIAPEX ANGLE OF FLAME \\
\hline 19 & TBURN & $.90000 D+00$ & BURNOUT TIME (SEC) \\
\hline 2 & ZUFZZ & $.82050 D+01$ & FLAME EXTINCTION COEF. ( $I / M)$ \\
\hline & סחו & & \\
\hline
\end{tabular}

DO YOU WANT TO CHANGE ANY MORE VALUES?. ENTER "Y" IF SO.

$\mathrm{N}$

MATERIAL NAMES CURRENTLY IN THE DATA BANK (JOT DOWN THE NUMBER(S) OF ITEM TO BE CHANGED):

1 GASOLINE

4 METHANE

7 POLYURETHANE

10 RED OAK
2 HEPTANE

5 PMMA

8 PROPANE

11 ARBITRARY
3 KEROSENE

6 POLYSTYRENE

9 PU FOAM

THIS PROGRAM HAS SIX USE OPTIONS:

A) ADD A MATERIAL TO THE DATA BANK

C) CHANGE MATERIAL DATA ALREADY IN THE BANK

D) DELETE A MATERIAL

E) EXIT PROGRAM; WRITE DATA BASE TO DISK FILE

S) SORT (ALPHABETIZE) THE DATA BANK

V) VIEW A MATERIAL IN THE BANK

ENTER YOUR CHOICE: A, C, D, E, S OR V $S$

SORTING DATA BASE

MATERIAL NAMES CURRENTLY IN THE DATA BANK (JOT DOWN THE NUMBER(S) OF ITEM TO BE CHANGED):

\section{ARBITRARY \\ 4 KEROSENE \\ 7 POLYSTYRENE}

10 PU FOAM

PRESS "RETURN
2 GASOLINE

5 METHANE

8 POLYURETHANE

11 RED OAK
3 HEPTANE

6 PMMA

9 PROPANE

THIS PROGRAM HAS SIX USE OPTIONS:

A) ADD A MATERIAL TO THE DATA BANK

C) CHANGE MATERIAL DATA ALREADY IN THE BANK

D) DELETE A MATERIAL 
E) EXIT PROGRAM; WRITE DATA BASE TO DISK FILE

S) SORT (ALPHABETIZE) THE DATA BANK

V) VIEW A MATERIAI IN THE BANK

ENTER YOUR CHOICE: A, C, D, E, S OR V

D

ENTER THE NUMBER OF THE MATERIAL TO BE DELETED FROM THE DATA BANK 1

THE MATERIAL TO BE DELETED IS

1 ARBITRARY

PROCEED WITH DELETION? ANS ( $Y / N)$

$Y$

MATERIAL NAMES CURRENTLY IN THE DATA BANK (JOT DOWN THE NUMBER(S) OF ITEM TO BE CHANGED):

1 GASOLINE

4 METHANE

7 POLYURETHANE

10 RED OAK

PRESS "RETURN" <CR> TO CONTINUE

THIS PROGRAM HAS SIX USE OPTIONS:

A) ADD A MATERIAL TO THE DATA BANK

C) CHANGE MATERIAL DATA ALREADY IN THE BANK

D) DELETE A MATERIAI

E) EXIT PROGRAM; WRITE DATA BASE TO DISK FILE

S) SORT (ALPHABETIZE) THE DATA BANK

V) VIEW A MATERIAL IN THE BANK

ENTER YOUR CHOICE: A, C, D, E, S OR V

$E$

STOP
3 KEROSENE

6 POLYSTYRENE

9 PU FOAM 
To run in "batch" merely requires that the computer be "told" to run FIRST, and then to provide the answers to the same questions that are asked during interactive use. The first procedure is machine-dependent; that is, it varies with the operating system. The second item - the answers to the questions - are given in a batch file; we will call it BTCHIN for convenience. If we refer to Examples 4.1 and 4.7 , we see that the simplest batch file we can have consists of 11 lines and an extra carriage return:

FIROUT
PLOTUT
$\mathrm{N}$
$\mathrm{N}$
$\mathrm{Y}$
SOMINP
$\mathrm{N}$
$\mathrm{N}$
$\mathrm{N}$
any number
any number
$<\mathrm{CR}>$

The SOMINP appearing in the sixth line above is just an example name for some input file, prepared in the usual way - i.e., during interactive runningsaved with that name. It is then available for either interactive or batch use. 
Since you will not (necessarily) be there in person to run the program, a little "control" program (file) must be written in order to instruct the computer to run FIRST. The details of how this is done will vary from one computer to another, but they have a generic similarity: the control program always does three things - it

1. signs you on (i.e.,- logs you on),

2. starts execution of the progrma with a named batch file

3. signs you off

Thus in the example above, the control file signed you on the machine, called up the executable version of FIRST, and directed it to use the file BTCHIN, displayed on the previous page; that file acts as your surrogate, and answers the questions "asked" by FIRST. BTCHIN specifies, in this example, that SOMINP be used as the input file. After the program has been run, you are automatically signed off.

It must again be stressed that the form and the preparation of the control file are machine-dependent (more precisely, they depend on the operating system with which the user works). Therefore we will not attempt to give an explicit example of a control file. The batch file, on the other hand, is almost machine-independent (any dependence appears in the forms of file names permitted by the computer). 
When the third question, "WILL THIS BE USED FOR ... BATCH RUNS?", is answered with "Yes", output to the viedo screen is suppressed, which is appropriate when there is no one there to observe the screen. Moreover, some machines may have difficulty finding enough space for all the output, in batch mode, so that this alleviates that potential problem. On the other hand, an analogous difficulty has been found for the opposite case: one version of the operating system for a PE 3252 computer found it impossible to allocate adequate space for the creation of the batch files when the "Y" option was chosen. Thus it is not possible, with the present program, to operate successfully in all machine environments. Should difficulties appear when "Y" is chosen, therefore, it is advisable to use "N" (but choose an output interval longer than the run length). 


\section{OUTPUT}

There are two places where output appears: on the terminal screen, and in one or more files (stored on the disk, and therefore usually referred to as disk files). In section 6.1 below, the names of the disk files are discused; in section 6.2 the appearance of the disk files is first discussed, then that of the running output on the screen.

\subsection{Output File Names}

As discussed in section 4.1, the output files must be named by the user (there are no default names). The output files may be named fairly arbitrarily, but OUTPUT should be avoided; also FILES and BCHDAT are "reserved" names, and may not be used. ${ }^{10}$ The file names may have up to fourteen characters (each); of these, the last four may be a period plus a three-character "extension" (except for the CYBER, which forbids the period); the first two may be drive specifiers (for PC's). Warning: your operating system may not permit as many as 14 characters; check first. Precisely because some systems are fairly restrictive, only six-character (or fewer) file names have been used in FIRST - e.g. FIROUT rather than FIRE.OUT, BCHDAT rather then BATCH.DAT, etc. The output plot file PLOTUT is used when graphical output is requested (see section 6.4). For illustrative purposes only, we will assume that the name FIROUT has been chosen for the output file, just as shown in section 5 .

On a VAX with VMS operating system, version numbers are automatically appended after the extension, so that if several runs were made, the results would appear in FIROUT;1, FIROUT;2, etc. The operating system used on the Perkin-Elmer machine (and many others) does not have this feature; hence the program deletes any preexisting file with the name now chosen for the output file (FIROUT, here) before a new run is made with output going into a file of that name. Thus, if a record is desired of a given run, the contents of FIROUT must be printed out, or the file must be renamed, or some other name

10 The file FILES consists of the names of input files produced by the user; it is opened in subroutine SEARCH. 
must be chosen for the new output file. There can be more output; this will be discussed in section 6.4 .

\subsection{Standard Form of Output}

The first thing to appear on the disk file are the choices made by the user for the physics subroutines. Next is a "header" consisting of the user's input comments (if any). Following this is a list of the user's input: the geographical arrangements and the thermophysical data, as shown on the next page. On the page following that, some sample output is displayed (one notes that it is given to five significant figures; this is done not because we believe the results accurate to five places, but in order to be able to compare one output with another). 
PHYSICAL SUBROUTINES SELECTED:

OBJECT TEMPERATURES: 2 TMPO2

GAS ABSORPTION COEF : 2 ABSRB2

PLUME ENTRAINMENT: 1 AREA PLM RUN 1

FIRST VERSION 1 DEFAULT CASE. JUNE 4, 1987.

GEOMETRIC AND PHYSICAL PARAMETERS

ROOM NUMBER 1:

DIMENSIONS $(X, Y, Z)=$

AMBIENT TEMPERATURE $=300.0$

2.4384

3.6576

2.4384)

A PHOTOELECTRIC SMOKE DETECTOR IS PRESENT IN THE ROOM:

ABSORPTION COEEFICIENT THRESHOLD FOR ALARM $=.033001 / \mathrm{M}$

LOCATION OF DETECTOR INPUT PORT(METERS BELOW CEILING) $=.020$

OBJECT NUMBER $1(I D=1)$ :

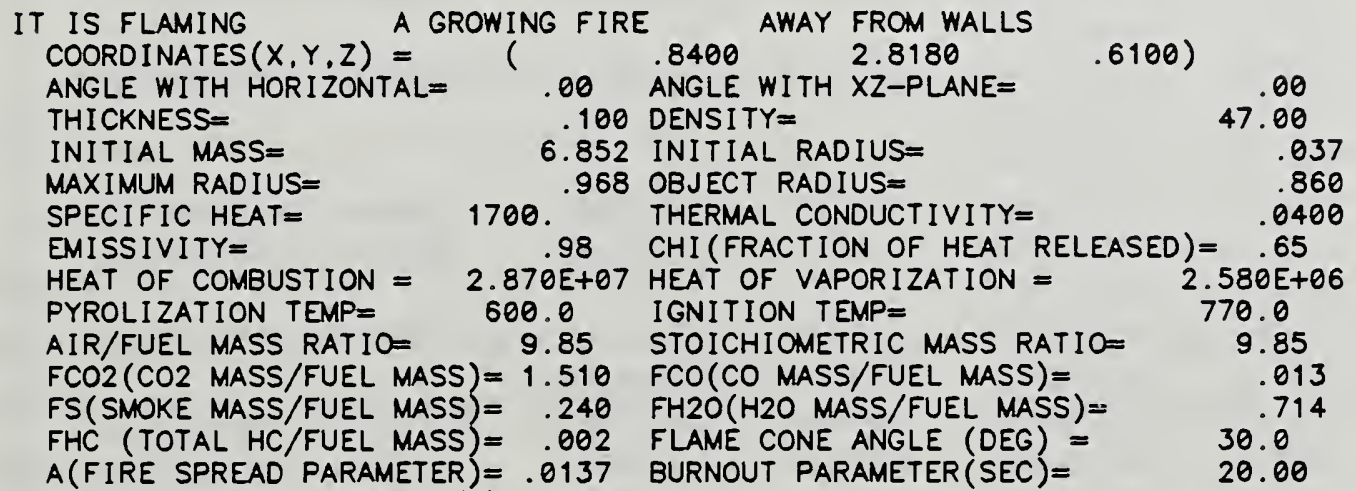

FLAME EXTINCT. COEF. ( $1 / M) 1.280$

BURNOUT PARAMETER $($ SEC $)=$

30.0

OBJECT NUMBER $2(I D=2)$ :

IT IS NON FLAMING

A GROWING FIRE

$\operatorname{COORDINATES}(X, Y, Z)=$

ANGLE WITH HORIZONTAL=

$(.00$

$\begin{array}{ll}2.1800 & 2.8180 \\ .00 & \text { ANGLE WITH XZ-PLANE }=\end{array}$

THICKNESS=
INITIAL MASS

MAXIMUM RADIUS=

SPECIFIC HEAT =

100 DENSITY

1.096 INITIAL RADIUS=

466 OBJECT RADIUS=

1700 .

THERMAL CONDUCTIVITY=

EMISSIVITY=

HEAT OF COMBUSTION =

PYROLIZATION TEMP=

2. $870 E+07$

CHI (FRACTION OF HEAT RELEASED) $=.65$

AIR/FUEL MASS RATIO= 600.0

9.85

FCO2(CO2 MASS/FUEL MASS $)=1.510$

FS(SMOKE MASS/FUEL MASS) $=.240$

FHC (TOTAL HC/FUEL MASS) $=.002$

A(FIRE SPREAD PARAMETER) $=.0137$

FLAME EXTINCT. COEF. ( $1 / \mathrm{M}) 1.280$

VENT NUMBER 1

(WIDTH, HEIGHT, DEPTH) $=($

OZATION =

IGNITION TEMP=

STOICHIOMETRIC MASS RATIO= 9.85

FCO(CO MASS/FUEL MASS $)=$

FH2O(H2O MASS/FUEL MASS) =

FLAME CONE ANGLE (DEG) =

$.8640)$

BURNOUT PARAMETER(SEC) $=$

.013

.714

30.0

20.00

WALL NUMBER 1 :

THICKNESS =

.7620

2.0320

$.4064)$

SPECIFIC HEAT =

.0254 DENSITY $=$

1062.

THERMAL CONDUCTIVITY=

800.00

1340

SPECIFIC HEAT OF AIR= 1004 .

FOR AIR:

HEAT TRANSFER COEFF $=\quad 10.00$ PLUME ENTRAINMENT COEFF=

.10

FOR LAYER GASES:

MAX. HEAT TRANSFER COEFF $=50.00$ MIN. HEAT TRANSFER COEFF $=$

5.00

FOR VENTS:

FLOW COEFFICIENT $=$

.68

ITERATION LIMIT: 100 TOLERANCE: $1.0 E-04$

MAX TIME STEP: 2.00, MIN TIME STEP: .00098 
The regular (default) output has this appearance:

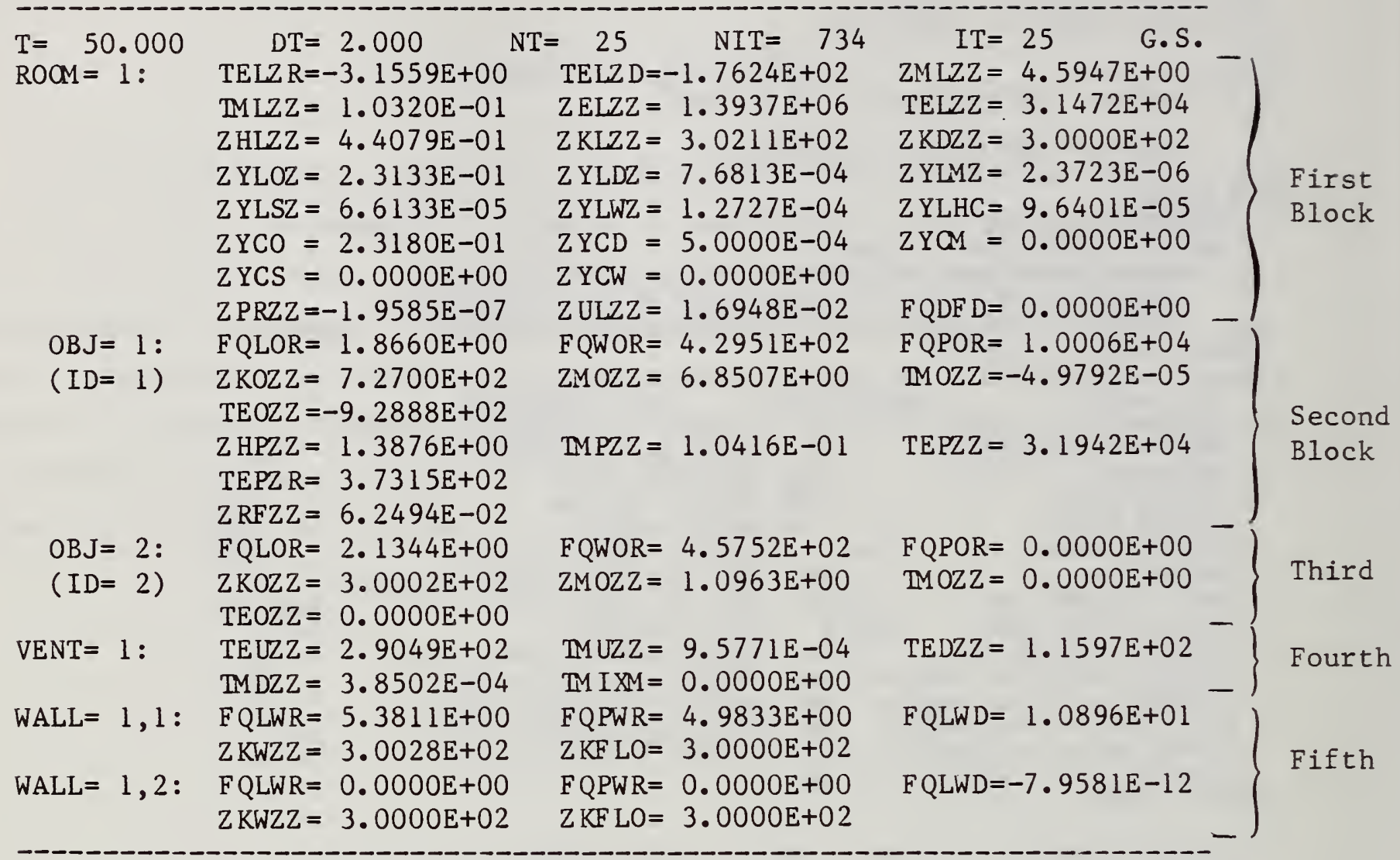

This appears on the screen every 20 seconds (default interval) of fire time (not time on your clock!), unless another interval is specified by the user. It appears on the disk file (i.e., in file FIROUT for example shown in this guide) every 10 seconds of fire time, again unless something other than ten seconds has been specified by the user. It is appropriate to note here that the screen output "scrolls" past - that is, it moves across the screen continuously, making it impossible to study; this is usually not a problem, especially as most operating systems permit the user to "freeze" the image by holding down the CONTROL and the $\mathrm{C}, \mathrm{S}$, or $\mathrm{T}$ keys simultaneously (or by some other keyboard command).

The top line gives the following information:

$T$ is the time in seconds since the start of the run - i.e., since ignition of the first item.

DT is $\Delta \mathrm{T}$, the last time increment (in seconds). 
NT is the total number of time steps needed to get to this point. Thus, $\mathrm{T} / \mathrm{NT}$ gives the average time increment, $\langle\Delta t\rangle$.

NIT is the total number of iterations required to get to this point.

IT is the number of iterations required to converge to the time step shown (i.e., from $t-\Delta t$ to $t$ ).

G.S. stands for "Gauss-Seidel", the numerical technique upon which is based the method of solution for the simultaneous coupled equations of the model. This is indicated, because there is an alternate technique built in, the Newton method, chosen automatically by the computer, when required. The latter is hardly used any longer, however, because of improvements in the physics.

The remainder of the output gives values of the variables which are calculated. The first block of data (23 items), labeled ROOM, gives values of 15 variables pertaining to the upper gas layer in the room, such as its temperature, species concentrations, etc.; and 6 to the lower gas layer. It also includes the convective heat flux to the floor, and the pressure difference (at the floor) between inside and outside pressure (this drives the flows through the vents).

The symbols identifying these variables are neither euphonious nor mnemonic. However, they are rational, and are explained in section 9.1; a "dictionary" of these symbols is given in section 9.2. The next block of data (12 items), labeled OBJECT \#1, gives values of variables pertaining to object \#1: the fluxes falling on its surface, its mass, the pyrolysis rate when it's pyrolyzing, the energy released when it's burning, etc.

The third block of data ( 7 items), labeled OBJECT \#2, does the same thing for the second item. It has five fewer entries because it is not yet burning. There are as many of these blocks as there are objects, of course.

The fourth block (5 items), labeled VENT \#1, pertains to the mass and energy fluxes through that vent.

The final block ( 8 items), labeled WALL, gives the fluxes falling on the upper wall and ceiling from several sources, and the resulting surface 
temperatures as well as the floor/lower wall temperature (which, even though reported, is not in fact varied in this version).

The first index in the label ( $1, i)$ refers to "wall number 1 " (in this version there is only one wall/ceiling); the second index refers to the interior of the room ( $i=1)$, or the exterior $(i=2)$.

Appropriate comments appear between outputs, both on the user's screen and on the disk file, when various interesting things happen. Thus, the ignition of an object is announced together with the time this occurs. Similarly, when oxygen starvation begins and/or ends for a burning object, the burnout of an object, and the activation of a photoelectric detector (if one is present) are all announced.

More information appears on the screen than on the disk file: after the regular block of output, some abbreviated information on the progress of the calculation is flashed on the screen, as shown here:

$$
\begin{aligned}
& (\mathrm{NT}=26 \quad \mathrm{~T}=52.000 \\
& \mathrm{IT}=37
\end{aligned}
$$

One of these double lines appears for each time step (or attempted time step). If the number of iterations required to converge exceeds the current maximum (100 is the default), the message "NOT CONVERGED" will appear.

If the lower-layer temperature is calculated to be higher than the calculated upper-layer temperature during iteration, the message

COLD LAYER TEMPERATURE A HIGHER THAN LAYER B 
appears on the screen; A is the lower-layer temperature, B is the upper-layer temperature.

The thickness of each layer is calculated independently. Their sum must equal the height of the room. As long as this sum differs from the actual room height by less than one part in a thousand, no message appears on the screen. But when the error is greater than $10^{-3}=0.1 \%$, the message

Layer height sum error... 8 ,

appears on the screen.

\subsection{Short Form}

As is seen from the appearance of the regular output, there is a minimum of 23 lines of output per (chosen or default) output interval, and three extra lines for every extra (non-burning) object. This results in a rather thick stack of paper if a long run is made; since only a few of the variables will generally be of interest to a user, much of that is a waste. Therefore an alternative output format has been devised, which produces only one line of output per output interval. This tabulates eight user-chosen variables. If the user does not choose the variables, a default set is output.

The output resulting from a $500-\mathrm{sec}$ run of a case similar to the reference (default) case (see section 2) is given on the next two pages. We note that the header for each column is the code name for a particular variable; the argument for each variable refers to the room number ( $K R=1$ ) for the room variables, or to the object number ( $\mathrm{KO}=1$ or 2$)$ for the object variables. Above each header is a short description of what that variable is; these descriptions do not in fact appear in the output, they are only included here for clarification. 


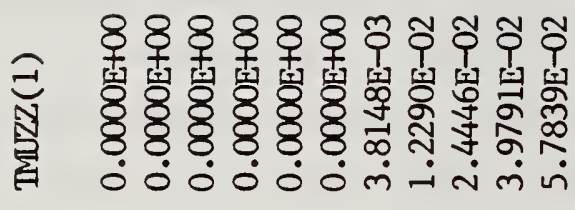

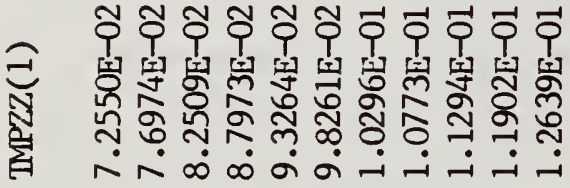

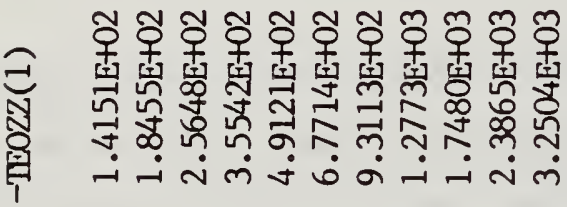

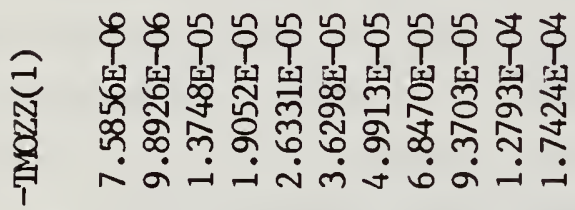

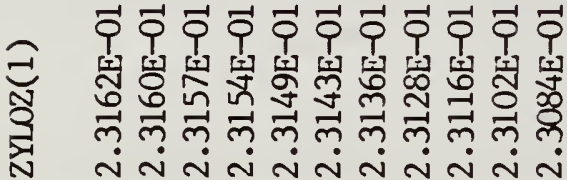

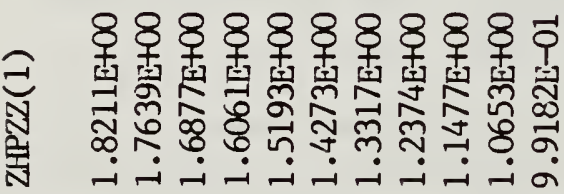

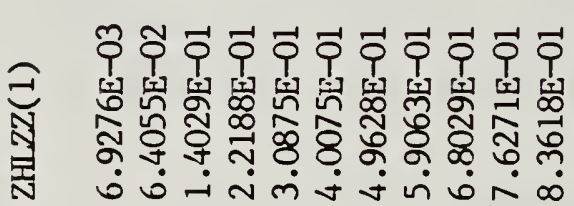

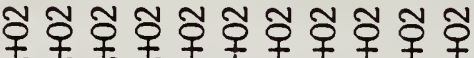

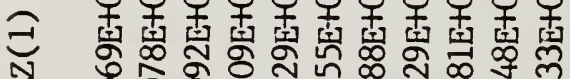

స్ㄱ

疽

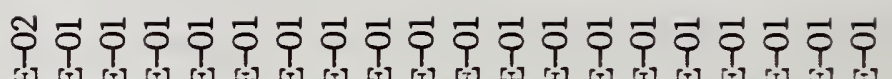

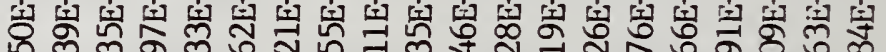
फ

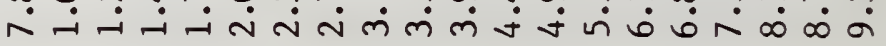

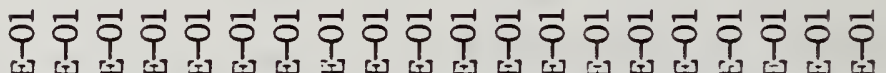

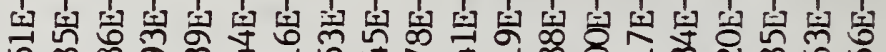

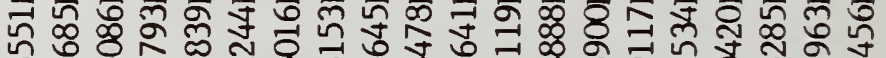

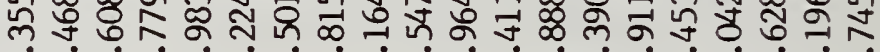

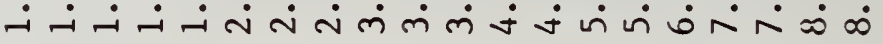

ๆ

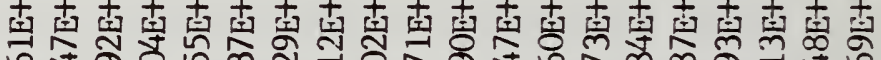

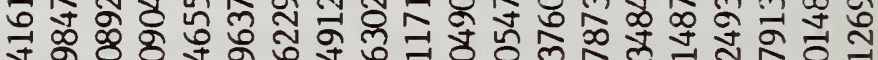

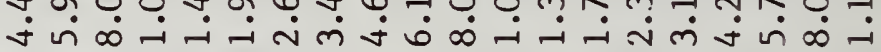

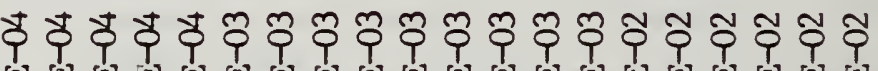

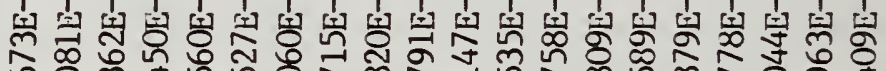

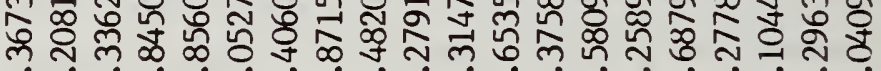

ที่

ঞ̊

II

.

$\stackrel{\omega}{2}$

7

$\stackrel{\text { कृ }}{4}$

虫

安

$\neg$

శ్

平

4

过

兽

,

.

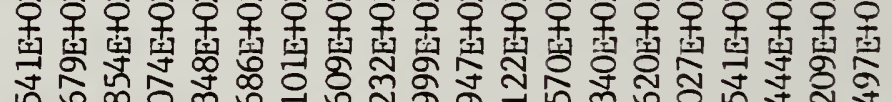
पे

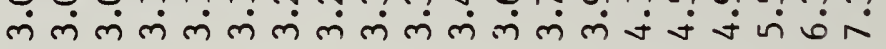

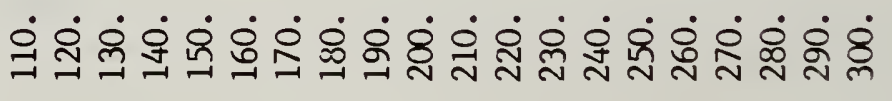




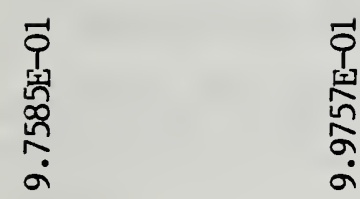

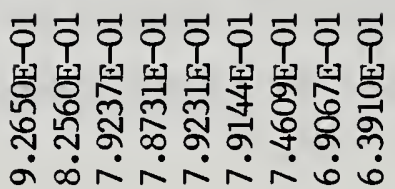

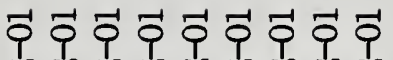

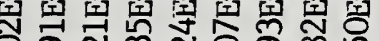

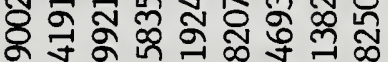
ம்
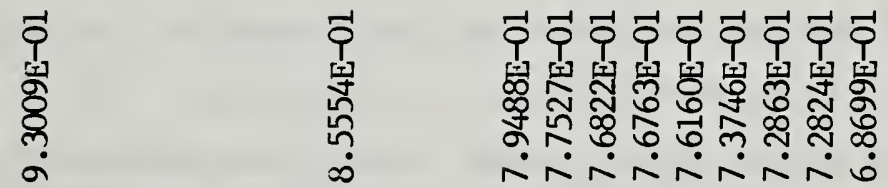

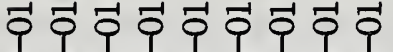

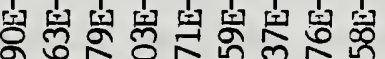
क्ते

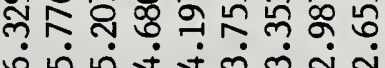

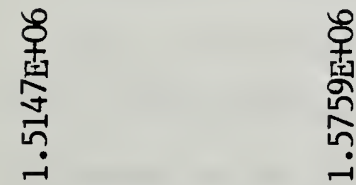

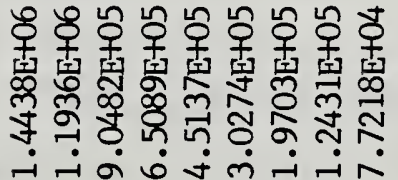

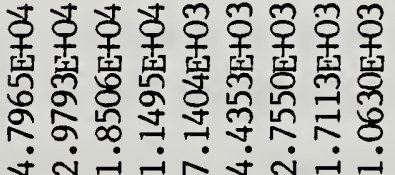

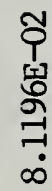

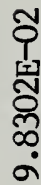

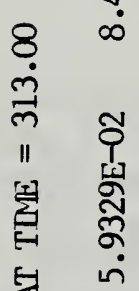

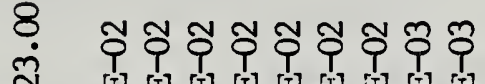

ज凷

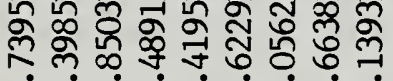

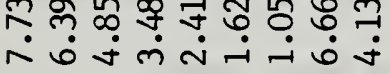

彳ิ 1

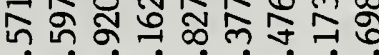
जं

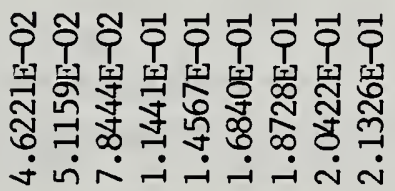

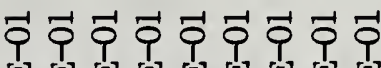

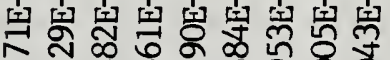

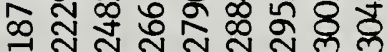
กัN

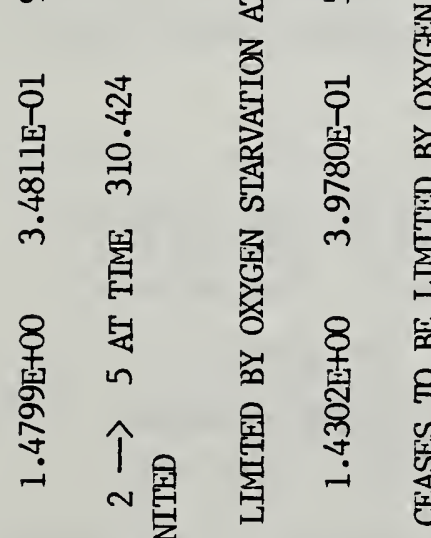

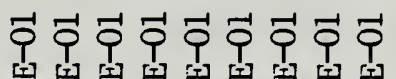

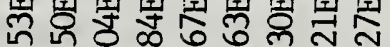
然岁资 in $\dot{0} \dot{0} \dot{0} \dot{0}$ in

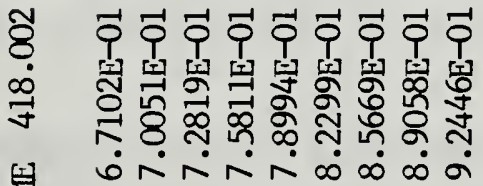
녈

88888888

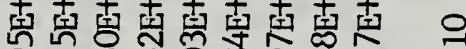

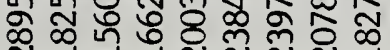

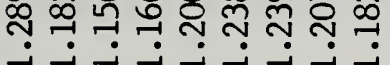

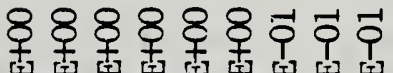

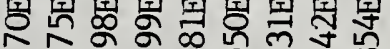

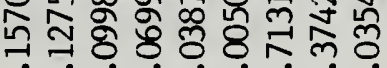
i.

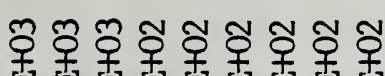

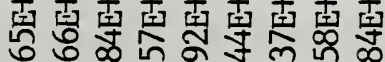

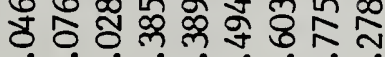

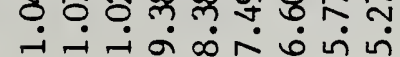
붕 뎡 동

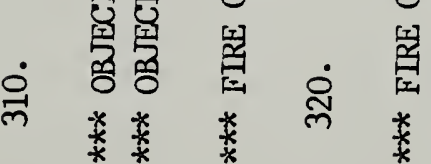

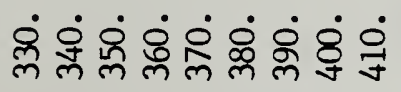

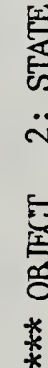

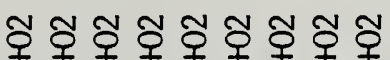

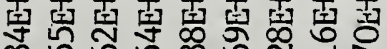
品 बू

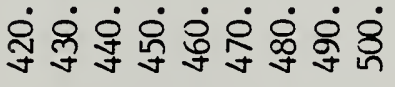


We also see that messages appear when certain noteworthy events occur (such as ignition of the second item at $306.6 \mathrm{sec}$ ). There are also somewhat more cryptic notes, such as "state $2 \rightarrow 5$ " or "state $5 \rightarrow 10$ ". These numbered "states" refer to the status of an object. State 2 means "heating", 5 means "flaming", and 10 means "consumed" (burned up). Other numberd states (such as 4 for "smoldering") are not yet incorporated into the program. "Oxygen starvation" means that insufficient oxygen is being entrained into the fire plume for complete combustion of the fuel vapor.

In the following three pages, a sample session at the terminal is reproduced, illustrating how to change the list of variables (if desired). We see from the table on the second of the three pages there are 70 variables available from among which to choose 8. They are identified with two arguments. When the second argument is zero, only the first is significant, and its meaning is as described above (i.e., KR, KO, KV, etc., - see section 6.3). When the second argument is non-zero, it refers to the inside (1) or outside (2) of a wall, ceiling, or floor. Thus, FQPWR $(1,1)$ is ${ }^{11}$ the radiative heat flux from flame number one to the inside of the wall.

There are two important points to be made here:

(1) Although it is not stated in the instructions appearing on the screen, the numerical entries should be integers. Contrary to the instructions given in section 3.1, however, in this case the location of the integer is not important.

(2) Although this is not mentioned in the instructions on the screen either, if the carriage return ( $\angle R E T>$ ) key is struck, the default variable is entered (with the caveat indicated in the footnote in section 4.). This, too, is illustrated in the following example.

11 Item 63 in the list on p. 88. 
WILL THIS BE USED FOR FURTHER BATCH RUNS? ( $\mathrm{Y} / \mathrm{N})$ :

$\mathrm{N}$

WELCOME TO THE INPUT PORTION OF THE PROGRAM. THIS SECTION ALLOWS YOU TO INITIALIZE YOUR VARIABLES EITHER BY BLOCK DATA OR BY A PREEXISTING INPUT FILE. IT THEN ALLOWS YOU TO MAKE ANY CHANGES TO YOUR INPUT DATA AND GIVES YOU THE OPTION TO SAVE THESE CHANGES IN A FILE (NAMED BY YOU).

YOU HAVE A TOTAL OF 1 INPUT FILE(S)

AVAILABLE FOR USE

LEN.DAT

BEFORE CONTINUING, WOULD YOU LIKE ANY OF THESE INPUT FILES DELETED? (Y/N): $\mathrm{N}$

WOULD YOU LIKE ONE OF THESE INPUT DATA F ILES TO BE READ IN AND

INITIALIZE THE INPUT VARIABLES? ( $\mathrm{Y} / \mathrm{N})$ :

$\mathrm{N}$

YOUR INPUT DATA WILL BE BASED ON THE PROGRAM BLOCK-DATA DEFAULTS

WOULD YOU LIKE YOUR INPUT DATA DISPLAYED TO LET YOU SEE WHAT THE VARIABLES HAVE BEEN INITIALIZED TO? ( $\mathrm{Y} / \mathrm{N})$ :

$\mathrm{N}$

WOULD YOU LIKE TO MAKE ANY CHANGES TO THE INPUT DATA? (Y/N): Y

IN THE INPUT SEQUENCE TO FOLLOW, NOTE THAT AN INPUT ERROR

-- E.G. TYPING A LETTER WHERE A DIGIT IS REQUIRED --

CAUSES THE QUESTION TO BE REASKED.

THE SYMBOL 〈RET> STANDS FOR CARRIAGE RETURN, OR NEWLINE, OR

WHATEVER KEY ON THE TERM INAL IS USED TO ENTER DATA.

HIT 〈RET〉 TO CONTINUE

YOU HAVE 2 OPTIONS FOR CHANGING THE DATA:

1) A MENU FOR SELECTING YOUR AREAS OF CHANGE

2) RUN THROUGH THE WHOLE INPUT SEQUENCE, START TO FINISH

NOTE: IF YOU ARE NOT FAMILIAR WITH THE INPUT PROGRAM, IT IS BEST TO MAKE CHOICE 非 2 IN ORDER TO FAM ILIARIZE YOURSELF WITH THE DIFFERENT SECTIONS.

PLEASE ENTER THE ITEM NUMBER OF YOUR CHOICE 1

THE FOLLOWING LIST IS A BREAKUP OF THE MAIN SECTIONS OF THE PROGRAM. TO CHANGE THE DATA IN ANY ONE OF THESE SECTIONS, ENTER THE ITEM NUMBER OF YOUR CHOICE: 


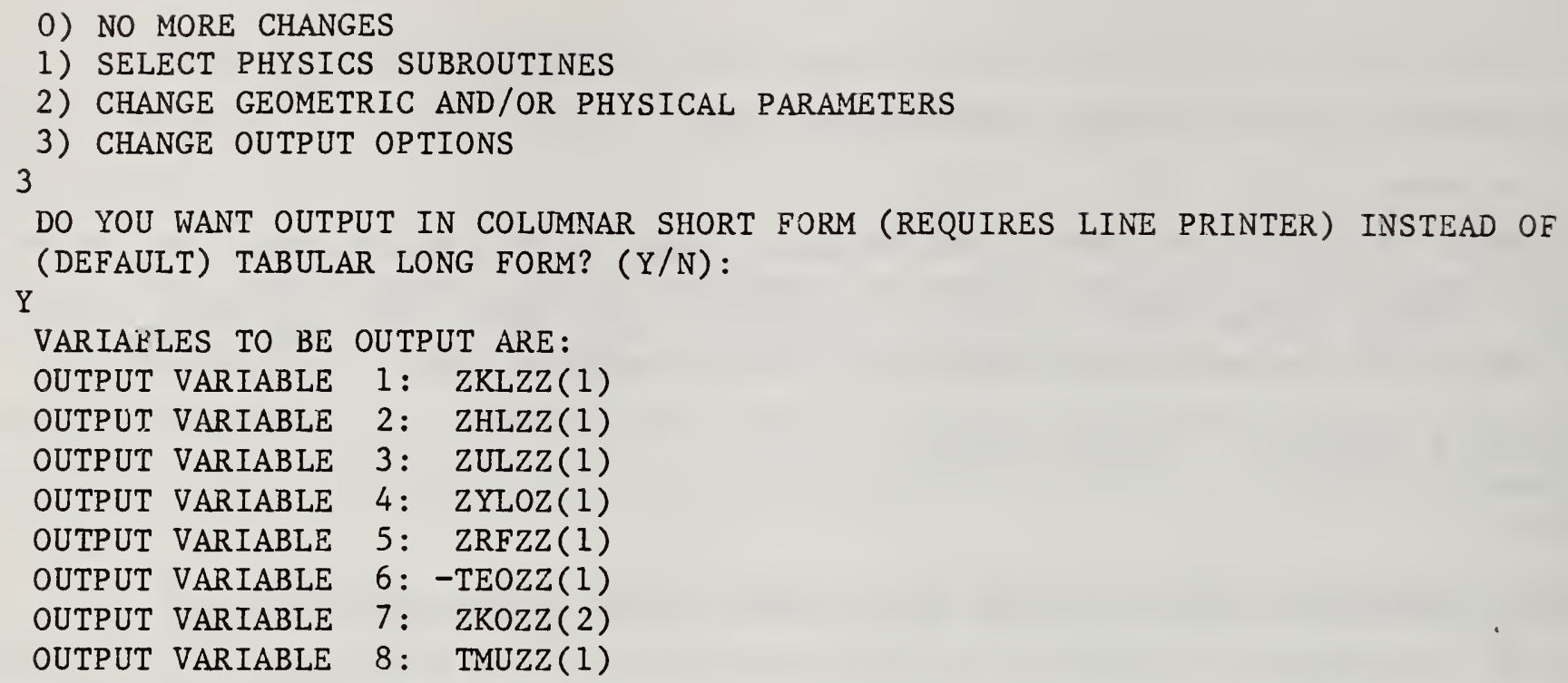
1) $\operatorname{TELZR}(1,0)$
16) $\operatorname{zMCZZ}(1,0)$
31) $\operatorname{ZMOZZ}(1,0)$
46) $\operatorname{TEPZR}(2,0)$
2) $\operatorname{TELZD}(1,0)$
17) $\operatorname{ZECZZ}(1,0)$
32) $\operatorname{ZMOZZ}(2,0)$
47) $\operatorname{ZRFZZ}(1,0)$
3) $\operatorname{ZMLZZ}(1,0)$
18) $\operatorname{TMCZZ}(1,0)$
33) $\operatorname{TMOZZ}(1,0)$
48) $\operatorname{ZRFZZ}(2,0)$
4) $\operatorname{TMLZZ}(1,0)$
19) $\operatorname{TECZZ}(1,0)$
34) $\operatorname{TMOZZ}(2,0)$
5) $\operatorname{ZELZZ}(1,0)$
20) $\operatorname{ZKDZZ}(1,0)$
35) $\operatorname{TEOZZ}(1,0)$
49) $\operatorname{TPSI}(1,0)$
6) $\operatorname{TELZZ}(1,0)$
21) $\operatorname{ZYLHC}(1,0)$
36) $\operatorname{TEOZZ}(2,0)$
50) $\operatorname{TPSI}(2,0)$
7) $\operatorname{ZHLZZ}(1,0)$
22) $\operatorname{FQDFD}(1,0)$
37) $\operatorname{ZHPZZ}(1,0)$
51) $\operatorname{TMBZZ}(1,0)$
8) $\operatorname{ZKLZZ}(1,0)$
23) $\operatorname{FQLOR}(1,0)$
38) $\operatorname{ZHPZZ}(2,0)$
52) $\operatorname{TMBZZ}(2,0)$
9) $\operatorname{ZYLOZ}(1,0)$
24) $\operatorname{FQLOR}(2,0)$
39) $\operatorname{TMPZZ}(1,0)$
53) $\operatorname{TeUzz}(1,0)$
10) $\operatorname{ZYLDZ}(1,0)$
25) $\operatorname{FQWOR}(1,0)$
40) $\operatorname{TMPZZ}(2,0)$
54) $\operatorname{TMUZZ}(1,0)$
11) $\operatorname{ZYLMZ}(1,0)$
26) $\operatorname{FQWOR}(2,0)$
41) $\operatorname{TEPZZ}(1,0)$
55) $\operatorname{TEDzZ}(1,0)$
12) $\operatorname{ZYLSZ}(1,0)$
27) $\mathrm{FQPOR}(1,0)$
42) $\operatorname{TEPZZ}(2,0)$
56) $\operatorname{midzz}(1,0)$
13) $\operatorname{ZYLWZ}(1,0)$
28) $\mathrm{FQPOR}(2,0)$
43) $\operatorname{TMplU}(1,0)$
57) $\operatorname{TMIXM}(1,0)$
14) $\operatorname{ZPRZZ}(1,0)$
29) $\operatorname{ZKOzZ}(1,0)$
44) $\operatorname{TMPLU}(2,0)$
58) $\operatorname{ZKVZZ}(1,0)$
15) $\operatorname{ZULZZ}(1,0)$
30) $\operatorname{ZKOZZ}(2,0)$
45) $\operatorname{TEPZR}(1,0)$
59) $\operatorname{AQUW}(1,0)$
60) $\mathrm{AQDW}(1,0)$

Enter $\langle C R\rangle$ to continue

61) $\operatorname{FQLWR}(1,1)$

64) $\mathrm{FQPWR}(1,2)$

67) $\operatorname{ZKWZZ}(1,1)$

68) $\operatorname{ZKWZZ}(1,2)$

62) $\operatorname{FQLWR}(1,2)$

65) $\operatorname{FQLWD}(1,1)$

69) $\operatorname{ZKFLO}(1,1)$

70) $2 \operatorname{KFLO}(1,2)$

Enter $\langle\mathrm{CR}\rangle$ to continue

RESPOND TO EACH OF THE FOLLOWING PROMPTS BY ENTERING THE NUMBER CORRESPONDING TO THE DESIRED VARIABLE IN THE TABLE ABOVE. ENTER A "-" SIGN BEFORE THE NUMBER TO OUTPUT THE NEGATIVE OF THAT VARIABLE'S VALUE. NUMBER OF VARIABLE FOR OUTPUT IN COLUMN 1 (DEFAULT IS 8, ZKLZZ $(1,0)$ ): 8 NUMBER OF VARIABLE FOR OUTPUT IN COLUMN 2 (DEFAULT IS 7, ZHLZZ $(1,0)$ ): 7 
NUMBER OF VARIABLE FOR OUTPUT IN COLUMN 3 (DEFAULT IS 15, ZULZZ $(1,0)$ ): 37

NUMBER OF VARIABLE FOR OUTPUT IN COLUMN 4 (DEFAULT IS 9, ZYLOZ $(1,0)$ ):

$-33$

NUMBER OF VARIABLE FOR OUTPUT IN COLUMN 5 (DEFAULT IS 47, ZRFZZ $(1,0)$ ):

$-35$

NUMBER OF VARIABLE FOR OUTPUT IN COLUMN 6 (DEFAULT IS $-35,-\operatorname{TEOZZ}(1,0)$ ): 54

NUMBER OF VARIABLE FOR OUTPUT IN COLUMN 7 (DEFAULT IS 30, ZKOZZ $(2,0)$ ): 39

NUMBR OF VARIABLE FOR OUTPUT IN COLUMN 8 (DEFAULT IS 54 , TMUZZ $(1,0)$ ): 9

VARIABLES TO BE OUTPUT ARE:

OUTPUT VARIABLE 1: ZKLZZ(1)

OUTPUT VARIABLE 2: ZHLZZ(1)

OUTPUT VARIABLE 3: ZHPZZ(1)

OUTPUT VARIABLE 4: -TMOZZ(1)

OUTPUT VARIABLE 5: -TEOZZ(1)

OUTPUT VARIABLE 6: TMUZZ(1)

OUTPUT VARIABLE 7: TMPZZ(1)

OUTPUT VARIABLE 8: ZYLOZ(1)

DO YOU WANT TO CHANGE THIS LIST? ( $\mathrm{Y} / \mathrm{N})$ : 


\subsection{Graphical Output}

Some years back, a method was devised to provide graphics if desired. Refer to example 2, section 4; the third item up from the bottom on the nextto-last page, reads, "DO YOU WANT THE TERMINAL OUTPUT IN GRAPHICAL FORM?" When that question is answered in the affirmative (i.e., "Y"), a second question appears: "DO YOU WANT TO SAVE (THE) GRAPHICAL OUTPUT (ON LU\#14)?" LU\#14 means "Logical Unit 14" and corresponds to the output plot file named by the user; it was named PLOTUT in sections 4.1 and 5 . If the answer to this second question is "No", then the graphical displays appear on the screen. If the answer is "Yes", then there is no graphical display on the screen, but only in file PLOTUT - i.e., the second disk (output) file.

When the graphical display appears on the screen, the tabular output does not. The display scrolls by, and must be stopped if examination is desired. Some samples of the graphical output are shown below; they correspond to various stages of the fire for the default case.

As we can see from the first figure, thirteen items of information are displayed: on the top line, the dimensions of the room and a temperature are displayed; the temperature is marked " $\mathrm{T}_{\mathrm{amb}}$ " apparently standing for the ambient temperature. In fact, this is misleadingly labeled - it is the temperature of the lower layer in the room. On the second line, the time (after ignition) and the heat release rate from combustion are listed. The asterisks form the outline of the ceiling, floor, and walls of the room, displayed in a side view. Note that the floor and ceiling extend beyond the room; the doorway sill is represented by a square bracket. The ceiling/wall temperature appears as "Twall" (as if embedded in the ceiling). The hot layer is represented by rows of dots. When the layer is thick enough so that there are at least two such rows representing it (which is the case at $t=40 \mathrm{sec}$ ), its temperature and the oxygen mass fraction are superimposed on one of the rows. Just outside the room, the mass outflow rate from the hot layer is given; in this case (at $t=40$ ) the layer is not yet below the soffit and hence the flow is zero. The column of $\mathrm{P}^{\prime} \mathrm{s}$ represents the thermal plume rising from the flame into the layer. The width of this column reflects the width of the 
flame base and thermal plume. At the bottom of that column FF appears representing the flame. Below that is a row of $1^{\prime} s$, bounded by square brackets; that represents the fuel slab, and its mass is listed just underneath it.

Finally, just below the floor, the flux to object \#2 (when it exists) is listed, as well as the mass-loss (pyrolysis) rate of the fuel slab. In the second figure, corresponding to $t=60 \mathrm{sec}$, we see that the layer has gotten so thick that gas spills out of the room at the rate shown.

In the third figure, corresponding to $t=120 \mathrm{sec}$, we see that temperatures and flow rates have increased; the fire radius has also grown, as well as the corresponding flame height. Hence the plume is thicker. At $t=160$, the flame is so high that it enters the hot layer. At $t=200$, the increasing sootiness of the layer is indicated by having a darker shading of the layer via double rows of dots replacing the single rows. At $t=220$, the layer is still more opaque and that's indicated by using small circles, rather than dots, for the "shading". At $300 \mathrm{sec}$, just before ignition of the target item, the flame has almost spread to the edge of the fuel slab. Finally, at $320 \mathrm{sec}$, the layer has fallen still lower, because the ignited second item (not shown) has put much more gas into the upper layer, making it thicker still; the flame over object 1 no longer shows, at this level of graphic resolution. 
Length $=2.44 \mathrm{M} \quad$ Width $=3.66 \mathrm{M} \quad$ Height $=2.44 \mathrm{M} \quad$ Tamb $=26.84 \mathrm{C}$ Time $=$ 40. Sec. Heat Release Rate $=4.90 \mathrm{E}-01 \mathrm{KW}$

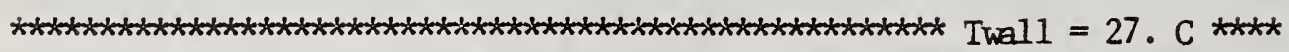
Vent Flow $\quad * \ldots$. Tlayer $=28$. C $\ldots$ oxygen $=23.1 \% \ldots \ldots \ldots \ldots \ldots \ldots$

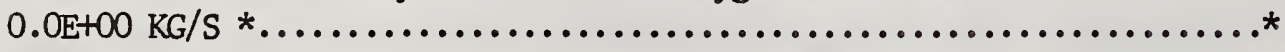
*

PP

PP

PP

PP

PP

PP

PP

FF

[1111111111111111111111111111]

FUEL $=6.85 \mathrm{KG}$

\section{GRAPHICAL DISPLAY 2 (60 SEC)}

Length $=2.44 \mathrm{M} \quad$ Width $=3.66 \mathrm{M} \quad$ Height $=2.44 \mathrm{M} \quad$ Tamb $=26.84 \mathrm{C}$

Time $=60 . \mathrm{Sec} . \quad$ Heat Release Rate $=9 \cdot 31 \mathrm{E}-01 \mathrm{~kW}$

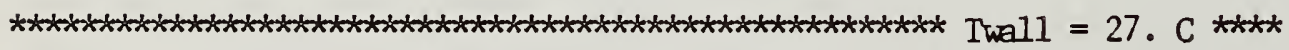
Vent Flow $\quad * \ldots$ Tlayer $=29$. C $\ldots$ Oxygen $=23.1 \% \ldots \ldots \ldots \ldots \ldots$

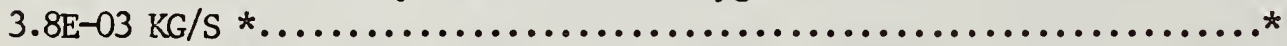

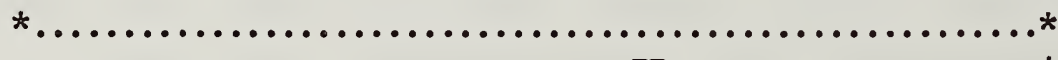
PP

PP

PP

PP

PP

PP

FF

[1111111111111111111111111111]

FUEL $=6.85 \mathrm{KG}$ 
Length $=2.44 \mathrm{M} \quad$ Width $=3.66 \mathrm{M} \quad$ Height $=2.44 \mathrm{M} \quad$ Tamb $=26.85 \mathrm{C}$ Time $=120$. Sec. Heat Release Rate $=5.98 \mathrm{E}+00 \mathrm{KW}$

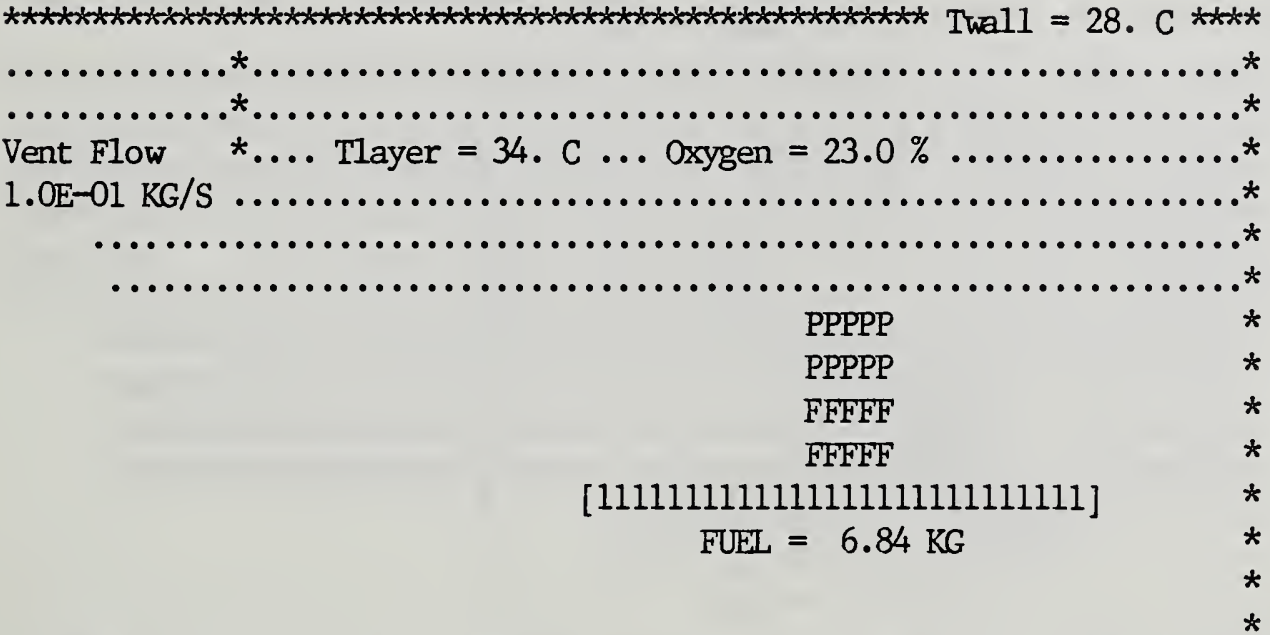

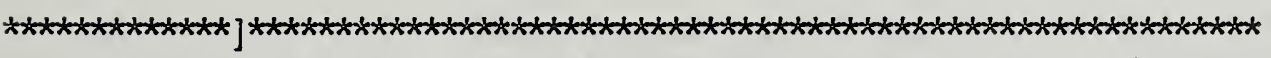
Obj. 2 Flux $=4.53 \mathrm{E}-01 \mathrm{KW} / \mathrm{M}^{* *} 2 \quad$ Burn Rate $=3.20 \mathrm{E}-04 \mathrm{KG} / \mathrm{Sec}$

GRAPHICAL DISPLAY 4 (160 SEC)

Length $=2.44 \mathrm{M} \quad$ Width $=3.66 \mathrm{M} \quad$ Height $=2.44 \mathrm{M} \quad$ Tamb $=26.92 \mathrm{C}$

Time $=160$. Sec. Heat Release Rate $=1.96 \mathrm{E}+01 \mathrm{KW}$

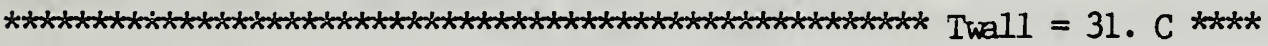
.................................................... .....................................................*

Vent Flow $\quad$..... Tlayer $=44 . \mathrm{C} \ldots$ Oxygen $=22.8 \% \ldots \ldots \ldots \ldots \ldots \ldots$

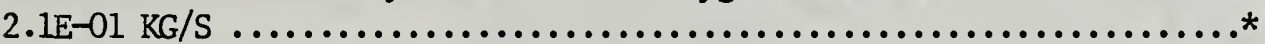
............................................

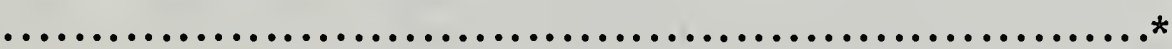

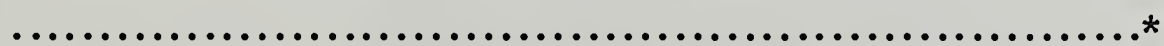
FFFFFFF FFFFFFF * FFFFFFF * [1111111111111111111111111111] * FUEL $=6.82 \mathrm{KG} \quad$ *

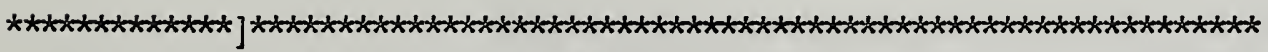
Obj. 2 Flux $=4.40 \mathrm{E}-01 \mathrm{KW} / \mathrm{M}^{* * 2} 2$ Bum Rate $=1.05 \mathrm{E}-03 \mathrm{KG} / \mathrm{Sec}$ 
GRAPHICAL DISPLAY 5 (200 SEC)

Length $=2.44 \mathrm{M} \quad$ Width $=3.66 \mathrm{M}$ Height $=2.44 \mathrm{M} \quad$ Tamb $=27.34 \mathrm{C}$ Time $=200 . \mathrm{Sec} . \quad$ Heat Release Rate $=6 \cdot 12 \mathrm{E}+01 \mathrm{KW}$

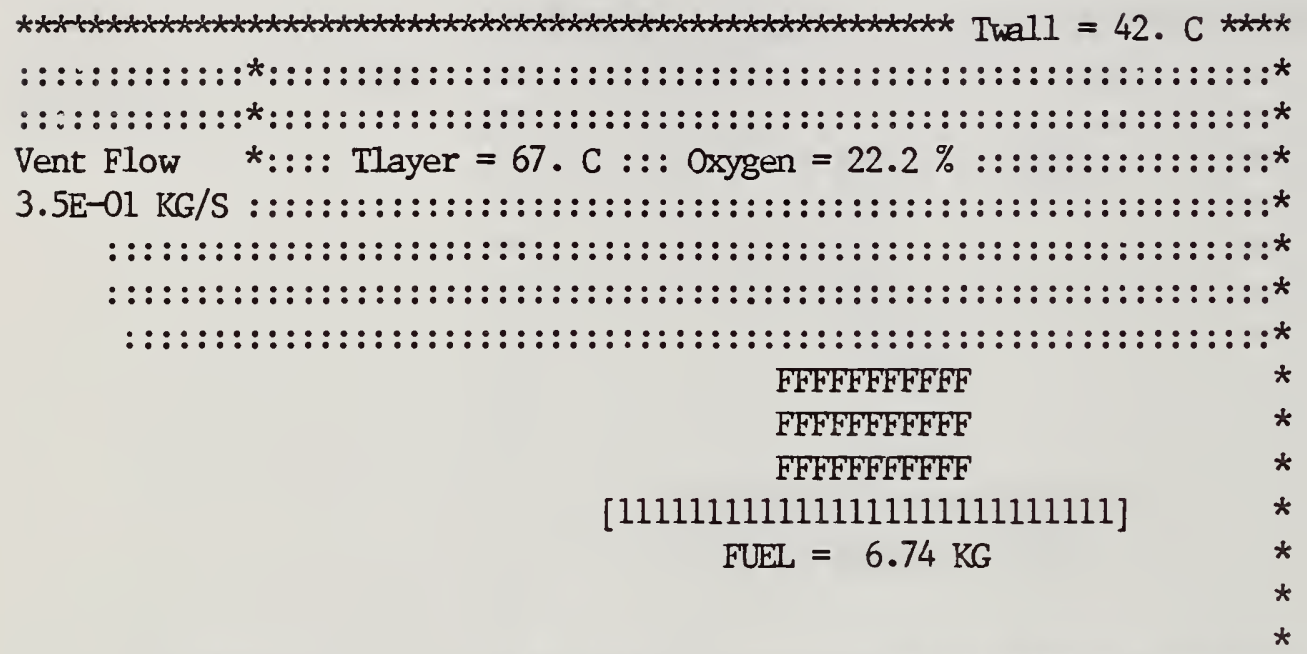

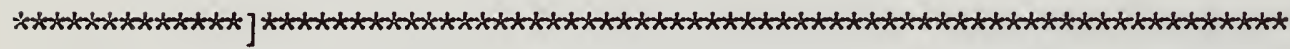
Obj. 2 Flux $=4.67 \mathrm{E}-01 \mathrm{KW} / \mathrm{M} * 22 \quad$ Burn Rate $=3.28 \mathrm{E}-03 \mathrm{KG} / \mathrm{Sec}$

GRAPHICAL DISPLAY 6 (220 SEC)

Length $=2.44 \mathrm{M} \quad$ Width $=3.66 \mathrm{M}$ Height $=2.44 \mathrm{M} \quad$ Tamb $=27.98 \mathrm{C}$

Time $=220$. Sec. Heat Release Rate $=1.05 \mathrm{E}+02 \mathrm{KW}$

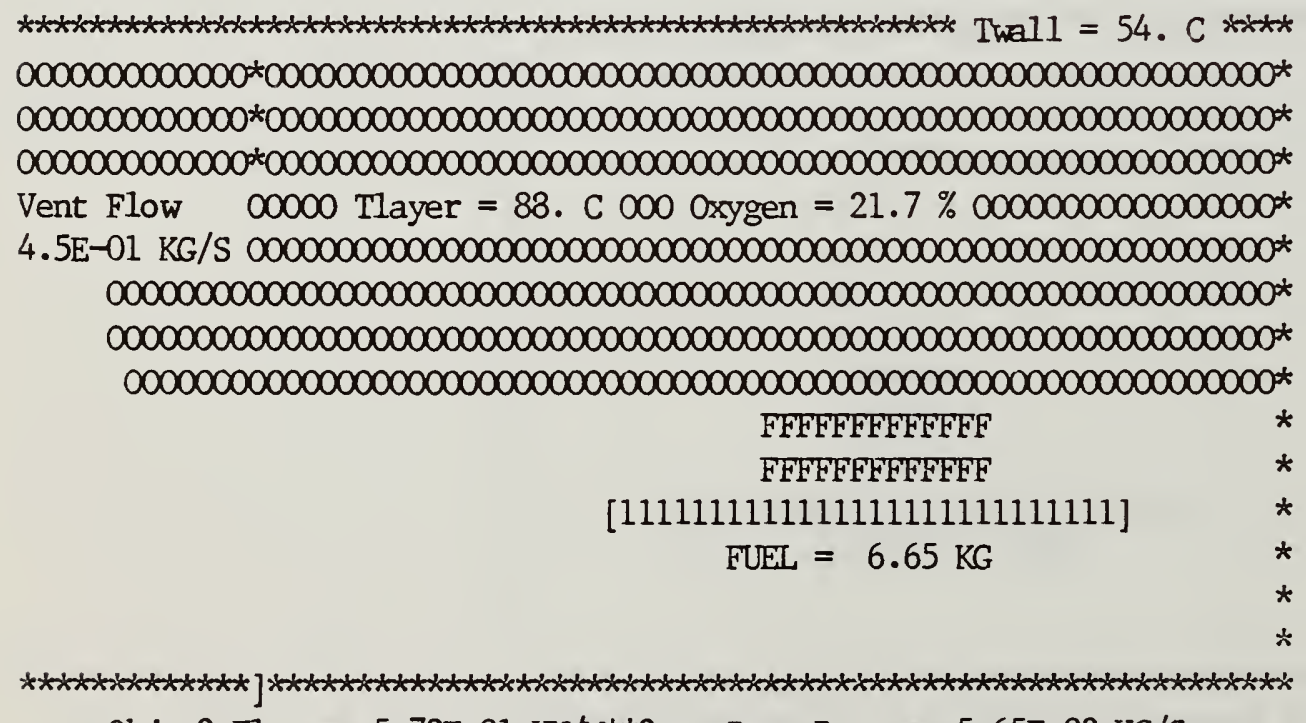

Obj. 2 Flux $=5.72 \mathrm{E}-01 \mathrm{KW} / \mathrm{M} * 22$ Burn Rate $=5.65 \mathrm{E}-03 \mathrm{KG} / \mathrm{Sec}$ 
Length $=2.44 \mathrm{M}$ Width $=3.66 \mathrm{M}$ Height $=2.44 \mathrm{M} \quad$ Tamb $=67.50 \mathrm{C}$ Time $=300$. Sec. $\quad$ Heat Release Rate $=1 \cdot 13 \mathrm{E}+03 \mathrm{KW}$

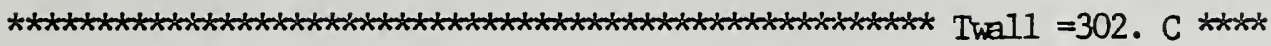
$0000000000000 * * 000000000000000000000000000000000000000000000000000000000 *$ $00000000000000^{*} 0000000000000000000000000000000000000000000000000000000000 *$ $00000000000000 * 000000000000000000000000000000000000000000000000000000000 *$ Vent Flow $\quad 00000$ Tlayer $=462$. C 000 Oxygen $=13.3 \% 000000000000000 \%$ 9.4E- $01 \mathrm{KG} / \mathrm{S} 0000000000000000000000000000000000000000000000000000000000^{*}$ $0000000000000000000000000000000000000000000000000000000000000000000^{*}$ 0000000000000000000000000000000000000000000000000000000000000000000 * 0000000000000000000000000000000000000000000000000000000000000000000 * $00000000000000000000000000000000000000000000000000000000000000000 \%$ FFFFFFFFFFFFFFFFFFFFFFFFFFFF * [1111111111111111111111111111] * FUEL $=4.90 \mathrm{KG}$

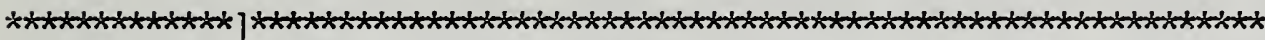
Obj. 2 Flux $=1.54 \mathrm{E}+01 \mathrm{KW} / \mathrm{M} \star 2 \quad$ Burn Rate $=6.04 \mathrm{E}-02 \mathrm{KG} / \mathrm{Sec}$

GRAPHICAL DISPLAY 8 (320 SEC)

Length $=2.44 \mathrm{M}$ Width $=3.66 \mathrm{M}$ Height $=2.44 \mathrm{M} \quad$ Tamb $=225.39 \mathrm{C}$

Time $=320$. Sec. $\quad$ Heat Release Rate $=1.58 \mathrm{E}+03 \mathrm{KW}$

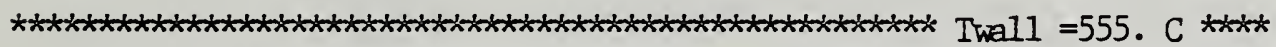
$0000000000000 * 000000000000000000000000000000000000000000000000000000000 *$ $0000000000000 * 000000000000000000000000000000000000000000000000000000000^{*}$ $0000000000000 * 000000000000000000000000000000000000000000000000000000000 *$ Vent Flow $\quad 00000$ Tlayer $=699$. C 000 Oxygen $=5.9 \% 00000000000000000 *$ $1.0 \mathrm{E}+00 \mathrm{KG} / \mathrm{S} 0000000000000000000000000000000000000000000000000000000000^{*}$ $000000000000000000000000000000000000000000000000000000000000000000^{*}$ $0000000000000000000000000000000000000000000000000000000000000000000 *$ 000000000000000000000000000000000000000000000000000000000000000000 * $00000000000000000000000000000000000000000000000000000000000000000 *$ $\begin{array}{cc}\text { FFFFFFFFFFFFFFFFFFFFFFHFFFF } & \text { * } \\ {[111111111111111111111111111]} & \text { * } \\ \text { FUEL }=3.35 \mathrm{KG} & \text { * } \\ & \text { * }\end{array}$

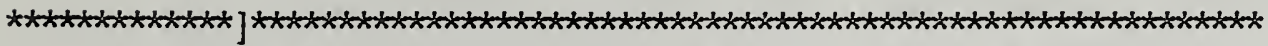
Obj. 2 Flux $=7.30 \mathrm{E}+02 \mathrm{KW} / \mathrm{M} \star 2 \quad$ Bum Rate $=8.45 \mathrm{E}-02 \mathrm{KG} / \mathrm{Sec}$ 


\section{THE DEBUG OPTION}

The debugger is available for programmers or skilled users for tracking down difficulties, should they appear. Even though the numerical technique now in place is fairly rugged and converges some 988 of the time, there are occasions when the calculation will "hang up". Often that difficulty can be overcome by using one of the techniques outlined in section 8, item 11. However, even those will not always work. This is especially true if the program is altered in such a way as to introduce a mathematical discontinuity in the program. In that case, the program can be rerun, with the DEBUG option selected to cut in just before the difficulty appears. Referring again to example 2 (in section 4.2), we see that if use of the debugger is desired, the fourth from the last question in that series is to be answered "Yes". (In the example, the default answer "No" was selected by using a carriage return.) This question does not automatically appear in the menu-driven mode, on the other hand; one has to request "changes in the output options" (choice \#3), in order to invoke the "debugger". In response to "Yes", eight further questions are asked: When should the debugger start? How often should output go to the TTY thereafter (again, $20 \mathrm{sec}$ is default)? How often to the disk? Should the message "leaving subroutine..." appear every time the calculation leaves a subroutine? (This option is useful in bracketing the location of arithmetic errors.) Should output be displayed after each iteration? Do you want a list of the variables "in the system" at every rescaling? Or, do you want just those entering or leaving "the system" upon rescaling? Finally, do you want these questions reasked at a later time (and what time is that)?

Experience has shown that the most useful option is the one which gives the output after each iteration; this allows the calculations to be followed in detail and errors or difficulties can often be tracked down this way.

An interesting use of the debugger is the following: if a run "hangs up" at some moment $t_{c}$, due to a numerical instability, sometimes it is possible to sidestep the trouble merely by invoking the debugger at a time earlier than $t_{c}$, which was skipped over. Thus, if $t_{c}=308$ (say), and there were calculations made at (say) $t=150$ and 152 (but not at $t=151$ ), then 
invoking the debugger at 151 forces an extra calculation there; the resulting numerical differences thereafter might succeed in bypassing the trouble at 308. In case of difficulty during execution of the program, DEBUG was automatically invoked in Mark 5, permitting the (interactive) user to stop or to proceed in a number of ways. This feature has been dropped in FIRST, in part because that would create difficulties when running in BATCH mode.

In order to examine various arrays or other calculations which are not displayed, such as the matrix elements of a Jacobian, it is necessary to have recourse to the more powerful debugging and tracing options generally available via the operating system.

\section{EXTENDING THE UTILITY OF THE PROGRAM}

Although this program (as any program is) limited in what it can do, its utility can be (and has been) extended by the use of a little ingenuity. We might call these "tricks of the trade". A number of examples are given here, but evidently the list can be extended. However, the cautionary words which were written in the FOREWORD regarding the limitations of the model apply even more strongly here; such "tricks" will be best used by experts. Items 5, 6, 8 , and 10 below are suggestions; they have not been checked against full-scale tests.

1. Suppose a fire grows and spreads, but does not grow exponentially. It can be simulated by a gas burner, rather than as a "growing fire"; the growth is handled by varying the gas flow rate (in a prescribed manner); the spread can be (albeit crudely) approximated by turning on extra burners (or new burners of larger size) as time goes on.

2. In a similar way, a moving heat source can be approximated by turning on a gas burner; then turning it off but turning on an adjacent burner, and so on. Alternatively, by using several growing fires, each ignited by the previous one, as the latter burns out.

3. An elongated source can be approximated by simultaneously turning on a set of small-diameter adjacent burners. 
4. The effect of a fire set on a gasoline spill on a carpet (by an arsonist) has been simulated by taking about $10 \%$ of the gasoline mass to be in the vapor phase and calling it object \#l; the remaining 908 is object \#2; and the carpet is \#3. Then object \#1 is taken to be a growing fire, and its fire-growth parameter is adjusted so that it is consumed in a few seconds. Object \#2 is taken to be a pool fire, and its heat of vaporization is chosen so that it is consumed at a rate comparable to that of a large liquid pool fire (about $4 \mathrm{~mm} / \mathrm{min}$ ), as Blinov and Khudiakov found [24]. Whether the rug then ignites and whether the flame propagates depends on its ignition temperature, its size, and its thermophysical properties. Evidently the sections of rug drenched in gasoline cannot become hotter than "the" boiling point of gasoline until the latter has all evaporated; but adjacent sections will get quite hot and (presumably) ignite.

5. Although there is not (yet) an algorithm inserted for ceiling venting (i.e., for venting through a horizontal vent), it can be reasonably well approximated by substituting a narrow (say, $1 \mathrm{~cm}$ high) slit just below the ceiling, of a width such that the total vent area is that of the desired ceiling vent.

6. Most rooms have leaks around door-and window-frames, electrical outlets, etc. A simple way to model these leaks is via a vertical slit in a wall. These leaks will not be noticeable except when the doors and windows are closed.

7. The program does not yet have a wall-burning algorithm. Nevertheless, wall fires have successfully been mimicked, using the existing growing-fire algorithm (for horizontal slabs), as follows: The wall can be approximated as being a slab of material located in the center of the room, whose total area is the maximum wall area that could get involved, and at a height about a third of the way up the door opening (so that the interface will not fall below the level of this fictitious object, possibly starving it of oxygen when the layer is highly vitiated). Given an ignition source, it is not difficult to estimate how long it takes to ignite the wall, if the flame "attaches" itself to it (the flux then is about $3 \mathrm{~W} / \mathrm{cm}^{2}$ ). A first run is then made, and the object's temperature at the time the wall would be igniting is noted. The run is then repeated, with that temperature as the ignition temperature of the object.

Finally, a value must be chosen for the spread-rate parameter A (see section 3.1 , note 15). Now, many wall fires spread (upward) exponentially, just as horizontal fires do (see, for example, Orloff et. al, [24a]):

$$
Z_{p}=Z_{o} e^{\beta t}
$$


where $\mathrm{Z}_{\mathrm{p}}$ is the pyrolysis height. It is easy to show that for the equivalent horizontal slab, $\mathrm{p}=\beta / 2 .{ }^{12}$ Thus

$\mathrm{A} \cong 2 \beta / 3 \kappa$

(A is an input value (p. 9) described in note 15, p. 13). The initial height $Z_{0}$ corresponds, in this approximation to the initial radius $r_{0}$ in horizontal spread. For PMMA, $\beta \cong 0.0039 \mathrm{sec}^{-1}$ and $\kappa \cong 1.5 \mathrm{~m}^{-1}$. Hence $\mathrm{A} \cong 1.7 \mathrm{~mm} / \mathrm{sec}$ for PMMA. (For other materials, A will probably not differ from this by large factors.) However, lateral spread is slower, and a somewhat smaller value might be best.

8. Although FIRST is only a single-room model, it can sometimes be used as a two-room model: if the fire room is adjacent to or lies within a much larger enclosure, then the large enclosure will respond to the fire room much as the out-of-doors would. The progress of the fire in the initial room can be calculated independently, therefore, and the emerging hot gases are a source for the larger room. The hot gas emerges at the rate $\dot{m}_{u}(t)$, and we can take it to be a variable burner (at the appropriate height). However, the gas enthalpy rate is $\dot{E}_{u}(t)$, so that the effective heat of combustion of this "burner gas",

$$
\Delta \mathrm{H}_{c}(t) \equiv \dot{\mathrm{E}}_{\mathrm{u}}(t) / \dot{\mathrm{m}}_{\mathrm{u}}(t)-\mathrm{c}_{\mathrm{p}} \mathrm{T}_{\mathrm{a}},
$$

is a function of time, rather than a constant. Since we must choose a constant for it as an input value, the simplest (and perhaps best) value to choose for it is

$$
\overline{\Delta \mathrm{H}}_{\mathrm{c}}=\int \dot{\mathrm{E}}_{\mathrm{u}}(t) d t / \int \dot{\mathrm{m}}_{\mathrm{u}}(t) d t-\mathrm{c}_{\mathrm{p}} \mathrm{T}_{\mathrm{a}},
$$

the integrations being over the entire duration of the fire.

9. A good liquid-pool fire algorithm has not yet been built into the model. One reason is the radition blocking has not been incorporated into the flame model. However, that can be approximated by taking the fire surface to have a smaller absorption coefficient than it really does, or equivalently, to assume that the heat of vaporization $\left(H_{v}\right)$ is larger than it actually is. The magnitude of the adjustment that must be made (in either quantity) can be fairly easily found by noting that most liquid pools have similar regression velocities (about $4 \mathrm{~mm} / \mathrm{min}$ ) in the asymptotic limit (see ref. [24]). 
10. A wind incident on a house will have little effect on the fluid flows in a room, if there is only one vent open (such as the window) because a stagnation region is immediately established. If there is cross-ventilation, however, the wind can sweep through the room. This is easily simulated by invoking two (extra) forced vents, with the appropriate volumetric throughput.

11. Occasionally the calculation will fail to converge. Often the case can be run successfully by making a trifling change in the input - e.g., change a dimension or a position by a few millimeters; or change $\gamma$ (the air/fuel mass ratio) up or down; perhaps increase or decrease $\Delta t$; often changing the convergence criterion (up or down) will help. If the failure occurs at or soon after a steep change in $\dot{V}(t)$ (for a forced-ventilation run), or $\dot{m}_{g}(t$ ) (for a burner run), making the slope more gradual could easily be the solution to the problem.

12. As pointed out elsewhere in this report, if the walls, ceiling and floor are made of different materials, a reasonable approximation can be made by taking an area-weighted average of $k, \rho$, and $c$. On the other hand, if they are of different thicknesses as well, then the appropriate weighting may be more complicated (this will be so if one of them is so thin that the thermal wave will reach the other side well before the end of the run).

13. As discussed earlier (see item 19, section 3.1), if there are many flammable target objects in the room, it may be necessary to lump a number of objects (say, numbers 2 to $n$ ) into a single effective object. The behavior of this effective object is:

a) It must ignite at the same time as object 2 ignites:

$$
t_{e}=t_{2}
$$

b) The pyrolyzing area should spread approximately as the totality spreads - i.e.,

$$
R_{e}^{2}(t) \simeq \sum_{i=2}^{n} R_{i}^{2}(t)
$$

The resulting flame and its radition will not be quite correct; to first order, however, this may be adequate.

c) More important still, we must have the power output of the single effective object mimic the computed behavior of the ensemble of objects: 


$$
\dot{E}_{e}(t)=\sum_{i=2}^{n} \dot{E}_{i}(t)
$$

(Note that the power output of object $i$ is zero until it ignites at time $t_{i g}(i)$; that is, $\dot{E}_{2}(t)=0$ for $t<t_{i g}(2) \equiv$ $t_{2}, \dot{E}_{3}(t)=0$ for $t<t_{3}$, etc $)$.

d) Evidently, the initial mass of the effective object is the sum of the (initial) masses of the component objects; that is,

$$
\mathrm{m}_{\mathrm{e}}=\sum_{i=2}^{\mathrm{n}} \mathrm{m}_{\mathrm{o}}(\mathrm{i})
$$

Assuming the effective object burns as a growing fire, there are thirteen thermophysical parameters of the effective object that can be adjusted to yield the indicated approximations: $k, \rho, c, H_{c}, H v, \kappa_{f}, T_{i g}, \chi, \gamma, \gamma s, \psi, t_{b}$, and $A$. Of these, the first three appear as the product k $\rho c$ in the expression for the heating to ignition. This brings the effective number of parameters to eleven.

We must begin by making a run with the initial fire (object 1), and objects 2, 3, and 4. We note the time of ignition of object 2; that will also be the ignition time for the effective object, as stated by eq. (2). We then note when object 3 ignites, and the object radii and total heat outputs at time $t_{3}$. We do the same for the ignition of object 4. The run is interrupted at that point, and a first effective object made, which is a combination of objects 2 and 3 , of mass $m_{2}+m_{3}$; call it object $e_{1}$. A second run is then made, with objects $1, e_{1}, 4$, and 5 . Then $e_{1}$ and 4 can be combined into $e_{2}$, as in the first run. We proceed (in principle) in this way until all the objects have been ignited.

The difficulty is that how the eleven parameters are to be chosen so as to yield all the above, even in an approximate or least-squares sense, is not clear to the authors. The simplest (and crudest) method is to choose $A_{e}$ so that eq. (4) is satisfied for a time late in the fire. An equally simple alternative is to use the variable gas burner option so as to satisfy the computed values of power output, as in eq. (4), at each stage. This bypasses the problem of what parameters to choose, but

(a) it will give incorrect values for radiation, and 
(b) small-radius burners cannot yield high power outputs.

Both those difficulties can be reduced by using two (or three) variable burners, of increasing size.

The final difficulty is that if the number of objects is large, a large number of runs will be (apparently) necessary. In fact, however, after a relatively modest number of objects have ignited, a pattern will probably become clear, enabling the user to generalize the simulation without having to make a great many runs.

14. Furniture items have fairly typical rate-of-heat-release curves (ref. [25]), so that reasonable results for the progress of a fire can be approximated by specifying such a curve (via the variable gas burner). Such curves are generally found for burning in the open, however; the model may modify this output due to the effects of ventilation limitation, oxygen starvation, and radiative feedback from the enclosure. Alternatively, a furniture item may be modeled as several interacting objects, as in ref. [26, 27].

15. A wood crib can be approximated reasonably well as follows: the total surface area of the sticks, $A_{s}$, is calculated. If we subtract the area where the sticks overlap, that leaves about $80 \%$ exposed. Then take the "maximum radius" of the object to be such that

$$
\pi R_{\mathrm{max}}^{2}=0.8 \mathrm{~A}_{\mathrm{s}}
$$

For the spread-rate parameter, use $\mathrm{A} \simeq 0.032 \mathrm{~m} / \mathrm{s}$. Finally, use the point-source plume. One caution: any flammable target item must be placed sufficiently distant from the crib, that the program will not find it (spuriously) to be ignited by contact with the flame, when the fire radius reaches $R_{\max }$.

16. A vent can be opened at a predetermined time or temperature. See Appendix B.

\section{NOTATION}

\subsection{The Method}

It is usual practice to use FORTRAN symbols in ways suggesting common names and then to supply a dictionary of the symbols actually used. However, a fire in a large building has a large number of geometric, compositional, and physical properties. To avoid arbitrary selection of symbols for closely 
related things (e.g., the $x$ coordinate of many objects) we have selected a naming system which uses the first six characters for preassigned purposes.

This results in labels which are not euphonious, nor universally satisfactory: not every variable we want to use can be described according to our scheme. This is principally due to the limitation to only six alphanumeric characters for a name; nevertheless, it has served reasonably well..

The FORTRAN name of any quantity will be selected as follows:

$\begin{array}{lllll}1 & 2 & 3 & 4 & 5\end{array}$

(1) Position 1 is used for derivatives, with respect to:

Z nothing

$\mathrm{T}$ time $\quad \frac{\partial}{\partial t},(\cdot)$

$\mathrm{X}, \mathrm{Y}, \mathrm{W}$ space

$\frac{\partial}{\partial x}, \frac{\partial}{\partial y}, \frac{\partial}{\partial z},()^{\prime}$

A area

$\frac{\partial^{2}}{\partial x \partial y},() "$ per unit area

V volume

$\frac{\partial^{3}}{\partial x \partial y \partial z},(){ }^{\prime \prime}$ per unit volume

F area and time $\frac{\partial^{3}}{\partial t \partial x \partial y},(\cdot)^{\prime \prime}-$ i.e., a flux

S space and time $\frac{\partial^{4}}{\partial t \partial x \partial y \partial z},(\cdot)^{\prime \prime},-$ - i.e., a source

D difference $\Delta$; exact definition to be specified by the user 
(2) Position 2 is used for a physical quantity:

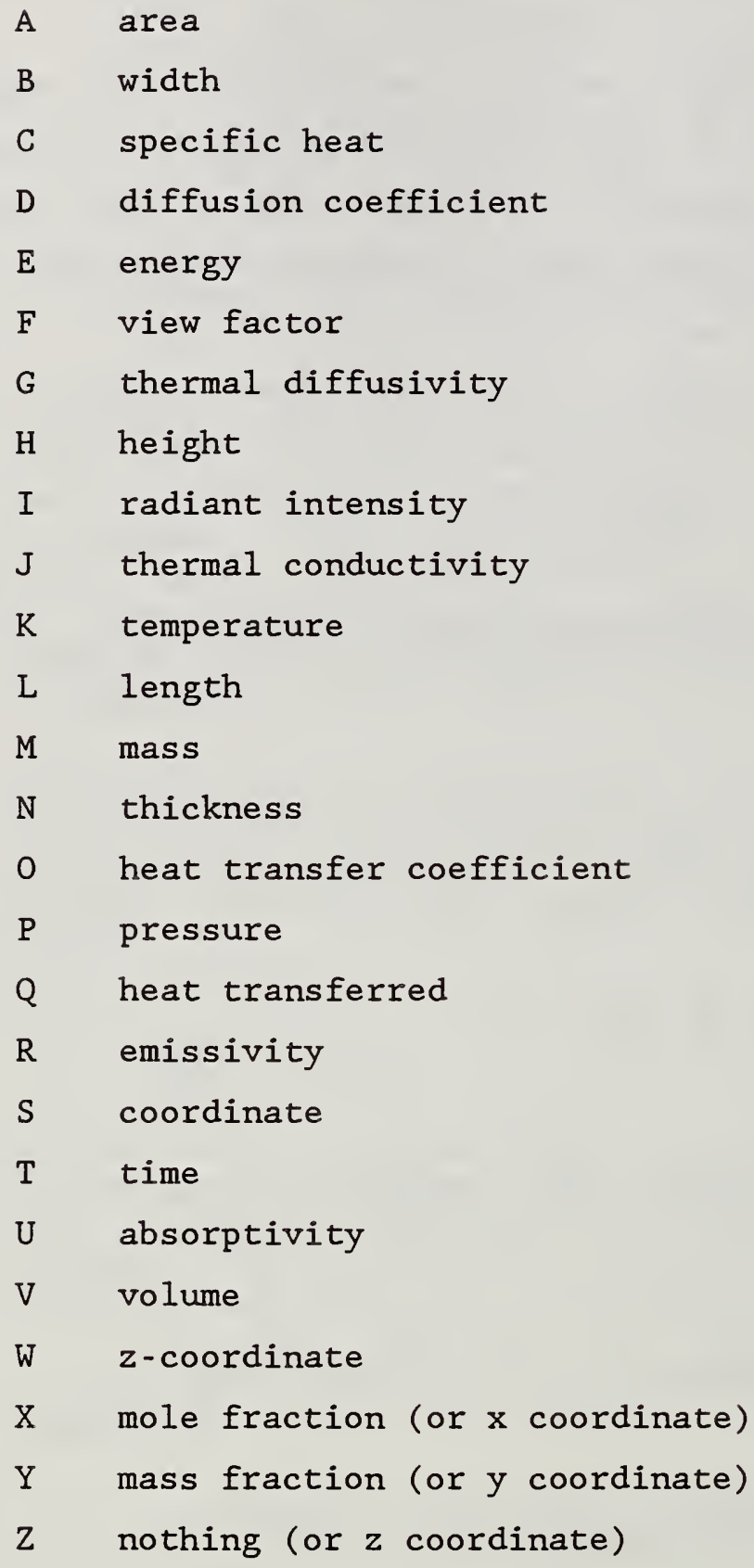

(3) Position 3 specifies an object, place, or direction:
A ambient
C $\operatorname{cool}$ (lower) layer
D down (as in "below")
F fuel 
L hot (upper) layer

0 object (will include all objects, distinguished by subscripts)

P plume

R room

$\mathrm{U}$ upper (as in "above")

$\mathrm{V}$ vent

W $z$-direction, or wall

$\mathrm{Y} \quad \mathrm{y}$-direction

$\mathrm{z}$ nothing

(4) Position 4 specifies a composition variable:

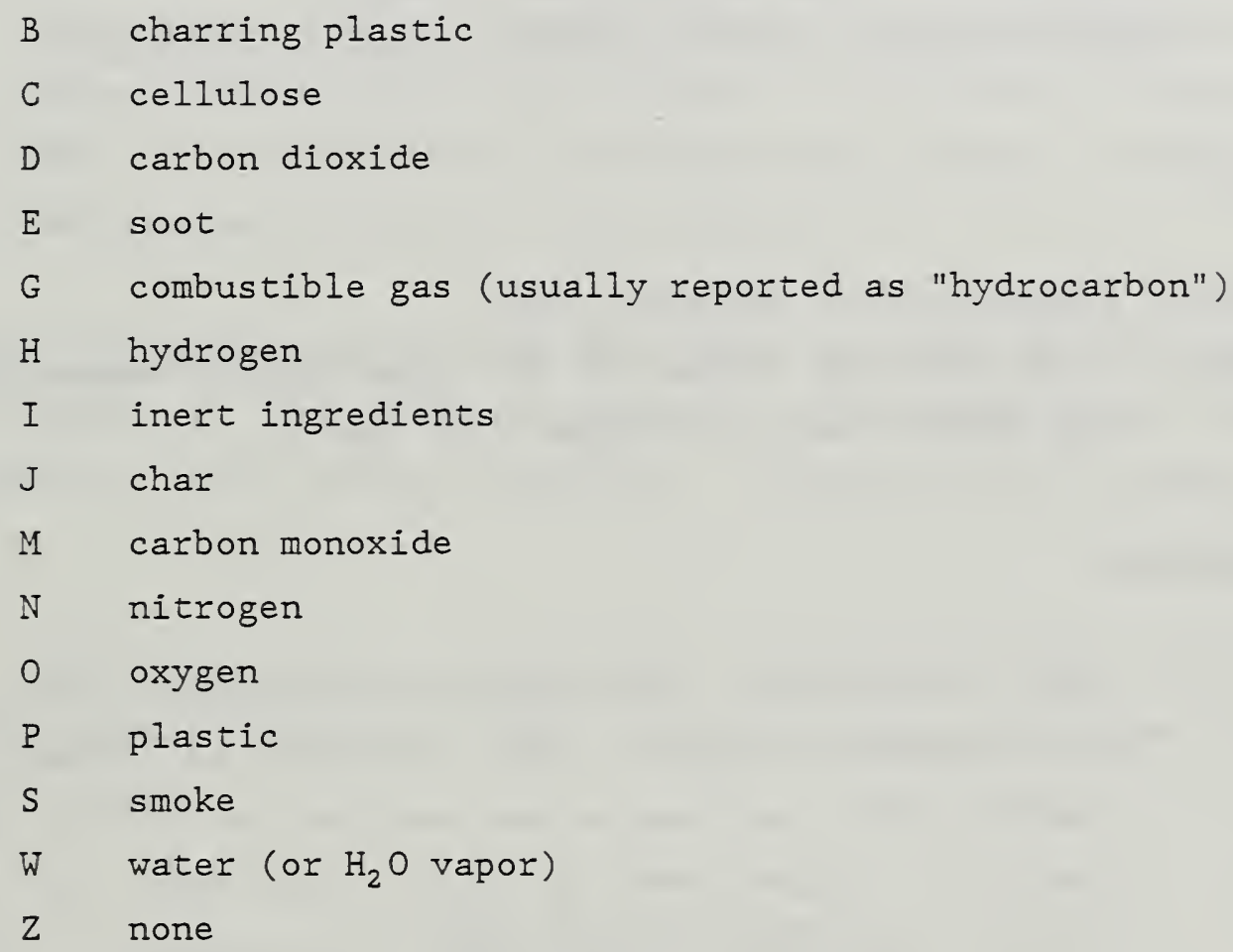

(5) Position 5 specifies special conditions:
A ambient
$B$ boundary condition
C critical condition (user defined)
D convection
E outside 


$\begin{array}{ll}\text { F } & \text { final condition } \\ \text { I } & \text { initial condition } \\ \text { M } & \text { maximum value } \\ \text { N } & \text { minimum value } \\ \text { R } & \text { radition } \\ \text { S } & \text { sum } \\ \text { Z } & \text { none }\end{array}$

(6) Position 6 is normally left blank. However, it is also used as a suffix for numerical handling:

o (zero) or P: value at previous timestep

1 value on output from the current physical subroutine

Examples:

ZKLZZ: Temperature of the upper layer.

TKLZZ: Time rate of change of the upper layer temperature (not explicitly used in the model, so far).

\section{Exceptions}

This notation has performed well except for one purpose: the transfer of heat or mass, in which it is desirable to indicate both the source and destination of the indicated quantity. Since most of these quantities are computed initially as fluxes we have made an exception to the above rules as follows:

If the first character is F (flux: $F$, in position 1 ) then the character in position 3 is the source of the indicated quantity while the character in position 4 is the destination of the indicated quantity. 
Examples:

FQLWD $(2,1)$ : Flux of heat from the upper layer to the inside of (upper) wall \#2, via convection.

FMLDZ: $\quad$ Flux of mass from the upper layer to the lower layer (not used in this program, but see TMIXUM)

For constants of nature (e.g., g), mathematical constants (e.g., $\pi$ ) and other universal quantities, the common symbol will be used $(G, P I)$.

There are a number of input parameters (not variables) for which the naming convection has not been used (or used only in part), such as ZKOPY, the temperature at which pyrolysis begins, or ZKOIG, the temperature of ignition (for an object).

While all of the above rules have been carried over from Mark 5, a few new terms appear in FIRST (mostly related to the lower layer) which do not quite conform to this naming convention. These are all included in section 9.2.

The dictionary which follows will illustrate these rules and will present all quantities used in FIRST. The dictionary also shows the subscript character (if any).

\subsection{Dictionary of Symbols}

FORTRAN Symbol

$\operatorname{AFIRE}(K O)=A$

ALPHA $=\alpha$
Description

Spread rate (or fire growth) parameter for object KO (see section 3.1, esp. note 15)

Plume entrainment coefficient (taken to be 0.1 ) 
$\operatorname{ANGH}(\mathrm{KO})=\theta_{\mathrm{B}}$

$\operatorname{ANGV}(\mathrm{KO})=\gamma$

AQDW

AQUW

$\mathrm{BETA}=\beta$

$C D=c_{d}$

$\mathrm{CHI}(\mathrm{KO})=\chi$

$C P=c_{p}$

$\mathrm{DT}=\Delta \mathrm{t}$

DTINIT $=\Delta t_{0}$

$E B(K O)=e_{b}$

ECEIL

EFLOR
Angle which (plane) surface of object Ko makes with the horizontal (in degrees). At present, if this angle is input as $90^{\circ}$ - i.e., a vertical object; if $<45^{\circ}$, it is taken to be $0^{\circ}$.. i.e., a horizontal object.

ingle which vertical surface of object Ko makes with the plane $\mathrm{xz}$, i.e., the wall running along the $\mathrm{x}$-axis (in degrees).

Convective energy transferred to unit area of floor or lower part of wall (areas adjacent to the lower layer).

Same as AQDW, but corresponding to the ceiling and upper wall, adjacent to the hot (upper) layer. In $\mathrm{W} / \mathrm{m}^{2}$.

A convenient combination of parameters TMPO01: $\quad \beta \equiv 1 / \sqrt{\pi \rho c \kappa}$

Vent flow coefficient (we use 0.68 ).

Fraction of combustion energy $H_{c}$ actually released in open-air burning.

Specific heat of air at STP (1004.0 Joules $/ \mathrm{kg}^{\circ} \mathrm{C}$ ).

Size of current timestep. This increment is in seconds.

Initial step size in seconds. This will remain the maximum step size in the calculation.

Emissivity/absorptivity of surface of object KO (unless otherwise specified, we take $e_{b}=0.98$ ).

Emissivity of extended ceiling; taken to be 0.82 in BLOCK DATA; no provision has yet been made to have it an input parameter.

Emissivity of extended floor; remarks on its value are identical to the remarks made for ECEIL. 
$F C O(K O)=f_{C O}^{\prime}$

$\mathrm{FCO} 2(\mathrm{KO})=\mathrm{f}_{\mathrm{CO} 2}^{\prime}$

$\mathrm{FH} 2 \mathrm{O}(\mathrm{KO})=\mathrm{f}_{\mathrm{H} 2 \mathrm{O}}^{\prime}$

$F S(K O)=f_{s}^{\prime}$

FQDFD (KR)

$\operatorname{FQLOR}(\mathrm{KO})=\dot{\mathrm{q}}_{\mathrm{L} O}^{\prime \prime}=\phi_{\mathrm{LO}}$

FQLWD $(K W, J S I D E)=$

$\dot{\mathrm{q}}_{\mathrm{L} W D}^{\prime \prime}, \dot{\mathrm{q}}_{A W D}^{\prime \prime}$ or $\phi_{\mathrm{LWD}}, \phi_{\mathrm{AWD}}$

$\operatorname{FQLWR}(\mathrm{KW}, \mathrm{J})=\phi_{\mathrm{LWR}}, \phi_{\mathrm{AWR}}$

$\mathrm{FQPOR}(\mathrm{KO})=\dot{\mathrm{q}}_{\mathrm{PO}}^{\prime \prime}$

$\mathrm{FQPP}=\phi_{f f}$

$\mathrm{FQPP}(\mathrm{KO} 1, \mathrm{KO} 2)=\phi_{12}$

$\operatorname{FQPWR}(\mathrm{KW}, \mathrm{J})=\sum_{\mathrm{f}} \phi_{\mathrm{FW}}$

FQWOR $(\mathrm{KO})=\dot{\mathrm{q}}_{\text {WैO }}$

G
Mass fraction of (combustible part of) object $\mathrm{KO}$ evolved as $\mathrm{CO}$, when it burns in the open.

Mass fraction of object $\mathrm{KO}$ evolved as $\mathrm{CO}_{2}$, when it burns.

Mass fraction of object evolved as $\mathrm{H}_{2} \mathrm{O}$, when it burns.

Mass fraction of object KO evolved as smoke ( $C$ and condensed hydrocarbons), when it burns.

Convective heat flux from the lower layer to the floor $\left(\mathrm{W} / \mathrm{m}^{2}\right)$.

Radiative flux to surface of object KO, from the hot layer in the enclosure $\left(W / m^{2}\right)$.

Convective heat flux to side JSIDE of wall $\mathrm{KW}$, from the hot layer (in $\mathrm{W} / \mathrm{m}^{2}$ ). Thus, FQLWD $(K W, 1)$ is the flux from the inside of the room to the interior surface of the wall/ceiling. FQLWD $(\mathrm{KW}, 2)$ is the flux (from outside) to the exterior surface of the extended ceiling.

Radiative flux to side $\mathrm{J}$ of wall $\mathrm{KW}$, from the hot layer $\left(\mathrm{W} / \mathrm{m}^{2}\right)$.

Radiative flux to surface of object $\mathrm{KO}$, from the flame(s) $\left(W / m^{2}\right)$.

Flux from flame-flame interaction. Nonzero only if target is also burning.

When objects $\mathrm{KO} 1$ and $\mathrm{KO} 2$ are both flaming, this is the flux impinging on the base of K02 due to absorption by its flame, of radition for $\mathrm{KOl}^{\prime} \mathrm{s}$ flame.

Radiative flux to side JSIDE of wall KW, from the flame(s) $\left(\mathrm{W} / \mathrm{m}^{2}\right)$.

Radiative flux to surface of object $\mathrm{KO}$, from the hot walls and ceiling (Watts $/ \mathrm{m}^{2}$ ).

Acceleration due to gravity $(9.8066$ $\left.\mathrm{m} / \sec ^{2}\right)$. 


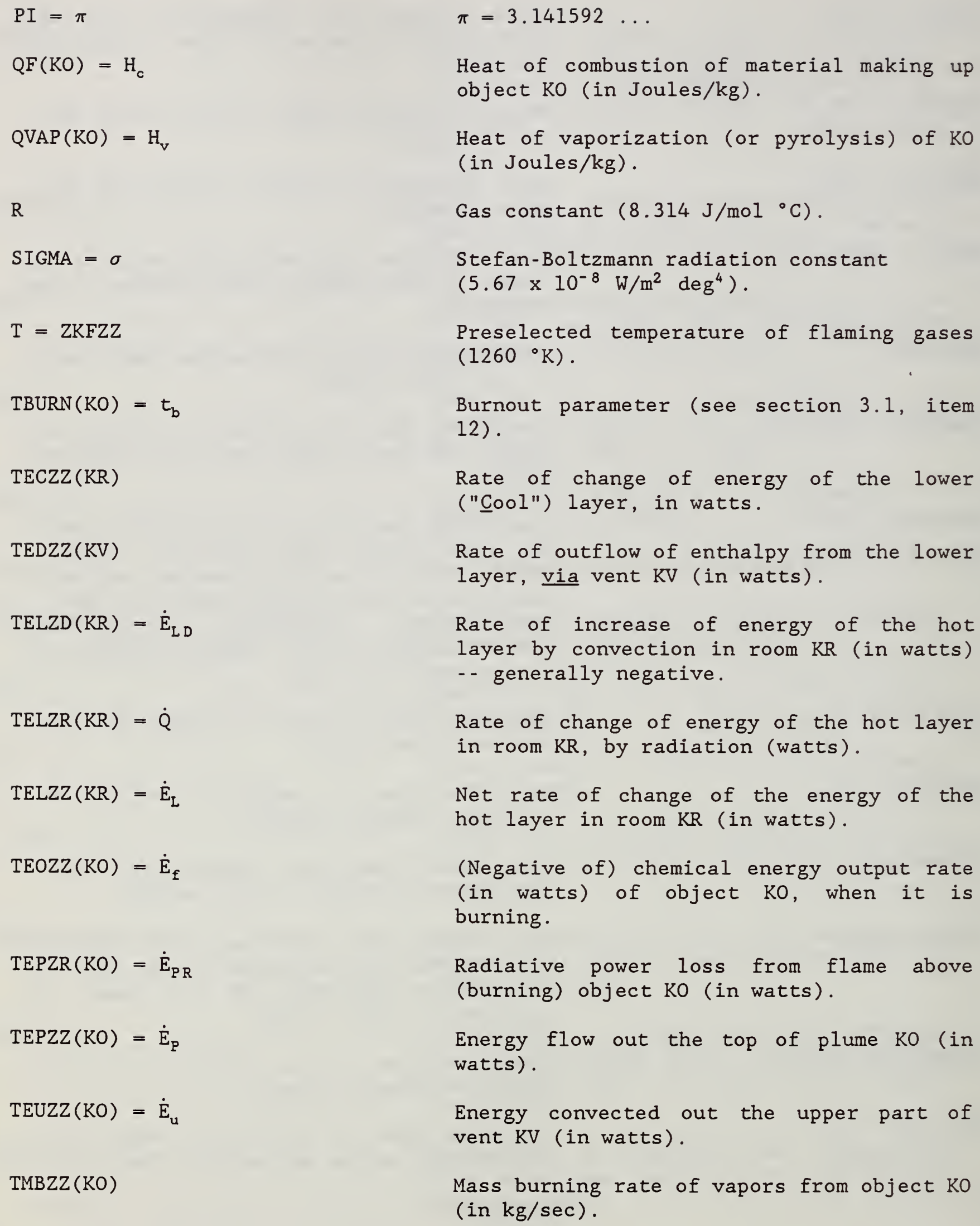

$\operatorname{TMBZZ}(\mathrm{KO})$

Heat of combustion of material making up object $\mathrm{KO}$ (in Joules $/ \mathrm{kg}$ ).

Heat of vaporization (or pyrolysis) of $\mathrm{KO}$ (in Joules $/ \mathrm{kg}$ ).

Gas constant $\left(8.314 \mathrm{~J} / \mathrm{mol}{ }^{\circ} \mathrm{C}\right)$.

Stefan-Boltzmann radiation constant $\left(5.67 \times 10^{-8} \mathrm{~W} / \mathrm{m}^{2} \mathrm{deg}^{4}\right)$.

Preselected temperature of flaming gases $\left(1260^{\circ} \mathrm{K}\right)$.

Burnout parameter (see section 3.1, item 12).

Rate of change of energy of the lower ("Cool") layer, in watts.

Rate of outflow of enthalpy from the lower layer, via vent $\mathrm{KV}$ (in watts).

Rate of increase of energy of the hot layer by convection in room $\mathrm{KR}$ (in watts) - generally negative.

Rate of change of energy of the hot layer in room $\mathrm{KR}$, by radiation (watts).

Net rate of change of the energy of the hot layer in room $\mathrm{KR}$ (in watts).

(Negative of) chemical energy output rate (in watts) of object $\mathrm{KO}$, when it is burning.

Radiative power loss from flame above (burning) object $\mathrm{KO}$ (in watts).

Energy flow out the top of plume KO (in watts).

Energy convected out the upper part of vent $\mathrm{KV}$ (in watts).

Mass burning rate of vapors from object KO (in $\mathrm{kg} / \mathrm{sec}$ ). 
$\operatorname{TMCZZ}(\mathrm{KR})$

$\operatorname{TMDZZ}(K V)=\dot{\mathrm{m}}_{\mathrm{d}}$

$\operatorname{TMFGZ}(\mathrm{KO})=\dot{\mathrm{m}}_{\mathrm{g}}$

$\operatorname{TMIXM}(K V)$

TMIXUM

$\operatorname{TMLZZ}(\mathrm{KR})=\dot{\mathrm{m}}_{\mathrm{L}}$

$\operatorname{TMOZZ}(\mathrm{KO})=\dot{\mathrm{m}}_{\mathrm{f}}$

$\operatorname{TMPLU}(\mathrm{KO})=\dot{\mathrm{m}}_{e}^{\prime}$

$\operatorname{TMPZZ}(\mathrm{KO})=\dot{\mathrm{m}}_{\mathrm{p}}$

$\operatorname{TMRZZ}(K R)=\dot{\mathrm{m}}$

$\operatorname{TMUZZ}(\mathrm{KV})=\dot{\mathrm{m}}_{\mathrm{u}}$

$\operatorname{PSI}(\mathrm{KO})=\psi$

$\operatorname{TPSI}(\mathrm{KO})=\tan \psi$

$\operatorname{VMAZZ}=\rho_{\mathrm{a}}$

$\operatorname{VMLZZ}(K R)=\rho_{\mathrm{L}}$

$\operatorname{VMOZZ}(\mathrm{KO})=\rho_{i}$
Rate of change of mass of the lower (cool) layer $(\mathrm{kg} / \mathrm{sec})$.

Mass outflow in the lower part of vent $\mathrm{KV}$. (A negative value means inflow.) In $\mathrm{kg} / \mathrm{sec}$.

Gas flow rate, when object $\mathrm{KO}$ is a gas burner (in $\mathrm{kg} / \mathrm{sec}$ ).

Mass flow rate from upper layer to lower layer at vent $\mathrm{KV}(\mathrm{kg} / \mathrm{sec})$.

Total mass flow from upper layer to lower layer in the room. This is the integral of FMLDZ over the surface area (see Examples).

Rate of increase of mass of the hot layer in room $\mathrm{KR}$. In $\mathrm{kg} / \mathrm{sec}$.

Rate of change of mass of object KO $(\mathrm{kg} / \mathrm{sec})$-- generally negative, of course.

Rate of entrainment of layer gases by the upper part of plume $\mathrm{KO}(\mathrm{kg} / \mathrm{sec})$ - - i.e., the part in the hot layer. In CFC V, $\dot{\mathrm{m}}_{\mathrm{e}}^{\prime}$ was taken to be zero.

Mass flow out the top of the plume over object $\mathrm{KO}$ (into layer) -- in $\mathrm{kg} / \mathrm{sec}$.

Net mass (out-) flow rate from room KR.

Mass flow out the upper part of vent $\mathrm{KV}$ $(\mathrm{kg} / \mathrm{sec})$.

Semiapex angle of cone modeling the flame over burning object kO (in degrees).

Tangent of $\psi$; actually, $\psi$ is not carried as a variable -- only TPSI.

Density of ambient air $\left(1.177 \mathrm{~kg} / \mathrm{m}^{3}\right.$ at $\left.300^{\circ} \mathrm{K}\right)$.

Density of hot layer in room $\mathrm{KR}$ (in $\left.\mathrm{kg} / \mathrm{m}^{3}\right)$.

Density of object $\mathrm{KO}$ (in $\mathrm{kg} / \mathrm{m}^{3}$ ). 


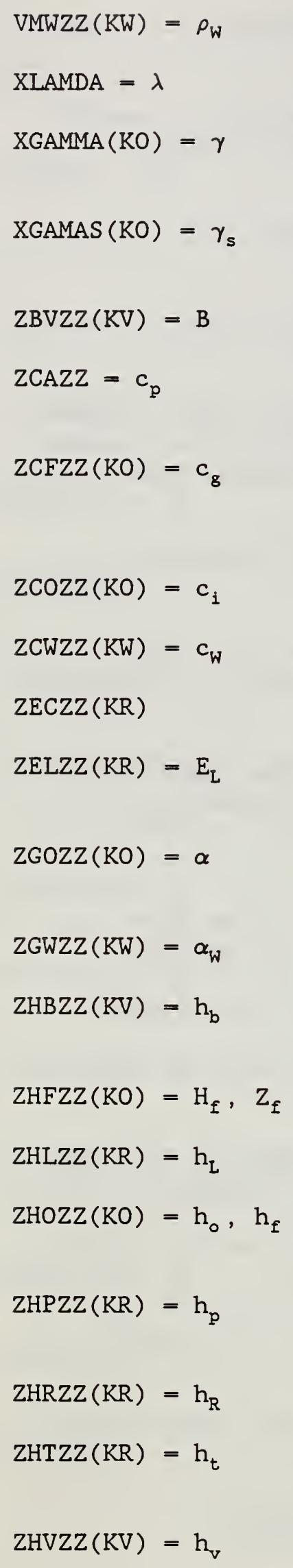

Specific heat of pyrolysis gases from object KO, when it's burning (in Joules/kg $\operatorname{deg} C$ ).

Specific heat of object $\mathrm{KO}(\mathrm{J} / \mathrm{kg}$ deg)

Specific heat of wall $\mathrm{KW}$ (in $\mathrm{J} / \mathrm{kg} \mathrm{deg}$ )

(Thermal) energy of lower (Cool) layer.

Energy of the hot layer in room KR (in Joules).

Thermal diffusivity of object ko (in $\mathrm{m}^{2} / \mathrm{sec}$ ).

Thermal diffusivity of wall $\mathrm{KW}\left(\mathrm{m}^{2} / \mathrm{sec}\right)$.

Height of vent sill above floor (in meters).

Height of flame (in meters).

Depth of the hot layer in room KR (in $\mathrm{m}$ ).

Height of surface of object ko above floor (in meters).

Height of plume ko (between hot surface and layer interface; in meters).

Height of room $\mathrm{KR}$ (in $\mathrm{m}$ ).

Distance of top of vent $\mathrm{KV}$ below ceiling - i.e., transom height (in $\mathrm{m}$ ).

Height of vent $\mathrm{KV}(\mathrm{m})$. 
$\mathrm{ZJOZZ}(\mathrm{KO})=\mathrm{k}$

$\mathrm{ZJWZZ}(\mathrm{KW})=\mathrm{k}_{\mathrm{W}}$

$\mathrm{ZKAZZ}=\mathrm{T}_{\mathrm{a}}$

ZKDZZ

ZKFLO

$\mathrm{ZKFZZ}=\mathrm{T}$

$\mathrm{ZKLZZ}(\mathrm{KR})=\mathrm{T}_{\mathrm{L}}$

$\mathrm{ZKOZZ}(\mathrm{KO})=\mathrm{T}_{\mathrm{s}}$

$\operatorname{ZKOIG}(\mathrm{KO})=\mathrm{T}_{\text {ig }}$

$\mathrm{ZKOPY}(\mathrm{KO})=\mathrm{T}_{\mathrm{p}}$

$\mathrm{ZKVZZ}(\mathrm{KV})$

ZKWZZ (KW, JSIDE)

$\operatorname{ZLAMDA}(\mathrm{KO})=\lambda$

$\operatorname{ZLRZX}(K R)=L_{x}$

$\operatorname{ZLRZY}(\mathrm{KR})=\mathrm{L}_{\mathrm{y}}$

$\mathrm{ZMCZZ}(\mathrm{KR})$

$\operatorname{ZMLZZ}(K R)=\mathrm{m}_{\mathrm{L}}$

$\mathrm{ZMOZO}(\mathrm{KO})=\mathrm{m}_{\circ}$
Thermal conductivity of object $\mathrm{KO}(\mathrm{W} / \mathrm{m}$ deg $\mathrm{K})$.

Thermal conductivity of wall KW (W/m deg K).

Temperature of ambient air (in degrees Kelvin; default value is $300^{\circ} \mathrm{K}$ ).

Temperature of the lower layer (in degrees $\mathrm{K})$.

Temperature of the floor and lower part of the walls.

Preselected temperature of flaming gases (1260 K).

Temperature of the hot (upper) layer in room $\mathrm{KR}\left({ }^{\circ} \mathrm{K}\right)$.

Temperature of the surface of object KO $\left({ }^{\circ} \mathrm{K}\right)$.

Temperature of ignition of object $\mathrm{KO}\left({ }^{\circ} \mathrm{K}\right)$.

Temperature at which object KO begins to pyrolyze $\left({ }^{\circ} \mathrm{K}\right)$.

Mean temperature of gases moving through vent KV (only use in forced vent routine).

Temperature of side JSIDE of wall KW (in $\left.{ }^{\circ} \mathrm{K}\right)$.

Radiation mean free path of photons in flame gases (i.e., absorption length -- in $\mathrm{m})$. This is just the reciprocal of $\kappa=$ ZUFZZ.

Dimension of room $\mathrm{KR}$ in $\mathrm{x}$-direction (in m).

Dimension of room $\mathrm{KR}$ in $\mathrm{y}$-direction (in m).

Mass of lower (cool) layer ( $\mathrm{kg})$.

Mass of hot layer in room $\mathrm{KR}$ (in $\mathrm{kg}$ ).

Original mass of pyrolyzable part of material in object $\mathrm{KO}(\mathrm{kg})$. 


$$
\begin{aligned}
& \mathrm{ZMOZZ}(\mathrm{KO})=\mathrm{m}_{\mathrm{f}} \\
& \mathrm{ZNOZZ}(\mathrm{KO})=\theta \\
& \mathrm{ZNWZZ}(\mathrm{KW})=\tau \\
& \mathrm{ZOAZN}=\mathrm{h}_{\mathrm{e}} \\
& \mathrm{ZOAZZ}=\mathrm{h} \\
& \mathrm{ZRFZZ}(\mathrm{KO})=\mathrm{R} \\
& \mathrm{ZRIG}(\mathrm{KO})=\mathrm{t}_{\mathrm{i}} \mathrm{g} \\
& \mathrm{ZRFZZ}(\mathrm{KR})=\mathrm{h}_{\mathrm{i}} \\
& \mathrm{ZRFZI}(\mathrm{KO})=\mathrm{R}_{\mathrm{i}} \\
& \mathrm{ZPAZM}=\mathrm{a}
\end{aligned}
$$

Mass of object kO as a function of time (kg) - - i.e., the remaining mass.

Thickness of object KO (meters).

Thickness of wall KW (m).

Minimum heat transfer coefficient of (quiescent, ambient) air. The default value is $5 \mathrm{~W} / \mathrm{m}^{2} \operatorname{deg} \mathrm{K}$, but it can be user-chosen.

Heat transfer coefficient of nonquiescent air. The default value is $10 \mathrm{~W} / \mathrm{m}^{2} \operatorname{deg} \mathrm{C}$, but it can be userchosen.

Heat transfer coefficient of hot layer gases (to ceiling/walls) in room $\mathrm{KR}$ (in $\left.\mathrm{W} / \mathrm{m}^{2} \mathrm{~K}\right)$.

Maximum heat transfer coefficient of hot layer gases (in $\mathrm{W} / \mathrm{m}^{2}{ }^{\circ} \mathrm{C}$ ). The default value is $50 \mathrm{~W} / \mathrm{m}^{2}{ }^{\circ} \mathrm{K}$, but it can be any value greater than that taken for ZOLZN.

Minimum heat transfer coefficient of hot layer gases. The default value is the same as ZOAZN, i.e., $5 \mathrm{~W} / \mathrm{m}^{2}{ }^{\circ} \mathrm{K}$, but it can be user-chosen.

Ambient air pressure; it is used as the reference pressure (in meters of air; 1 atm. $=8780 \mathrm{~m}$ ).

Pressure at center of floor of room KR, referred to $\mathrm{P}_{\mathrm{a}}$ (in meters of air equivalent).

Radius of object $\mathrm{KO}$, in meters (see description of $R_{0}$ in subroutine RNPO).

Augmented radius of object $\mathrm{KO}$-- i.e., maximum equivalent possible radius of fire, in $\mathrm{m}$ (see note (7), pp. 8-9).

Initial radius of fire on object $\mathrm{KO}$, in $\mathrm{m}$ (default value is $0.037 \mathrm{~m}$ ).

Radius of fire on object KO (in $\mathrm{m}$ ).

Time of ignition of object KO (in sec). 


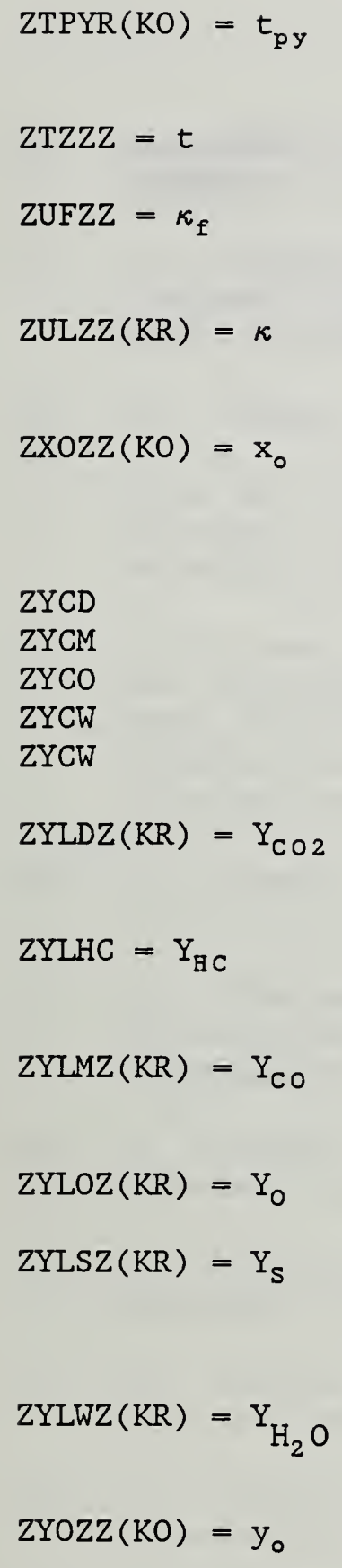

Time of start of pyrolysis of object KO (in sec).

Time from ignition (in sec).

Absorption coefficient of flame gases (default value is $1.28 \mathrm{~m}^{-1}$, for $\mathrm{PU}$ foam).

Absorption coefficient of hot layer (in $\mathrm{m}^{-1}$ ).

$\mathrm{X}$ coordinate of object $\mathrm{KO}$, with respect to the local coordinate system of the room it is in (in meters).

Mass fractions of $\mathrm{CO}_{2}, \mathrm{CO}, \mathrm{O}_{2}$, smoke, and $\mathrm{H}_{2} \mathrm{O}$ (respectively), in the lower layer. Analogous to ZYLiZ for the upper layer (in $\mathrm{kg} / \mathrm{kg}$ ).

Mass fraction of $\mathrm{CO}_{2}$ in hot layer in room $\mathrm{KR}$ (in $\mathrm{kg} / \mathrm{kg}$ ).

Mass fraction of hydrocarbons in the hot layer $(\mathrm{kg} / \mathrm{kg})$.

Mass fraction of $\mathrm{CO}$ in hot layer in room $\mathrm{KR}$ (in $\mathrm{kg} / \mathrm{kg}$ ).

Oxygen mass fraction in layer in room $\mathrm{KR}$.

Concentration (by mass) of smoke (particulates, mainly $C$, and condensed hydrocarbons) in the hot layer in room KR.

Mass fraction of $\mathrm{H}_{2} \mathrm{O}$ in the hot layer in room KR.

$Y$ coordinate of object $K O$ (in room $K R$ ), in meters. 
$\underline{\text { Subscript }}$

$\mathrm{J}$, or JSIDE

$\mathrm{KO}$

$\mathrm{KR}$

$\mathrm{KV}$

KW

\section{Purpose}

Present

Range

Identifies the side of the wall under consideration:

1. inside room

2. outside of room (open air)

Identifies the object

4

Identifies the room $(K R=1$ only)

Identifies the vent

5

Identifies the wall/ceiling (as with the room, there is only one in FIRST, though it has been DIMENSIONED to 5) 


\section{REFERENCES ${ }^{13}$}

[1] H.W. Emmons, H.E. Mitler, and L.N. Trefethen, "Computer Fire Code III", HFPTR No. 25, Harvard University (1978).

[2] H.E. Mitler and H.W. Emmons, "Documentation for CFC V, The Fifth Harvard Computer Fire Code", HFPTR No. 45, Harvard University (1981) and National Bureau of Standards GCR 81-344.

[3] H.E. Mitler, "The Harvard Fire Model", Fire Safety Journal 9, (1985) 7.

[4] W.G. Berl, Editor, International Symposium on the Use of Models in Fire Research, Publication 786, National Academy of Sciences/National Research Council, Washington, DC (1961).

[5] L.Y. Cooper, J.A. Rockett, H.E. Mitler, and D.W. Stroup, "A Program for the Development of a Benchmark Compartment Fire Model Computer Code", NBSR 85-3252 (1985). Also to appear in the Proceedings of the International Symposium on Mathematical Modeling of Fires and Related Fire Test Methods, to be held in New Orleans, Dec. 1986.

[6] H.W. Emmons, C.D. MacArthur, and R. Pape, "The Status of Fire Modeling in the U.S.", paper presented at US-Japan Panel on Fire Research (1979).

[7] W.T. Hathaway, "Survey on Fire Modeling Efforts with Application to Transportation Vehicles", Report \#DOT-TSC-OST-81-4, for the Department of Transportation, Transportation Systems Center, Cambridge, MA (1981).

[8] R. Friedman, "Status of Mathematical Modeling of Fires", Factory Mutual Research Corporation, FMRC Report RC 81-BT-5 (1981).

[9] J.S. Parikh et al, "Survey of the state of the Art of Mathematical Fire Modeling", Underwriters Laboratories Report, File NC 554 (1983).

[10] H.E. Mitler, "Comparison of Several Compartment Fire Models: An Interim Report", NBSIR 85-3233 (1985).

[11] H.E. Mitler, "Zone Modeling of Forced Ventilation Fires", Comb. Science \& Technology $\underline{39}$ (1984) 83 .

[12] A.T. Modak and R.L. Alpert, "Influence of Enclosures on Fire Growth, Vo1. 1: Guide to Test Data", FMRC, Norwood, MA; RC77-BT-14 (1977).

13 Abbreviations used in this list are:

FRMC = Factory Mutual Research Corporation

NBSIR = National Bureau of Standards Internal Report (available contact NBS)

HFPTR $=$ Home Fire Project Technical Report

$\mathrm{TR}=$ Technical Report 
[13] A.T. Modak, "Influence of Enclosures on Fire Growth, Vo1. II: Analysis", FMRC, Norwood, MA; RC78-BT-24 (1978).

[14] H.E. Mitler, "Comparison Between Theory and Experiment for a Burning Room", HFPTR 46, Harvard University, Cambridge, MA (1981).

[15] H.E. Mitler and J.A. Rockett, "How Accurate is Mathematical Fire Modeling?", Paper presented at the US-USSR Joint Seminar on Mathematical Modeling of Fires, Tbilisi, USSR. Published in the Georgian Academy of Sciences Journal (1981). NBSIR 86-3459 (1986).

[16] H.W. Emmons, "The Prediction of Fires in Buildings", 17th International Symposium on Combustion, The Combustion Institute, Pittsburgh, PA (1979) 1101 .

[17] H.E. Mitler, "The Physical Basis for the Harvard Computer Fire Code", HFPTR No. 34, Harvard University (1978).

[18] E.E. Zukoski, T. Kubota, and B. Cetegen, "Entrainment of Fire Plumes", Fire Safety Journal $\underline{3}(1980 / 81) 107$.

[19] B.M. Cetegen, E.E. Zukoski, and T. Kubota, "Entrainment and Flame Geometry of Fire Plumes", National Bureau of Standards GCR 82-402 (1982) Chapter 4.

[20] B.J. McCaffrey, "Purely Buoyant Diffusion Flames: Some Experimental Results", NBSIR 79-1910 (1979).

[21] T. Tokunaga, T. Sakai, K. Kawagoe, T. Tanaka, and Y. Hasemi, "Mass FLow Rate Formula for the Upward Current Above Diffusion Flames", Fire Science and Technology $\underline{2}$, No. 2 (1982) 117.

[22] M.A. Delichatsios, "Air Entrainment Into Buoyant Diffusion Jet Flames and Open Pool Fires", to be published in Combustion and Flame (1986).

[22a] J.A. Rockett, "A Comparison of Plume Models", to be published.

[23] G.H. Markstein, "Radiative Properties of Plastics Fires", in 17th International Symposium on Combustion, The Combustion Institute, Pittsburgh, PA (1978) 1053.

[24] V.I. Blinov and G.N. Khudiakov, "Certain Laws Governing Diffusive Burning of Liquids", Doklady Academia Nauk, SSSR 113 (1957) 1094.

[24a] L. Orloff, J. DeRis, and G.H. Markstein, "Upward Turbulent Fire Spread and Burning of Fuel Surface", in 15th International Symposium on Combustion, The Combustion Institute, Pittsburgh, PA (1974) 183.

[25] V. Babrauskas, "Upholstered Furniture Room Fires - Measurements, Comparison with Furniture Calorimeter Data, and Flashover Predictions", $\mathrm{J}$. of Fire Sciences 2 (1984) 5 . 
[26] J.A. Rockett, "Modeling of NBS Mattress Tests with the Harvard Mark V Fire Simulation", Fire and Materials 6 , No. 2 (1982) 80.

[27] J.A. Rockett, "Park Service Room Fire Test Simulations Using the Harvard Level 5.2 Computer Fire Model", Fire Science \& Technology 4 , No. 2 (1984) 135.

[28] CRC Handbook of Chemistry and Physics, 60th Ed., Chemical Rubber Publishing Co. (1979).

[29] A.M. Kanury, "Introduction to Combustion Phenomena", Gordon and Breach (1975).

[30] A. Tewarson, "Physico-Chemical and Combustion/Pyrolysis Properties of Polymeric Materials", FMRC TR OEON6.RC (1980). Also see NBS GCR 809295.

[31] C.C. Ndubizu, D.E. Ramaker, P.A. Tatum, and F.W. Williams, "A Model of Freely Burning Pool Fires", Comb. Science and Technology 31 (1983) 233.

[32] A. Tewarson, "Quantification of Fire Properties of Fuels and Interaction with Fire Environment", National Bureau of Standards GCR 82-395 (1982).

[33] A. Tewarson, J.L. Lee, and R.F. Pion, "The Influence of Oxygen Concentration on Fuel Parameters for Fire Modeling", 18th International Symposium on Combustion (1981) 563.

[34] D.D. Cline, W.A. von Riesemann, and J.M. Chavez, "Investigation of Twenty-Foot Separation Distance as a Fire Protection Method as Specified in 10 CFR 50, Appendix R", NUREG/CR-3192, Sandia National Labs (1983).

[35] J. Brandrup and E.H. Immergut, eds.; Polymer Handbook, 2nd ed., J. Wiley (1975).

[36] D. Gross, "Data Sources for Parameters Used in Predictive Modeling of Fire Growth and Smoke Spread", NBSIR 85-3223 (1985).

[37] L. Orloff, A.T. Modak, and R.L. Alpert, "Burning of Large-Scale Vertical Surfaces", in 17th International Symposium on Combustion, The Combustion Institute, Pittsburgh, PA (1978) 1345.

[38] F. Tamanini, "A Numerical Model for the Prediction of RadiationControlled Turbulent Wall Fires", in 17th International Symposium on Combustion, The Combustion Institute, Pittsburgh, PA (1978) 1075.

[39] A. Tewarson, "Experimental Evaluation of Flammability Parameters of Polymeric Materials", FMRC, J.I. IAGRl, Final Report for PRC (1979).

[40] A. Tewarson, private communication.

[41] J.A. Rockett, "Data for Room Fire Models", Comb. Sci. \& Technology $4 \underline{0}$ (1984) 137. 
Appendix A. Derivation of Values Used for Heptane in Table I

We assume that the heptane burns in the open according to 14

$$
\mathrm{C}_{7} \mathrm{H}_{16}+\mathrm{nO}_{2} \rightarrow \mathrm{aCO}_{2}+\mathrm{bCO}+\mathrm{cC}_{7} \mathrm{H}_{16}+\mathrm{dC}+\mathrm{eH}_{2} \mathrm{O}
$$

Then species balance yields

$$
\begin{aligned}
& C: \quad a+b+d=7(1-c) \\
& H: \quad e=8(1-c)
\end{aligned}
$$

and $\mathrm{n}$ is given by

$$
0: 2 a+b+e=2 n
$$

We have here assumed that soot is essentially carbon, and that the volatile hydrocarbons escapt as raw fuel. Then from the heats of combustion of $\mathrm{CO}$ and of $\mathrm{C}$, we can write

$$
x \cong 1-c-0.0639 b-0.0911 \mathrm{~d}
$$

Recently G. Mulholland and coworkers have made measurements on the openair burning of a $50-\mathrm{cm}$ diameter pool of heptane. They found ${ }^{15}$ that the soot fraction is

$f_{s}=0.013$

(grams of soot per gram of evaporated heptane). Since

$f_{s} \cong f_{c}=\frac{12}{100} d$

14 A similar approach is used in ref. [41].

15 Private communication. 


$$
\mathrm{d}=\frac{1.3}{12}=0.108
$$

Their measurements also indicate that the product $\mathrm{CO}$ is related to $\mathrm{CO}_{2}$ according to

$$
b=(6 \pm 1.5) \times 10^{-3} a
$$

A carbon balance shows that all the carbon is accounted for in the soot (C), $\mathrm{CO}$, and $\mathrm{CO}_{2}$, within one or two percent - i.e., the hydrocarbon fraction is very low. Finally, they found that the energy output is $41.9 \pm 0.5 \mathrm{~kJ} / \mathrm{g}$ of evaporated fuel. ${ }^{16}$ Since the theoretical heat release rate is $44.54 \mathrm{~kJ} / \mathrm{g}$,

$$
\chi_{\mathrm{A}}=0.94 \pm .03
$$

Tewarson et al found that $\chi_{\mathrm{A}}=0.83$ (see ref. [33]), but the burning probably took place under under-ventilated conditions. Taking the central value from eq. (6), eqs. (2) and (5) then become

$$
1.006 a=7(1-c)-0.108
$$

and

$$
\chi_{\mathrm{A}}=0.9875-0.9973 \mathrm{c}
$$

If we take the upper bound for the estimated error in the carbon balance, we can have $c=0.02$, corresponding to $\mathrm{a}=6.712$ and $\chi_{\mathrm{A}}=0.9675$. This last result lies just within the upper error bound on $\chi_{A}$ from eq. (7). It then follows from eq. (6) that $b=0.040$, and from eq. (3) that e $=7.840$. The molecular weight of heptane is 100 , that of $\mathrm{CO}$ is 28 , etc. It follows that

$$
f_{s} \quad f_{c} \quad 0.013
$$

16 The quoted uncertainty is statistical; the systematic error may be 28 or higher, adding an uncertainty of \pm 0.8 , included in eq. (7). 


$$
\begin{aligned}
& f_{\mathrm{CO}}=\frac{28}{100} b \cong 0.011 \\
& f_{\mathrm{CO}_{2}}=\frac{44}{100} a \cong 2.953 \\
& f_{\mathrm{HC}}=c=0.02
\end{aligned}
$$

and

$$
f_{\mathrm{H}_{2} \mathrm{O}}=\frac{18}{100} \mathrm{e}=1.411
$$

These are the values used in Table 1. The values found by Tewarson et al [33] correspond to substantially less complete combustion; this is probably due (as pointed out above) to their experiment having been carried out in underventilated conditions. 
Table 1. Thermophysical/chemical values chosen for the materials data bank. Entries marked "nr" are not relevant.

\begin{tabular}{|c|c|c|c|c|}
\hline Quantity & Methane & Heptane & PMMA & PU Foamtt \\
\hline 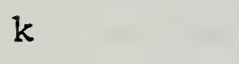 & $\mathrm{nr}$ & $0.14[30]$ & $0.19[35]$ & $0.040 \quad[36]$ \\
\hline$\rho$ & $\mathrm{nr}$ & $684[30]$ & 1180 [36] & 47 [39] \\
\hline$c_{p}$ & $\mathrm{nr}$ & $2243[28]$ & $1370 \quad[35]$ & $1700[36]$ \\
\hline$\epsilon_{\mathrm{b}}$ & $\mathrm{nr}$ & $0.42[31]$ & $0.93[37]$ & 0.98 \\
\hline$\gamma$ & & 15.18 & 11.5 & 9.85 \\
\hline$\gamma_{\mathrm{s}}$ & 17.25 & $15.18[30]$ & 8.28 & 9.85 \\
\hline$x$ & $0.999^{*}$ & $0.97^{* *}$ & $0.94 \quad[33]$ & $0.65[40]$ \\
\hline$\Delta \mathrm{H}_{\mathrm{c}} \times 10^{-7}$ & $5.294[28]$ & $4.46 \quad[33]$ & $2.52[30]$ & $2.87 \quad[30]$ \\
\hline$\Delta \mathrm{H}_{\mathrm{v}} \times 10^{-5}$ & $\mathrm{nr}$ & $3.62[28]$ & $16.11[37,38]$ & $25.8[39]$ \\
\hline$T_{\text {pyro }}$ & $\mathrm{nr}$ & $269.1 \quad[34]$ & $636[37]$ & $600[30]$ \\
\hline $\mathrm{f}_{\mathrm{CO}}$ & $2.7445^{*}$ & 2.953 & $2.1[33]$ & $1.51[30]$ \\
\hline$f_{c o}{ }^{2}$ & $.001 \dagger$ & $0.011[32]^{* *}$ & $0.011[33]$ & $0.013[30]$ \\
\hline$f_{s}$ & $.001 \dagger$ & $0.013^{* *}$ & $0.025 \quad[33]$ & $0.24 \quad[30]$ \\
\hline$f_{B C}$ & - & $0.02^{* *}$ & $0.001 \quad[30]$ & $0.002[30]$ \\
\hline $\mathrm{f}_{\mathrm{B}_{2}} \mathrm{O}$ & $2.25^{*}$ & $1.411^{* *}$ & $0.719^{*}$ & $0.714^{*}$ \\
\hline $\mathrm{A}^{2}$ & $\mathrm{nr}$ & $\mathrm{nr}$ & 0.0167 & 0.01372 \\
\hline $\mathrm{T}_{\mathrm{ig}}$ & $905.4 \quad[29]$ & $371.6=b p \quad[33]$ & $658 \quad[33]$ & 770 \\
\hline$\psi$ & 30 & 30 & 30 & 30 \\
\hline$t_{b}$ & nr & $\mathrm{nr}$ & 20 & 20 \\
\hline$\kappa_{f}$ & 0.4 to 1.0 & $0.85 \quad[31]$ & $1.5 \pm 0.3[23]$ & $1.28 \pm 0.17[23]$ \\
\hline
\end{tabular}

* Starred values are calculated from stoichiometry and accepted values of $f_{i}$.

$\dagger$ These values for methane are assumed to be the same as for methanol (see [30]).

** See Appendix A.

t† The tested foam was Tenneco \#7004, also given the designation I-A at FMRC. It is a flexible foam, with 36-40\% inert ingredients (mostly $\mathrm{CaCO}_{3}$ ). Aside

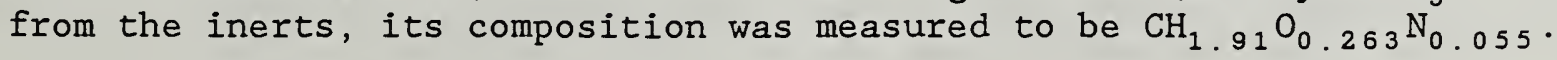


After this manuscript had been typed, yet another generalization of the program was implemented, which is important enough to warrant inclusion here: the option to open a new vent in the room during the fire (to simulate a breaking window, for example). There are two choices - it can be opened at a predetermined time (specified by the user) or at a predetermined upper layer temperature (in degrees Kelvin), likewise user-chosen. Thus, at the top of $p$. 33 (section 4.2), item no. 6 appears, "THIS VENT IS INITIALLY OPEN". If one does not want the vent to be open from the very beginning, this is the item to change. In changing it, note that one must not follow the usual format instruction (written, as usual, at the bottom of the "menu"). Instead, one must respond with three blank (spaces) and a "6", followed by another space, followed by $0 ., 1$. , or $2 \ldots$ " $1 . "$ corresponds to opening the vent at a predetermined time. Upon entering 61 , the statement "VENT SHOULD OPEN AT TIME = " will appear on the screen. The user must then enter the time as a real number - that is, with a decimal point ( $F$ format). Similarly, typing in " 6 2." elicits the response "VENT SHOULD OPEN AT HOT LAYER TEMPERATURE ="; the requested temperature must likewise be entered as a real number. Finally, " $60 . "$ corresponds to the vent being initially open. This option seems pointless on its face, since vents are always initially open, by default. However, a vent may have been added which is initially closed; this is the way it can be changed to being initially open.

Note that setting a vent to be initially closed, but to open at $t=0$, it is not the same as having a vent which is initially open. This is so, because when a vent is opened, it does so gradually, rather than instantaneously. 


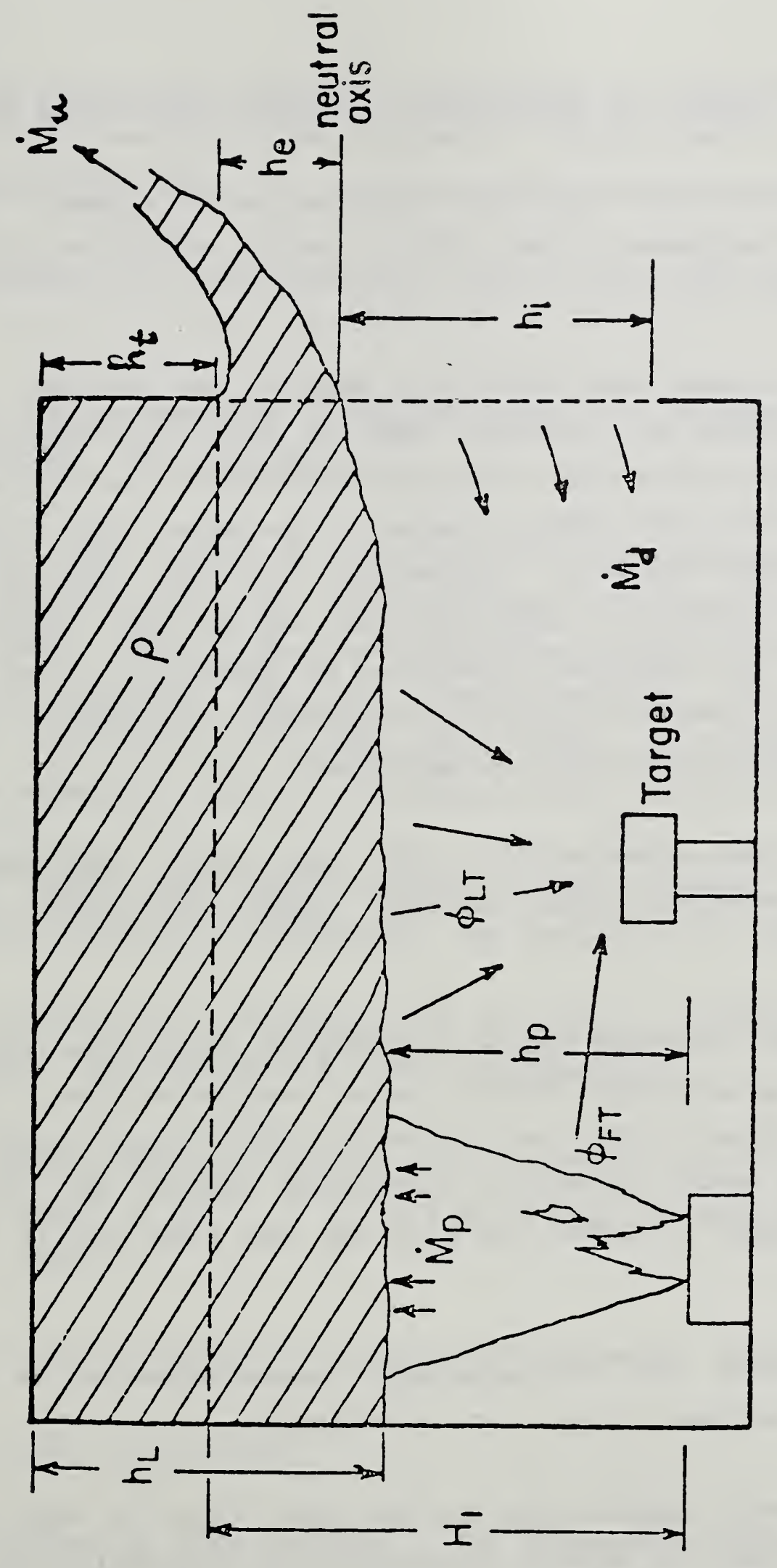

Figure 1. Schematic of the enclosure, showing mass fluxes in and out of the room and radiative fluxes to the target from the layer and the flame. 
Appendix C. Summary of Improvements in FIRST, Over Harvard Mark 5

1. FIRST includes forced ventilation (into or out of a room). The physics for this is explained in ref. [11]. Partial validation is also given therein. See section 4.5 .

2. Mixing of hot and cold flows at a vent is not included. That is, inflowing (cold) air entrains some of the outflowing hot gases, returning them to the room. Thus the lower layer heats up and becomes contaminated with the product species in the upper layer. Also, oxygen becomes somewhat depleted. Furthermore, the lower layer is no longer transparent, because of this pollution, and absorbs radiation passing through it. The algorithm is described in Appendix II of ref. [26]. It has not been directly validated by experiments, although it is based on correlations from two series of experiments.

3. Because of the existence of a cool lower layer which absorbs, the radiative exchanges among ceiling, layers, and floor have been reformulated.

4. The gas burner algorithm has been generalized so that the gas flow rate can be made an arbitrary (within limits) function of time. This allows the user to specify the fire (but only within certain bounds - if the fire becomes oxygen starved or ventilation limited, the fire strength will be limited, no matter how high the fuel flow rate is set). See section 4.4 .

5. FIRST calculates the (time-dependent) concentration of an additional species in the upper layer: total hydrocarbons.

6. Since the smoke concentration in the upper layer is calculated as a function of time, it is easy to specify when a photoelectric detector, which has a threshold response to smoke obscuration, will react. This has been done; see section 3.1, item 5. This algorithm also has not 
been validated, and (indeed) it is subject to refinement, for the case where it is immersed in the ceiling jet, rather than in the already-mixed layer.

7. It provides for a user-specified burnout rate. See section 3.1, item 12.

8. A vent can be opened at a specified time or at a specified upper-layer temperature. See Appendix B.

9. FIRST provides options for five additional plume options (corresponding to different correlations and/or theories). See section 3.3, p. 18, and ref. [22a]. None of the plume algorithms is exact (indeed, this is why there are several); each has a limited validity, in a given parameter range. The best way to assess the accuracy, is to examine the scatter in the experimental points, as given in refs. [2] and [17-22a].

10. A mass balance has been introduced into the program, to ensure global accuracy, as well as correctness. See section 6.2, p. 83 .

11. The possibility of building and accessing a materials database is included. See sections 3.6, 4.9, and Appendix A.

12. The input has been made a more "user-friendly", partly by having a menudriven input option. It is more forgiving of syntactical errors made during input.

13. There is now an option for running in batch mode. See section 5 .

14. A PC version is available.

15. The program is more modular. The program structure is basically unchanged form that described in great detail in ref. [2]. However, there are many more subroutines, because each subroutine now calculates 
just one variable (also see item 18, below). There is less use of COMMON, which contributes to the modularity, as well: wherever feasible, the variables needed in the subroutine are passed through the argument list.

16. The use of double precision has led to the numerics being far sturdier; that is, a run is far less likely to fail to go to completion.

17. There is greater flexibility in the use of numerical options: the user can specify the maximum number of iterations permitted before the program "gives up" and starts the given time step over with the time increment halved. The user also can specify the convergence criterion to be used for a particular calculation (see section 3.5).

18. The time integrations are now done in a separate subroutine (INTEGO), rather than within the subroutines which given the physical processes. The integrations are still being done by the trapezoided rule, but that can now be changed to Simpson's rule, or still-higher-order techniques, quite easily. 


\section{Appendix D. Limitations of FIRST}

Some of the limitations of this program are made clear in several of the references in the bibliography, notably [2], [3], and [16]. In the following list, the most notable limitations of the program are described, roughly in order of importance.

1. Wall fires are not included (but see section 8, item 7).

A fortiori, corner fires are not included either.

2. The program (i.e., the model) assumes that the fire cannot utilize the oxygen in the upper layer, during combustion.

3. Flor heating has not yet been incorporated into the program.

4. The program will not run properly if the room has thermally thin walls, or if a target object is thermally thin.

5. There is no extinguishment algorithm (such as a sprinkler).

6. It is a single-room model (but see section 8, item 8).

7. The walls, ceiling, and floor are assumed to all be of identical thickness and material (see section 8 , item 12).

8. A maximum of four objects can be followed.

9. The Co production rate is poorly calculated.

10. The program encounters numerical difficulties, sometimes, when the compartment dimensions are smaller than 1 meter on a side or larger than $250 \mathrm{~m}$ on a side.

11. The energy balance is not correctly calculated for cases where some of the flame extends outside the room. 
12. Flameover is not considered - i.e., burning out of any fuel accumulated in the upper layer.

13. Major changes in pressure are not permitted, so that fires in airtight compartments such as in submarines or high-flying aircraft cannot be calculated.

14. The ceiling-jet is neglected, so that transient heating effects of the ceiling or of sprinkler links cannot be properly taken into account.

15. Ceiling fires have not been included.

16. Vents in floors or ceilings have not been included (but see section 8 , item 5 ).

17. Mixing of the incoming and in situ gases has been neglected in the forced-venting algorithm.

There are also a number of subtler limitations. For example,

18. The very fact that this is a two-zone model means that stratification of the layer(s) cannot be taken into account.

19. The pyrolysis model assumes a steady state; also, that the material is thermally thick, homogeneous, and uniform; that it behaves as a pure substance with a unique heat of vaporization; and that it is inert.

20. The ignition criterion is the attainment of a specific surface temperature $\mathrm{T}_{i_{g}}$; this is not always an adequate criterion. Indeed, it cannot always even be implemented because of a lack of appropriate data for some materials. 
21. The compartment is always assumed to be a rectangular parallelepiped.

22. Just as for fuels, the walls and ceiling and floor) must be homogeneous and uniform, with constant thermal properties. Laminated materials are therefore not properly treated. The outgassing of moisture is not taken into account.

23. The spread model is not very sophisticated. Just as for pyrolysis, it does not take melting or charring into account.

24. Radiation blocking is not taken into account, so that liquid pool fires are not well described (but see section 8 , no. 9).

25. Consonant with item 13, the compressibility of the gases has not been taken into consideration. 
In the following list of symbols, the five-letter label for it is given (if it exists), and the description can then immediately be found in section 9.2. Otherwise, a section reference is given.

\begin{tabular}{|c|c|c|c|}
\hline Symbol & $\begin{array}{l}\text { Internal } \\
\text { Equivalent }\end{array}$ & Description & $\begin{array}{l}\text { Found in } \\
\text { Section: }\end{array}$ \\
\hline
\end{tabular}

$\mathrm{a}, \mathrm{b}$

$\mathrm{C}=\mathrm{c}_{\mathrm{i}}$

ZCOZZ

$\mathrm{C}_{\mathrm{p}}$

$f_{i}$

g

h

$h_{e}=h_{m i n}$

$\mathrm{h}_{\mathrm{max}}$

$h_{p}$

$\mathrm{h}_{\mathrm{t}}$

k

$\dot{\mathrm{m}}_{\mathrm{g}}$

m。

$\dot{\mathrm{m}}_{\mathrm{u}}$

m

p

$\tau_{b}$

A

ZCAZZ

G

ZOAZZ

ZOLZM

ZHPZZ

ZHTZZ

ZJOZZ

TMFGZ

ZMOZO

TMUZZ
Dimensions of a rectangular

3.1 object. (Also see ZOLZM, ZOLZN)

Mass fraction of species $i$ given off in combustion

ZOAZN, ZOLZN

Mass of fuel vapors

Parameter giving growth rate of a fire.

Burnout parameter

Spread-rate parameter
3.1

3.1

3.1

3.1

Fig. 1

3.1

3.1

3.1

Fig. 1

3.1

3.1

3.1

3.1

3.1

3.1

3.1

3.1 
$\mathrm{A}_{1}$

$A_{p}$

$\mathrm{A}_{\mathrm{s}}$

$C_{d}$

C

$\dot{\mathrm{E}}_{\mathrm{f}}$

$\dot{\mathrm{E}}_{\mathrm{u}}$

$\mathrm{H}_{\mathrm{c}}$ or $\Delta \mathrm{H}_{\mathrm{c}}$

$\mathrm{H}_{\mathrm{v}}$

IT

KO

$\mathrm{KR}$

$\mathrm{N}$

NIT

$N_{\circ}$

NT

$\mathrm{N}_{\mathrm{v}}$

$\mathrm{R}$

$\dot{\mathrm{R}}$

$\mathrm{R}_{1}$

$R_{m}=R_{\text {max }}$
Estimated value of A for

3.7

material i. See A

Value of $\mathrm{A}$ for $\mathrm{PU}$ foam

3.7

Total surface area of sticks

in a crib

8

3.1

3.1

3.1

(Lower) heat of combustion

3.1 of flammable gases from object

3.1

Heat of vaporization of gasifying material

Number of iterations required to converge at a given time step

Index number for object

6.3

Index number for room ( $K R=1$ for FIRST)

Total number of variables in the calculation

Total number of iterations required in the calculation up to the given time

$4.2,6.2$

6.3

2.1

$4.2,6.2$

Number of objects in the room

Number of time steps taken in the calculation up to the given time

Number of vents in the room

Time rate of change of the

fire radius
3.1

3.1

3.1

$4.2,6.2$

3.1

3.1 


\begin{tabular}{|c|c|c|c|}
\hline$R_{0}$ & ZRFZO & & 3.1 \\
\hline $\mathrm{T}=\mathrm{T}_{\mathrm{f}}$ & ZKFZZ & & 3.1 \\
\hline $\mathrm{T}_{\mathrm{a}}$ & ZKAZZ & & 3.1 \\
\hline $\mathrm{T}_{\mathrm{ig}}$ & ZKOIG & & 3.1 \\
\hline$T_{p}=T_{p y r o}$ & ZKOPY & & 3.1 \\
\hline$\dot{\mathrm{V}}$ & 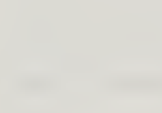 & $\begin{array}{l}\text { Volumetric flow rate } \\
\text { through a vent }\end{array}$ & 3.1 \\
\hline$\alpha$ & ALPHA & & 3.1 \\
\hline$\beta$ & & $\begin{array}{l}\text { Parameter giving upward } \\
\text { spread rate of a fire. Also } \\
\text { see BETA (different meaning). }\end{array}$ & 8 \\
\hline$\gamma$ & XGAMMA & (Also see ANGV) & 3.1 \\
\hline$\gamma_{s}$ & XGAMAS & & 3.1 \\
\hline$\epsilon$ & TOLER & $\begin{array}{l}\text { Maximum permitted relative } \\
\text { error, used in convergence } \\
\text { criterion }\end{array}$ & $2.2,3.5$ \\
\hline$\theta$ & ZNOZZ & & 3.1 \\
\hline$\kappa$ & ZULZZ & & 3.1 \\
\hline$\kappa_{f}$ & ZUFZZ & & 3.1 \\
\hline$\rho=\rho_{i}$ & VMOZZ & & 3.1 \\
\hline$\sigma$ & SIGMA & & 3.1 \\
\hline$\tau$ & ZNWZZ & & 3.1 \\
\hline$\phi_{\text {rad }}$ & & Radiation flux & 3.1 \\
\hline$x$ & $\mathrm{CHI}$ & & 3.1 \\
\hline$\psi$ & PSI & (see entry above TPSI) & 3.1 \\
\hline
\end{tabular}


NBS-114A (REV. 2-8C)

U.S. DEPT. OF COMM.

BIBLIOGRAPHIC DATA

SHEET (See instructions)

1. PUBLICATION OR

REPORT NO.

NBSIR-87/3595
2. Performing Organ. Report Nof 3. Publication Date

September 1987

4. TITLE AND SUBTITLE

USERS' GUIDE TO FIRST, A COMPREHENSIVE SINGLE-ROOM FIRE MODEL

\section{AUTHOR(S)}

Henri E. Mitler and John A. Rockett

6. PERFORMING ORGANIZATION (If joint or other than NBS, see instructions)

7. Contract Grant No.

MATIONAL BUREAU OF STANDARDS

DEPARTMENT OF COMMERCE

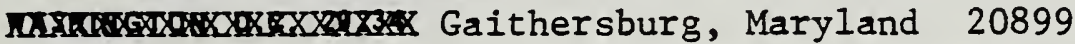

9. SPONSORING ORGANIZATION NAME AND COMPLETE ADDRESS (Street, City, State, ZIP)

8. Type of Report \& Period Covered

10. SUPPLEMENTARY NOTES

Document describes a computer program; SF-185, FIPS Software Summary, is attached.

11. ABSTRACT (A 200-word or less factual summary of most significant information. If document includes o significant bibliogrophy or literoture survey, mention it here)

This document is an instructional manual which will facilitate use of the computer program FIRST. (The name "FIRST" is an acronym; it stands for FIRe Simulation Technique). This is a prototype of a "benchmark" computer model of how a fire develops in a single compartment. Given a fire (or fires) ignited on one or more tuel sources, FIRST describes the principal phenomena which occur, such as the movement of gases in and out of the compartment, the growth of the fire(s), the development of a hot layer, etc. This guide is not meant to be documentation for the model, and so detailed descriptions of the physics or of the program structure have been kept to a minimum. The principal emphasis has been on how to input the information needed to run the program, and on the output obtained. Only a dozen pages of instructions are needed for the input, but an extensive section has been ircluded which gives "worked examples" of the use of the program. There is also a section which gives suggestions for using it to simulate fires and situations for which no explicit provision has been made. Finally, a short table of thermophysical data appropriate for running the program has been included.

12. KEY WORDS (Six to twelve entries; alphabetical order: copitalize only proper names; and separate key words by semicolons) compartment fires; computer model ; . fire models; manwals.

13. AVAILABILITY

X] Unlimited

For Official Distribution. Do Not Release to NTIS

Order From Superintendent of Documents, U.S. Government Printing Office, Washington, D.C. 20402.

14. NO. OF

PRINTED PAGES

Xrder From National Technical Information Service (NTIS), Springfield, VA. 22161 
